\title{
Site Selection, Drilling, and Completion of Two Horizontal Wells in the Devonian Shales of West Virginia
}

Final Report

\author{
William K. Overbey, Jr. \\ Richard S. Carden \\ C. David Locke \\ S. Phillip Salamy \\ T. K. Reeves \\ Harry R. Johnson
}

Work Performed Under Contract No.: DE-AC21-89MC25115

For

U.S. Department of Energy

Office of Fossil Energy

Morgantown Energy Technology Center

P.O. Box 880

Morgantown, West Virginia 26507-0880

By
BDM Engineering Services Company
7915 Jones Branch Drive
McLean, Virginia 22102

March 1992 


\section{ABSTRACT}

This report presents a summary of the geologic site selection studies, planning, drilling, completing, stimulating, and testing of two horizontal wells drilled in the Devonian Shales of the Appalachian Basin in West Virginia. Each horizontal well was designed and managed by BDM as the prime contractor to the Department of Energy. The first well was drilled with industry partner Cabot Oil and Gas Corporation in Putnam County, West Virginia. The second well was drilled with Consolidated Natural Gas Company in Calhoun County, West Virginia. This report summarizes four reports prepared by BDM which detail the site selection rationale and the drilling and completion operations of each well. Each horizontal well is currently producing commercial quantities of hydrocarbons. The successful application of horizontal well technology represent continued development of the technology for application to tight and unconventional natural gas resources of the United States. Continued technology development is expected to ultimately result in commercial horizontal well drilling activity by industry in the Appalachian Basin. 


\section{TABLE OF CONTENTS}

Page

1.0 EXECUTIVE SUMMARY

2.0 INTRODUCTION 3

3.0 GEOLOGIC STUDIES, LEASE ACQUISITION AND LOCATION DEVELOPMENT

3.1 Selection of Area and Site for the Hardy HW\#1 Well, 5 Putnam County, West Virginia

3.2 Selection of Area and Site for the Hunter Bennett 13 \#3997 Well, Calhoun County, West Virginia

3.2.1 Northern Caihoun County 19

3.2.2 The Boone-Logan County Line Area $\quad 24$

3.2.3 Southern Calhoun County 24

3.2.4 Selection of Area and Site $\quad 24$

$\begin{array}{ll}4.0 & \text { DRILLING OPERATIONS } \\ \end{array}$

4.1 Hardy HW\#1 Well 28

4.2 Hunter Bennett \#3997 Well 34

\begin{tabular}{ll}
5.0 & LOGGING OPERATIONS \\
\hline 2
\end{tabular}

5.1 Hardy HW\#1 Well 42

5.2 Hunter Bennett \#3997 Well 43

6.0 MOTOR PERFORMANCE AND BOTTOM HOLE ASSEMBLIES 43

6.1 Hardy HW\#1 Well 46 
6.1.1 Angle Build Section 46

6.1.2 Horizontal Section $\quad 47$

6.2. Hunter Bennett \#3997 49

6.2.1 Angle Build Section 49

6.2.2 Horizontal Section $\quad 51$

$\begin{array}{ll}7.0 \text { DIRECTIONAL CONTROL OPERATIONS } & 53\end{array}$

8.0. ANALYSIS OF DRILLIING OPERATIONS 54

$\begin{array}{ll}9.0 \text { COMPLETION OPERATIONS } & 55\end{array}$

9.1 Hardy HW\#1 Well 55

9.2 Hunter Bennett \#3997 Well 58

$\begin{array}{ll}10.0 \text { STIMULATION } & 59\end{array}$

10.1 Hardy HW\#1 Well 61

$\begin{array}{ll}10.2 \text { Hunter Bennett \#3997 Well } & 71\end{array}$

$\begin{array}{ll}11.0 \text { WELL TESTING OPERATIONS } & 77\end{array}$

11.1 Hardy HW\#1 Well 77

11.2 Hunter Bennett \#3997 Well 88

$\begin{array}{ll}12.0 \text { ECONOMIC ANALYSIS } & 90\end{array}$

12.1 Introduction 90

12.2 Economic Assumptions 90

$\begin{array}{ll}12.3 \text { Economic Results } & 97\end{array}$

$\begin{array}{ll}13.0 \text { CONCLUSIONS } & 107\end{array}$

$\begin{array}{ll}14.0 & \text { REFERENCES } \\ & 109\end{array}$ 


\section{LIST OF ILLUSTRATIONS}

\section{Eigure}

Page

Figure 3.1

A Simplified Map of Rome Trough Faulting in West Virginia

Figure 3.2

Simplified Cross Section of the Rome Trough

Figure 3.3A Development of Northwest Edge of Rome Trough

Figure 3.3B

Present Day Structure Along Northwest Edge of Rome Trough

Figure 3.4

Structural Trends, Western West Virginia

Figure 3.5

Cross-State and Local Structural Trends in Putnam County

Figure 3.6

Potential Locations for a Horizontal Well at Area Two

Figure 3.7

Potential Horizontal Well Locations in

Putnam County, WV - Area \#3

Figure 3.8

Relationship of Structural Elements to nrojected 300 mmcf Ultimate Recovery Area - Area \#2

Figure 3.9 Reservoir Quality vs Production, Putnam County

Figure 3.10

Prospect Area 1 and 2 in Calhoun County

Figure $3.11 \quad$ Prospect Area 3 in Boone and Logan Counties

Figure 3.12 
Figure 3.13 Diagrammatic Representation of Faulting in Calhoun County

Figure 3.14 Main Rome Trough Fault and Splay Faults at the Huron Shale Level From Seismic Control

Figure 3.15 Generalized Basement Fault Map of the Prospect 26 Area

Figure 3.16 Potential Horizontal Well Locations at Sand Ridge Prospect

Figure 3.17 Location Selected and Projected Structure on the Target Formation

Figure 4.1 Depth vs Days, Hardy HW\#1

Figure 4.2

Vertical View, Hardy HW\#1

Figure 4.3

Planned View, Hardy HW\#1

Figure 4.4

Depth vs Days, Hunter Bennett \#3997

Figure 4.5

Plan View, Hunter Bennett \#3997

Figure 4.6

Vertical View, Hunter Bennett \#3997

Figure 5.1

True Vertical Depth Presentation of Well Logs of the Hardy HW 1 Well with Gas Shows

Figure 5.2 Well Profile Relative to Target and Gas Shows While Drilling

Figure 6.1 Revised Structure Interpretation of Drill Site 
Figure 9.2 Location of Gas Shows Along Path of the Wellbore

Figure 9.3

Hunter Bennett \#3997. Well Schematic

Figure $10.1 \quad$ Nitrogen Breakdown (Prepad) on Zone 1

Figure 10.2 Foam Fracturing Treatment on Zone 1, Hardy HW\#1,Putnam County, WV

Figure 10.3 Second Nitrogen Breakdown (Prepad) for Zone 2

Figure 10.4 Pressure Response During Initial Foam Pad Injection

Figure 10.5 Nitrogen Pad Injection into Zone 2 After Perforating

Figure 10.6 Foam Frac on Zone 2

Figure 10.7 Initial Attempt to Frac zone 3-4 Using Sand-Laden Foam

Figure 10.8 Attempt at Injecting Foam After Screen-out in Zone 3-4

Figure $10.9 \quad$ Zone \#1 Stimulation, HB\#3997

Figure 10.10 Zone \#2 Stimulation, HB\#3997 76

Figure 11.1 Analysis of Pre-Stimulation Data Using RHM 81 Technique, Hardy HW\#1

Figure 11.2 Pressure Build-up Analysis for Pre-Stimulation Data Using Horner's Technique

Figure 11.3 Hardy \#1 Pre-Stimulation Type Curve Match 
Figure 11.4 Pressure Build-up Analysis for Post Stimulation 85 Data Using Horner's Technique

Figure 11.5 Hardy \#1 Post-Stimulation Type Curve Match 86

$\begin{array}{lll}\text { Figure } 11.6 \quad \text { Hardy \#1 Initial Production Data } & 87\end{array}$

$\begin{array}{lll}\text { Figure } 11.7 & \text { HB\#3997 Pulse Test } & 89\end{array}$

Figure 12.1 BDM/Cabot and BDM/CNGD Capital Investment 93

Figure 12.2 BDM/Cabot and BDM/CNGD Monthly 96

Gas Production

Figure 12.3 Devonian Shale Gas Production From Average 98

Vertical Well and Two Horizontal Wells

Figure 12.4 Base Case Analysis Projects BDM/CNGD Well as Economic

$\begin{array}{lll}\text { Figure } 12.5 \quad \text { Economic Results at } \$ 3.00 / \mathrm{Mcf}^{\prime} & 104\end{array}$

Figure 12.6 Economic Results at \$2.00/Mcf 105

$\begin{array}{lll}\text { Figure } 12.7 \quad \text { Economic Results at } \$ 4.00 / \mathrm{Mcf} & 106\end{array}$ 


\section{LIST OF TABLES}

Page

Table 3.1 Geologic Criteria Used in Screening for Viable

6 Horizontal Well Site Areas with Fractured Devonian Shale Gas Production

Table 3.2 Scoring of Site Selection Criteria and Ranking of Sites

Table 3.3 Scoring of Site Selection Criteria and Ranking of Areas

Table 6.1 Comparison of Rates of Penetration of Motors During Angle Building Drilling

Table 10.1 Summary of Frac Treatments

for the Hardy HW\#1

Table $11.1 \quad$ Basic Reservoir and Well Data

Table 11.2 Pre-Stimulation Well Test Analysis Results Wells

Table 12.2

Average Vertical Well Cash Flow Analysis (Base Case)

Table 12.3

BDM/CNGD Horizontal Well Cash Flow Analysis (Base Case) (Base Case) 


\subsection{EXECUTIVE SUMMARY}

This report summarizes the geologic studies, site selection, drilling, logging, completion, and well testing of two horizontal wells drilled in the gas-bearing Devonian Shale interval in the Appalachian Basin. Detailed technical information concerning each of the two wells reviewed in this volume will be found in the technical report for each well.

Cash flow analyses were undertaken for each horizontal well using the well-specific cost and production information available through the end of January 1992. These results, detailed in this volume, show that a horizontal well is economic over a wide range of economic conditions if: (1) The well cost can be controlled to between $\$ 500,000$ and $\$ 700,000$ and (2) If the well is likely to produce at least $140 \mathrm{Mcf} /$ day over the first year of operations, depending on the price of natural gas. Based on these criteria, the BDM/CNGD horizontal well is judged to be economic at a gas price of $\$ 2.00 /$ Mcf or greater.

This project was initiated under a contract awarded April 26, 1989 to BDM Engineering Services Company (BDMESC) of Morgantown, West Virginia by the U.S. Department of Energy (DOE), Morgantown Energy Technology Center (METC). To carry out the project, BDMESC subsequently entered into cost-sharing agreements with two industry partners, Cabot Oil and Gas Company of West Virginia and Consolidated Natural Gas Development Company (CNGD), a subsidiary of Consolidated Natural Gas Company.

Geologists from BDMESC worked with geologists from each company to examine the acreage under lease relative to the basin geology that controls natural fracture development in the Appalachian area. BDMESC and Cabot narrowed the search for a suitable site to a 40,000 acre area in Jackson and Putnam Counties, West Virginia. In a similar manner, the CNGD holdings became focused on a 19,000 acre area in Calhoun and Gilmer Counties, West Virginia.

Three potential Cabot sites and three potential CNGD sites were selected for more detailed geologic and engineering studies. These 
analyses, summarized in this volume, included analysis of the natural fracture system in the near vicinity of the candidate sites, estimating the horizontal well direction and length needed to intersect these natural fractures, and the collection and analysis of production and reservoir data from vertical wells drilled and completed in the candidate site area.

Each candidate sites was screened against criteria established for this project. The results were submitted by BDMESC to the DOE/METC for approval. Following extended negotiations with both the DOE and the industry partners, DOE approved two horizontal well drilling sites.

Two horizontal wells were successfully drilled and completed. Cabot's Hardy Well \#1 (HW\#1) was spudded on November 29, 1989, and was completed to a total measured depth of 6406 feet on December 29, 1989. The well was stimulateo in May 1990 and the initial openflow production test was 520 Mcfd. The well was produced since May 1990 reaching a peak production rate that average 115 Mcfd in July 1990. The $\mathrm{BDM} /$ Cabot well has demonstrated a very gradual decline in gas production of $3.5 \%$ year as compared with a decline rate of $6.5 \% /$ year for the average Devonian Shale vertical well. This more gradual rate of decline is most likely due to the increased drainage area of the horizontal well as compared with a conventional vertical well.

CNGD's Hunter Bennett Well \#3997 was spudded on November 9, 1991, and was drilled to a total measured depth of 5013 feet on December 14, 1991. Two of four potential intervals were stimulated in December 1991; the initial openflow production test was 860 Mcfd. Production from the two zones completed under the DOE contract was initiated in January 1992. Over the five weeks of production history available at the time of this report, the well has delivered in excess of $100 \mathrm{Mcfd}$ of natural gas and about 1 to 2 barrels of oil per day. With two of the better intervals not yet stimulated, the BDM/CNGD well has significant additional production potential over that recorded in the early well production history.

The BDM/CNGD well is projected to be economic, and comparable with that of a typical Devonian Shale vertical well. Moreover, further 
cost reductions in the horizontal well technology are expected as this new technology continues to mature.

The decision to invest in a conventional vertical well or in the evolving horizontal well technology is highly site-specific and the decision will depend on market economics and the technical information then at hand. Appalachian wells that normally book 300 to 400 million cubic feet of gas reserves would be a likely target for a horizontal well. The horizontal well should be capable of booking from 500 to 700 million cubic feet of reserves to generate sufficient cash flow needed to offset the higher costs of this approach. If the well can be located on or near a natural fracture system, a conventional well may be selected. The horizontal well will increase the probability of intersecting natural fractures in areas not as well defined. This project has demonstrated that the horizontal well can be competitive with a vertical well, and may ultimately prove to be a superior investment opportunity. The choice between vertical or horizontal then becomes a question of how much confidence the operator has in the geologic analyses that must proceed the selection of either type.

\subsection{INTRODUCTION}

The Department of Energy initiated research in the early 1970's related to ways to increase gas production from the vast Devonian Shale resources of the Appalachian area. The early work concentrated on the extent and characteristics of the resource by the U.S. Geological Survey, the State Geological Surveys of West Virginia, Kentucky, Ohio, Pennsylvania, and New York, BDM, and others. As the understanding of the extent and production characteristics of the Shale matured, DOE directed increasing attention to improved extraction technologies, with emphasis on horizontal drilling methods.

METC made several attempts to drill wells deviated to 60 degrees from the vertical in the Devonian Shales in 1972, 1976, and 1980. The first horizontal well drilled by DOE/METC was directed toward the production of gas from coal seams. The first such well was drilled in the Pittsburgh Coal in 1976. 
Horizontal well technology advanced rapidly in the United States in the 1980's, with the first successful horizontal well drilled in the continental U.S. in Texas in 1985. This well and the following two horizontal wells were drilled using mud as the circulating fluid. The BDM/DOE horizontal well (1986) was the first successful well drilled with air and it was the longest air-drilled well drilled to that point in the world.

Horizontal well technology continued to advance over these initial efforts in the United States. DOE sought to further encourage advanced extraction technology for application to the Devonian Shale resource and, in 1988, DOE issued a request for proposals to drill one or more such wells. In response to the request, BDM proposed to drill two horizontal wells cost-shared with industry partners. This report summarizes the results of this contract, including the projected economics of each of the two wells which were successfully drilled, completed, and placed on production under DOE contract.

\subsection{GEOLOGIC STUDIES, LEASE ACQUISITIONS AND LOCATION DEVELOPMENT}

BDM and its industry partners used reservoir pressure and cumulative production of gas from the Devonian shales to screen areas that should be studied in more detail for geologic siting purposes. Cabot provided information on 40,000 acres in Jackson, Putnam and Kanawha Counties West Virginia, while CNGD provided information on 30,000 acres located in Boone, Calhoun and Gilmer counties, West Virginia.

BDMESC conducted a systematic regional geologic study to determine the key structural elements that would have contributed to the fracturing of the Devonian Shales and thus locate areas where better quality reservoir conditions should be found. The results of these studies were compiled into topical reports and submitted to DOE/METC. A summary of the geographic area and specific site selection process for each well is presented in sections 3.1 and 3.2 below. 
3.1 Selection of Area and Site foi the Hardy HW\#1 Well, Putnam County, West Virginia

Contract specifications required that the horizontal well be drilled in an area of established production to avoid exploration risk. based on factors known to control Devonian shale gas production compiled set of geologic criteria to be used in selecting target areas and potential well sites. Table 3.1 presents these criteria which resulted in the initial selection of three areas for more detailed study.

Economical Devonian Shale gas production is very strongly related to the presence of well-developed natural fracture systems. Such fracture systems are most often generated by tectonic activity. During Pre-Cambrian time in the central West Virginia area, a rift-fault system was generated which produced faults in the basement rocks as indicated in Figures 3.1 and 3.2. The pull-apart (rift ) faults generated as shown in Figure 3.3, parts $A$ and $B$, were later modified by reverse movement along the old fault planes to produce a modification in structure as shown in Part C.

This rift system of faults and fractures was superposed over an older existing system (Grenville) which was generated during an earlier episode of continental collision. A third trend noted is one that is believed due to systematic earth rotational stresses which produces large scale regional fractures and has been labeled as Cross-strike Structural Discontinuity (CSD). These three trends, oriented $N-S, N-W$, and $N-E$, are identified in the western West Virginia area in Figure 3.4.

Examination of Landsat imagery and stream drainage maps and mapping of linear features revealed the major structural features in the Putnam County area which should have a bearing on the development of higher quality reservoir fracture system. Figure 3.5 presents the major structural trends in the Putnam County area and the location of the three areas considered for the horizontal well location.

A review of production records in all three areas resulted in the elimination of area \#1 because of an excessive water production. Potential locations of horizontal wells for areas \#2 and \#3 are shown in 
TABLE 3.1

\section{GEOLOGIC CRITERIA USED IN SCREENING FOR VIABLE HORIZONTAL WELL SITE AREAS WITH \\ FRACTURED DEVONIAN SHALE GAS PRODUCTION}

\section{GEOLOGIC CRITERIA}

1. Thickness of Huron Shale: >250 Feet.

2. Thickness of Lower Huron Shale: $>150$ Feet.

3. Grenville Trend (N-S) Faulting or Fracturing Present.

4. Rome Trough (SW-NE) Fauiting or Fracturing Present.

5. Cross-Strike Structural Discontinuity (CSD) Trend (N40-55 $\mathrm{W}$ ) Present.

6. Stress Ratio Favoratie: (Generally<4.0).

7. Gas Content of Shale: $>50 \mathrm{mcf} / \mathrm{ac}-\mathrm{ft}$.

8. Average Gas-In-Place per 160 Acres: $\geq 500$ mef.

9. Devonian Shales Estimated Ultimate Recoverable Reserves: $>300$ mmcf.

10. One or More 160-Acre Locations Available: (3000 Foot Well Spacing). 


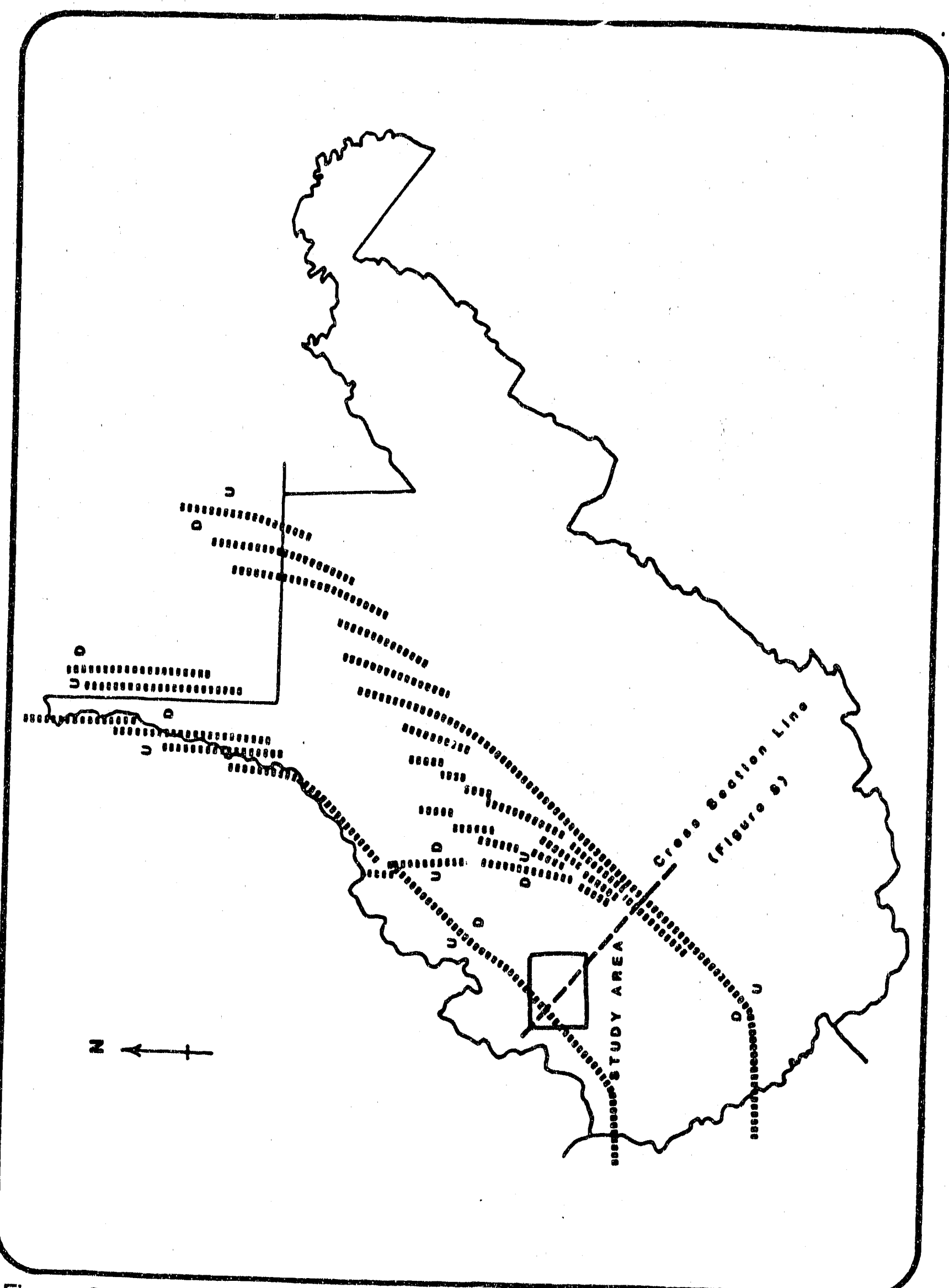

Figure 3.1 - A Simplified Map of Rome Trough Faulting in Mest Virginia 

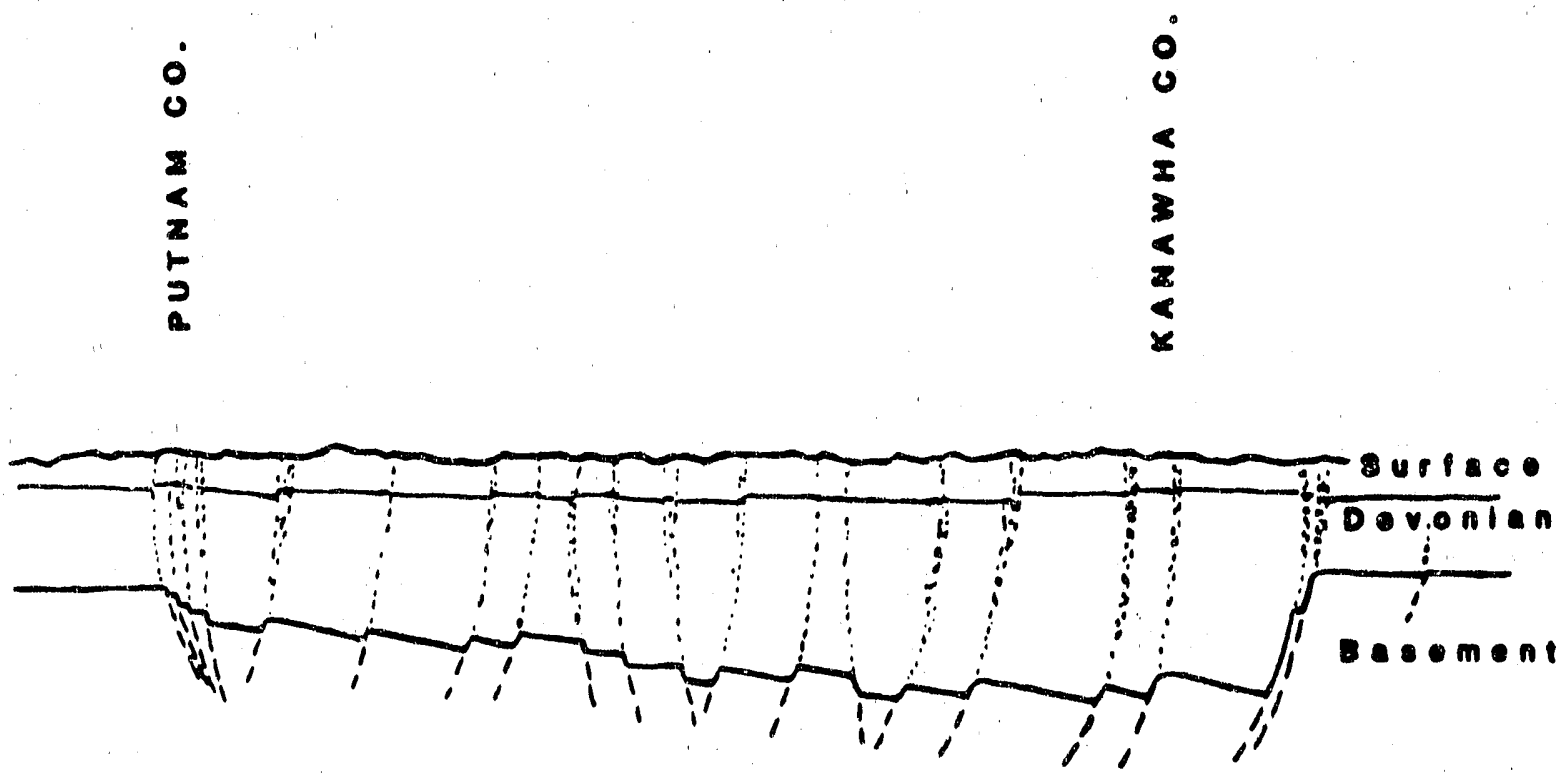

This cross section shows the multiple faults along the outer edges of the trough and the complexity of the trough floor.

Faults and fractures extend subvertically through the Devonian to the surface. Approximate vertical exaggeration $\times 2$.

Figure 3.2 - Simplifin Cross Section of the Rome Trough 


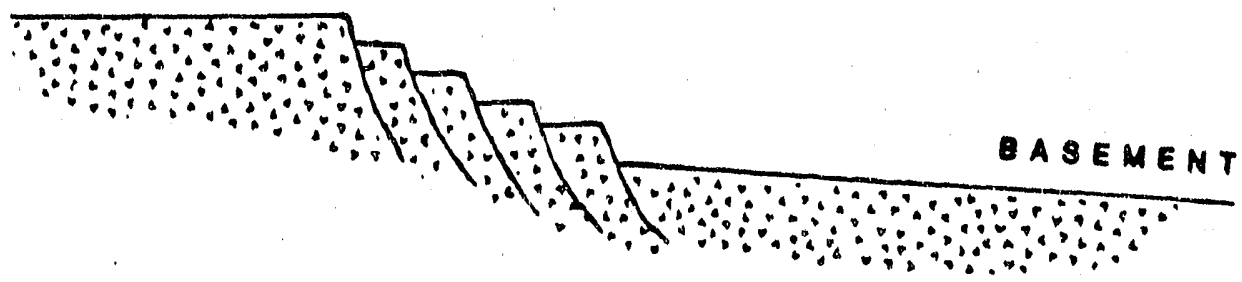

A - Onondaga is deposited over basement faults stepping down into trough.
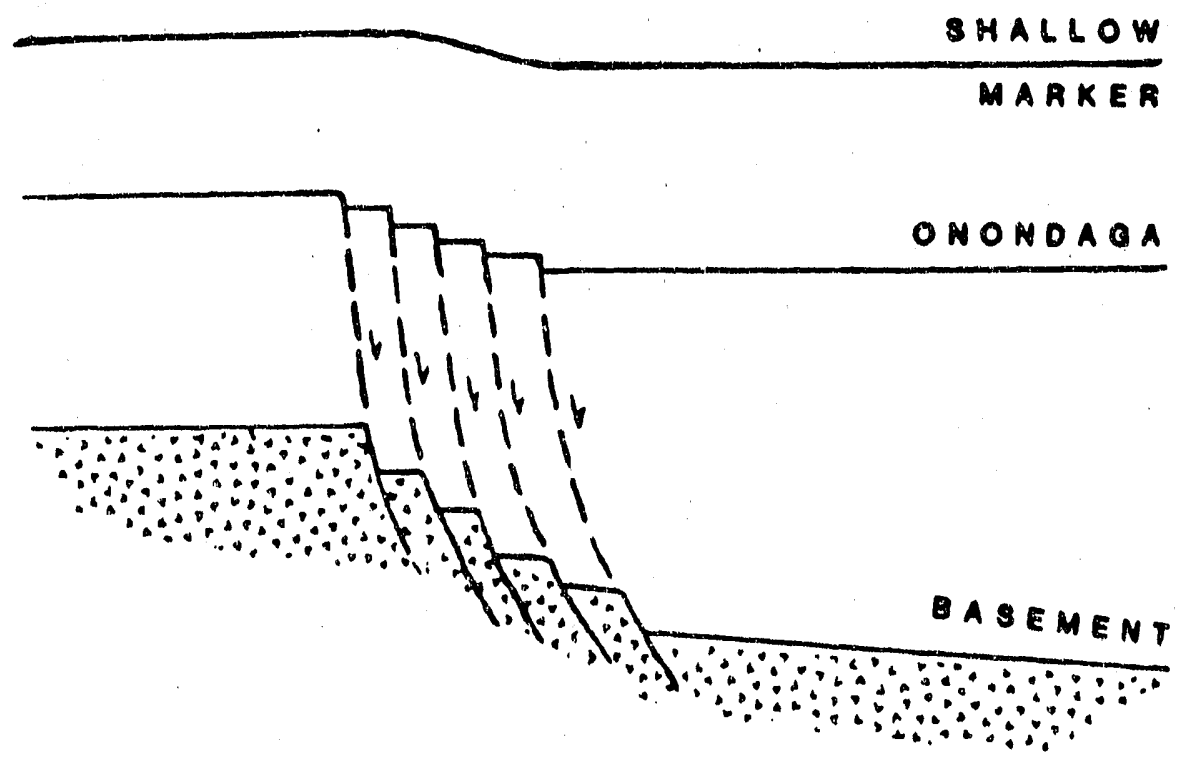

B - Basement activity continues with Onondaga faulted and shallow marker draped over trough edge.

Figure 3.3 A Development of Northwest Edge of the Rome Trough 
BHALLOW

MARER

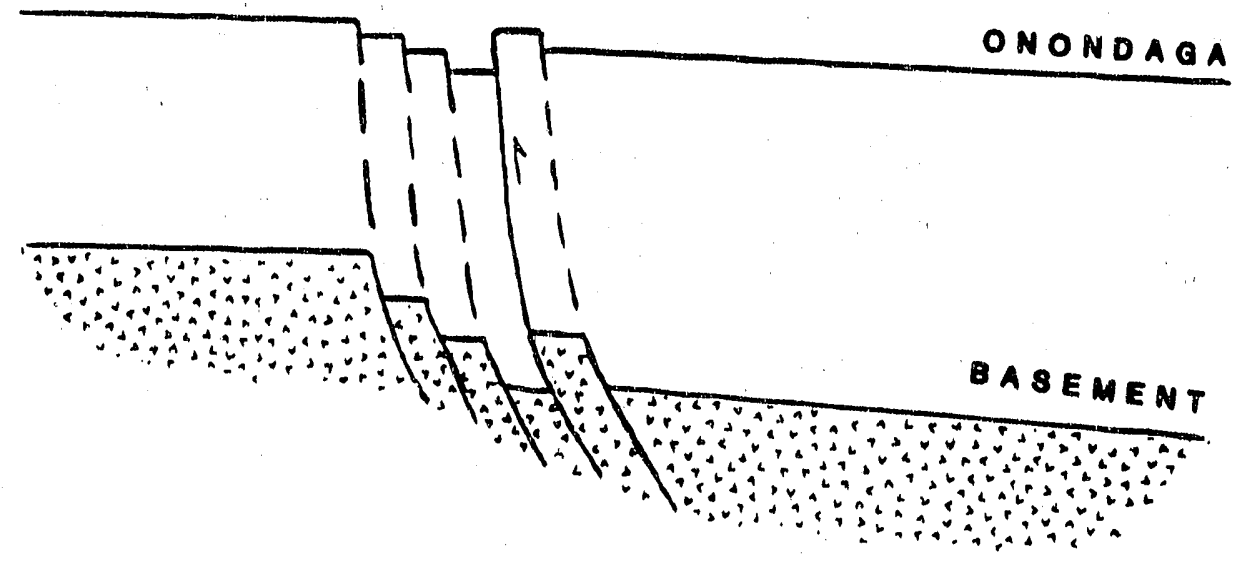

Late inversion of trough fault creates complex structures on the shallow marker.

Figure 3.3 B - Present Day Structure Along Morthwest Edge of Rome Trough 


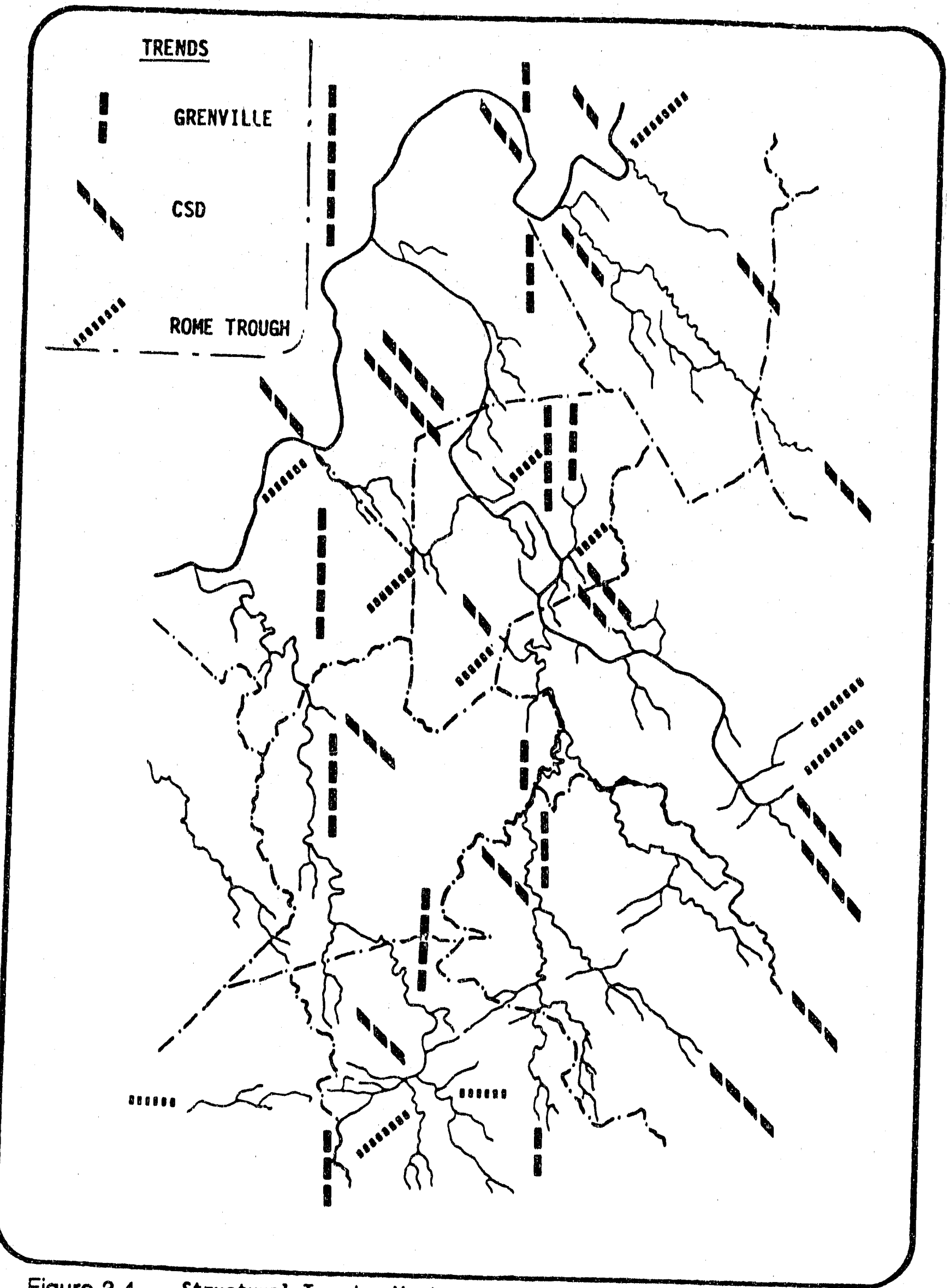

Figure 3.4 - Structural Trends, Nestern West Virginia 


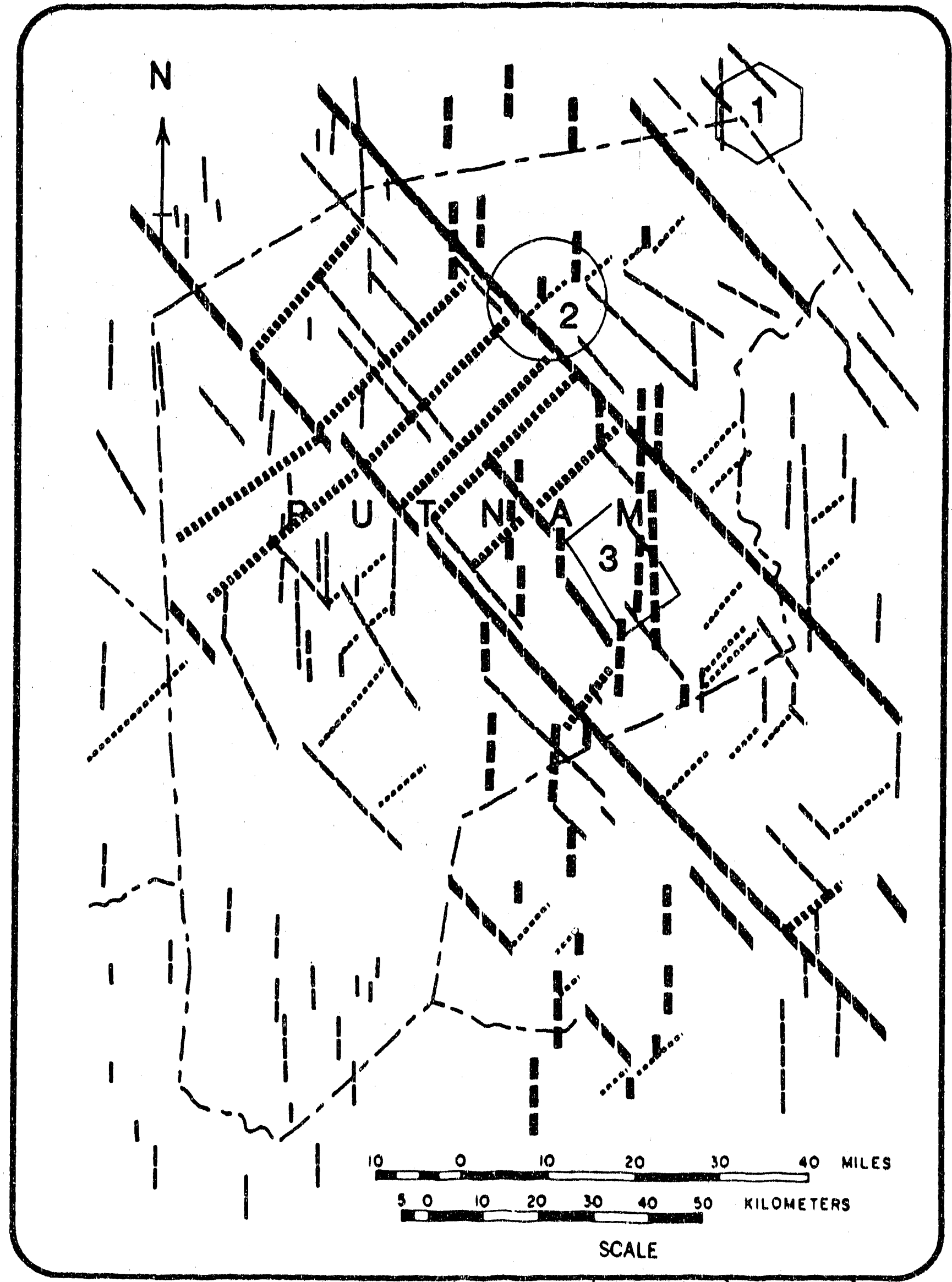

Figure 3.5 - Cross-State (Heavy Lines) and Local (Light Lines) Structural Trends in Putnam County 
Figures 3.6 and 3.7. These locations depict the sites where enough area was available to drill a horizontal well if the geology and production history were supportive.

The relationship between areas that were projected to produce 300 million cubic feet of gas and the primary structural features that had been mapped are presented in Figure 3.8. Figure 3.9 shows the relationship of Area \#2 and Area \#3 to a plot of production history versus reservoir quality. Reservoir Quality was defined as the number of cubic feet of gas produced as a function of the decline of 1 psi of reservoir pressure (mcf/psi).

As shown in Table 3.2, the average 5-year cumulative production for Area \#3 exceeded that of Area \#2 by about 20 million cubic feet of gas. Gas content and average gas-in-place figures however, were very close. The difference in 5year cumulative production was believed to be in the nature and extent of fracturing in the shales since there was little change in the actual gas content due to organic carbon sourcing material present. Area \#3 is located near a major CSD while Area \#2 was not. The CSD mapped in area three (3) was also supported by coal deposition trends.

BDMESC projected that successful wells could be drilled at either Area \#2 or Area \#3. Because BDMESC's Area \#3 proposed location was offsetting a dry hole (well not stimulated) in the target Devonian Shale, DOE/METC preferred the location in Area \#2 because of reduced risk. Cabot also believed that a successful well could be drilled in Area \#2 and agreed to accept DOE's recommendation.

3.2 Selection of Area and Site for the Hunter Bennett \#3997 Well, Calhoun County, West Virginia

As with the Cabot project, contract requirements for the CNGD well specified that the uncertainties of an exploratory location were to be avoided. The CNGD well site was to be in an area with good developmental well control, where oil production was less likely than natural gas production and where reasonably high formation pressures could be anticipated. 


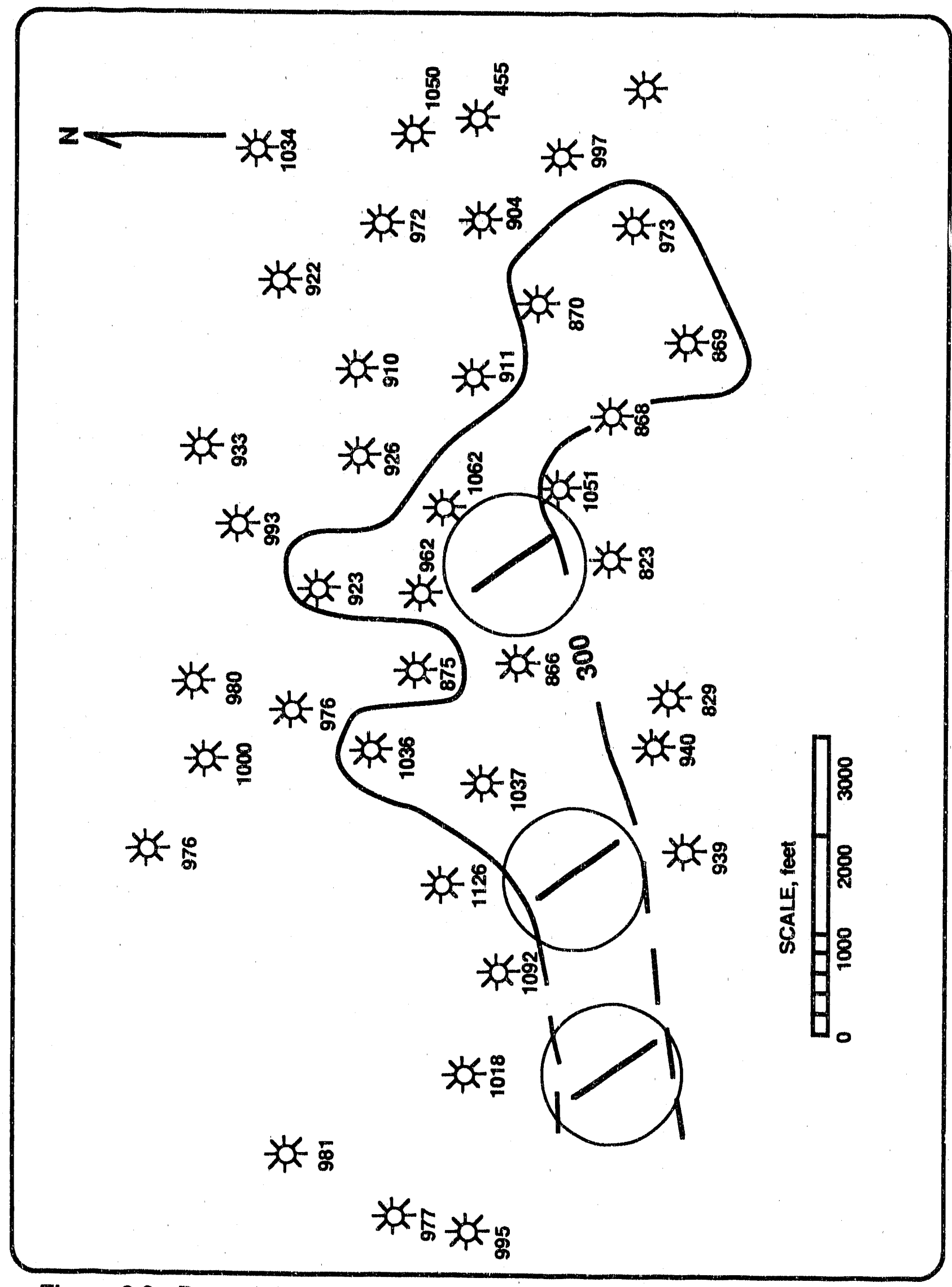

Figure 3.6 - Potential Locations for a Horizontal Well at Area Two 


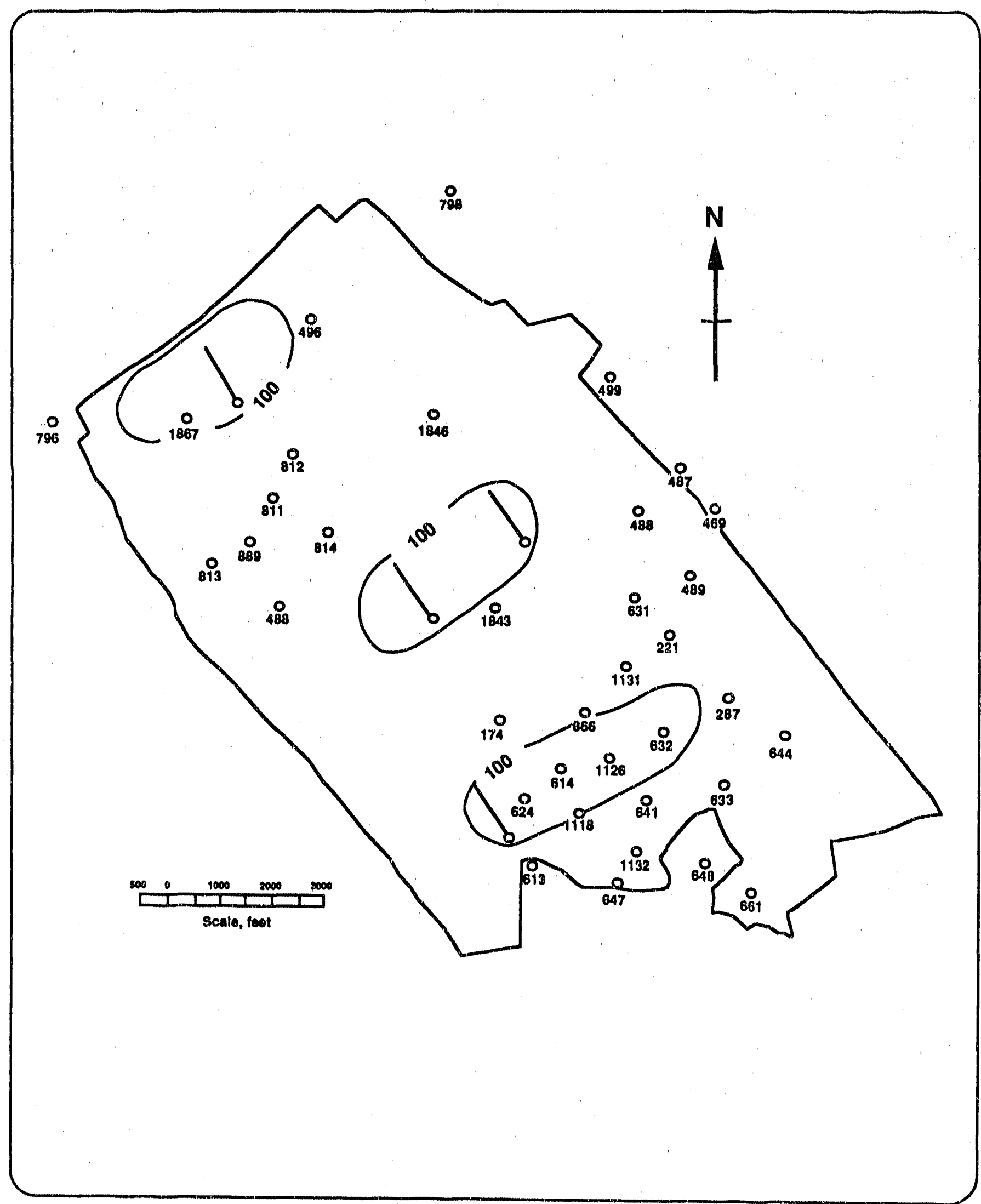

Figure 3.7 - Potential Horizontal well locations in Putnam County, WV - Area \#3 


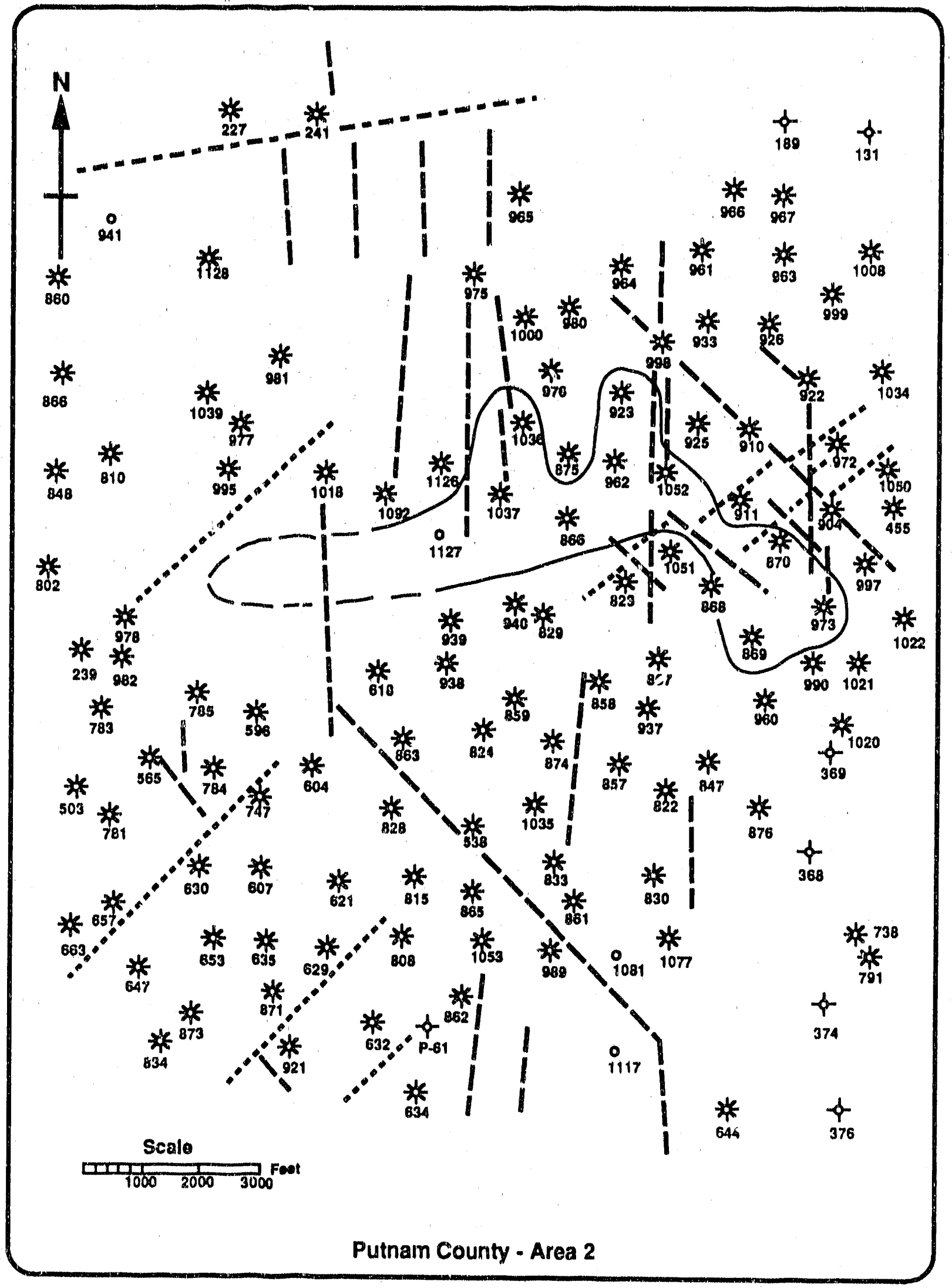

Figure 3.8 - Relationship of structural elements to projected 300 mmcf ultimate recovery area - Area \#2 


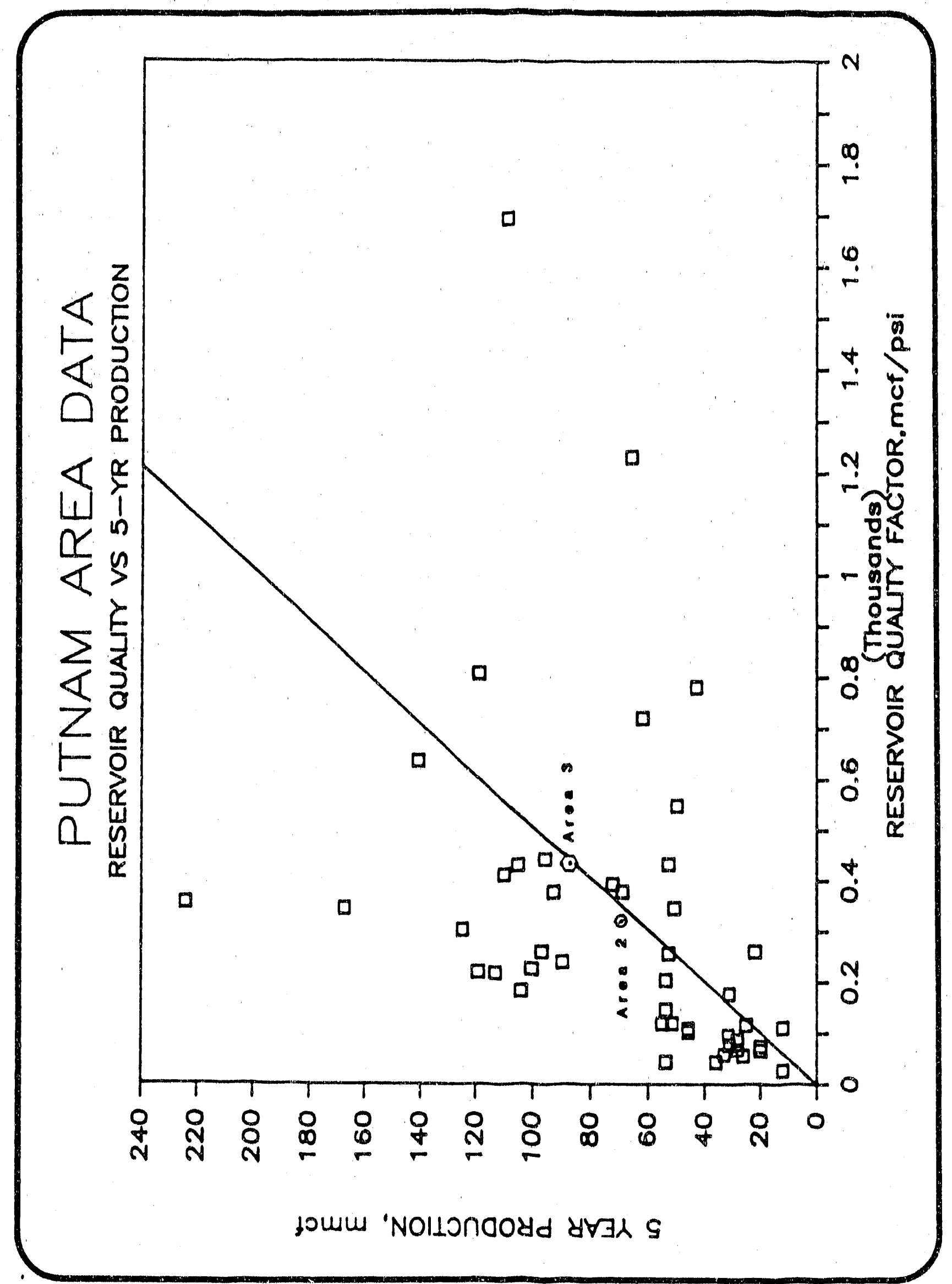

Figure 3.9 
Table 3.2

SCORING OF SITE SELECTION CRITERIA AND RANKING OF SITES

ENGINEERING PROPERTES

Thickness of Lower Huron

Average Initial Rock Pressure (psig)

Average Current Rock Pressure (psig)

Average Initial Open Flow After

Stimulation (met)

Average Five-Year Cumulative

Production (met)

Average Ultimate Cumulative

Production, (mmef)

Average Siress Ratio

Average Reservoir Quality Factor

Gas Content (mct/Acro-tt)

Average Gas-In-Place (160 Acres)

Coal Mines Present

Water Production

Composite Ranking

Individual Ranking

(n)

AREA H2 SITE RANK AREA STIE RANK

185

798 (58)

367

360

$67,800(13)$

231

0.35 (13)

322

7420.0

9.16 bef

No

Yes
1

1

1

2.

2

183

2

$693(20)$

289

365

1 
While Cabot had submitted acreage along the northwestern margin of the Rome Trough for consideration in their project, CNGD offered three large blocks of acreage, (Figures 3.10 and 3.11 ) two of which lay along the southeastern margin of the trougin, where Basement faulting was much more intense. The third area overlay one of the larger known intra-trough faults.

Figure 3.2 shows the basic asymmetry of the Rome Trough. Basement offsets along the northwestern margin of the rift appear to be on the order of hundreds of feet. The faults along the southwestern margin appear to have thousands of feet of offset, by way of contrast (Figure 3.12). These greater offsets have produced much more intense fracturing in the shales in the areas submitted for study by CNGD than in the Putnam County shales.

The areas suggested by CNGD lay in northern Calhoun County, in southern Calhoun County, and along the Boone-Logan county line. The first of these lay above a series of significant basement faults that had been identified by CNGD from seismic data (Figure 3.13). The southern Calhoun County and Boone-Logan areas were along or near the Rome Trough margin.

\subsubsection{Nerthern Caihoun County}

The northern Calhoun County block was reviewed, and several geologically promising locations were found, associated with good surface and subsurface indications of intense fracturing and good porosity development in the shales, but the data base there was comparatively limited, and the engineering data were insufficient to predict the required high formation pressures at the better geologic locations. Infill drilling patterns would have required well siting at locations that could not have been supported as "intensely fractured," based on the geology. In some of the well-drilled areas: rock pressures remained high, but there was little evidence for fracturing, and production had been mediocre to subeconomic. In the areas with good evidence of extensive faulting at the Basement level and of fracturing in the shales, there were some excellent, wells, but pressures were too low to meet the project requirements. 


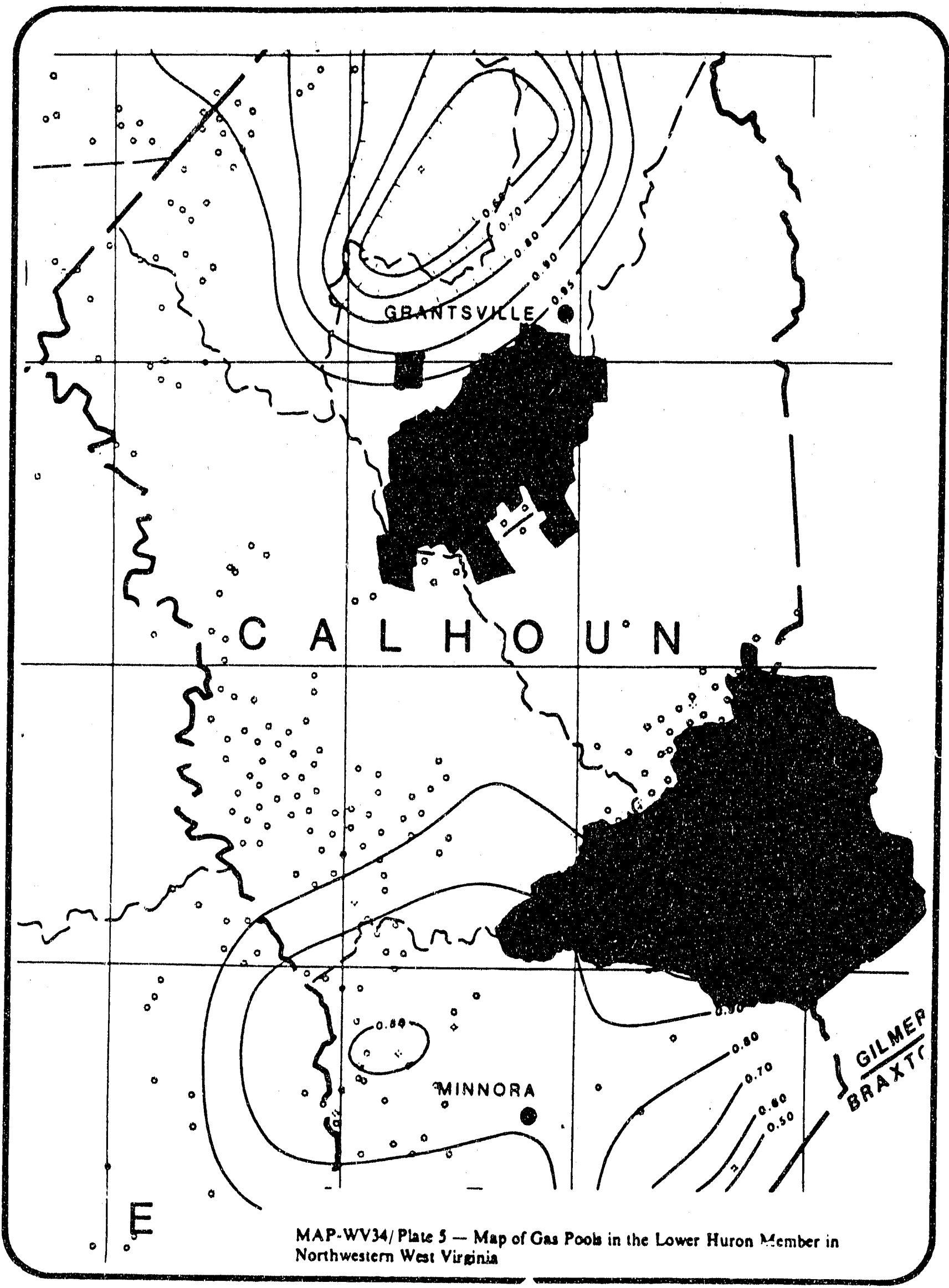

Figure 3.10 - Prospect Areas 1 and 2 in Calhoun County 


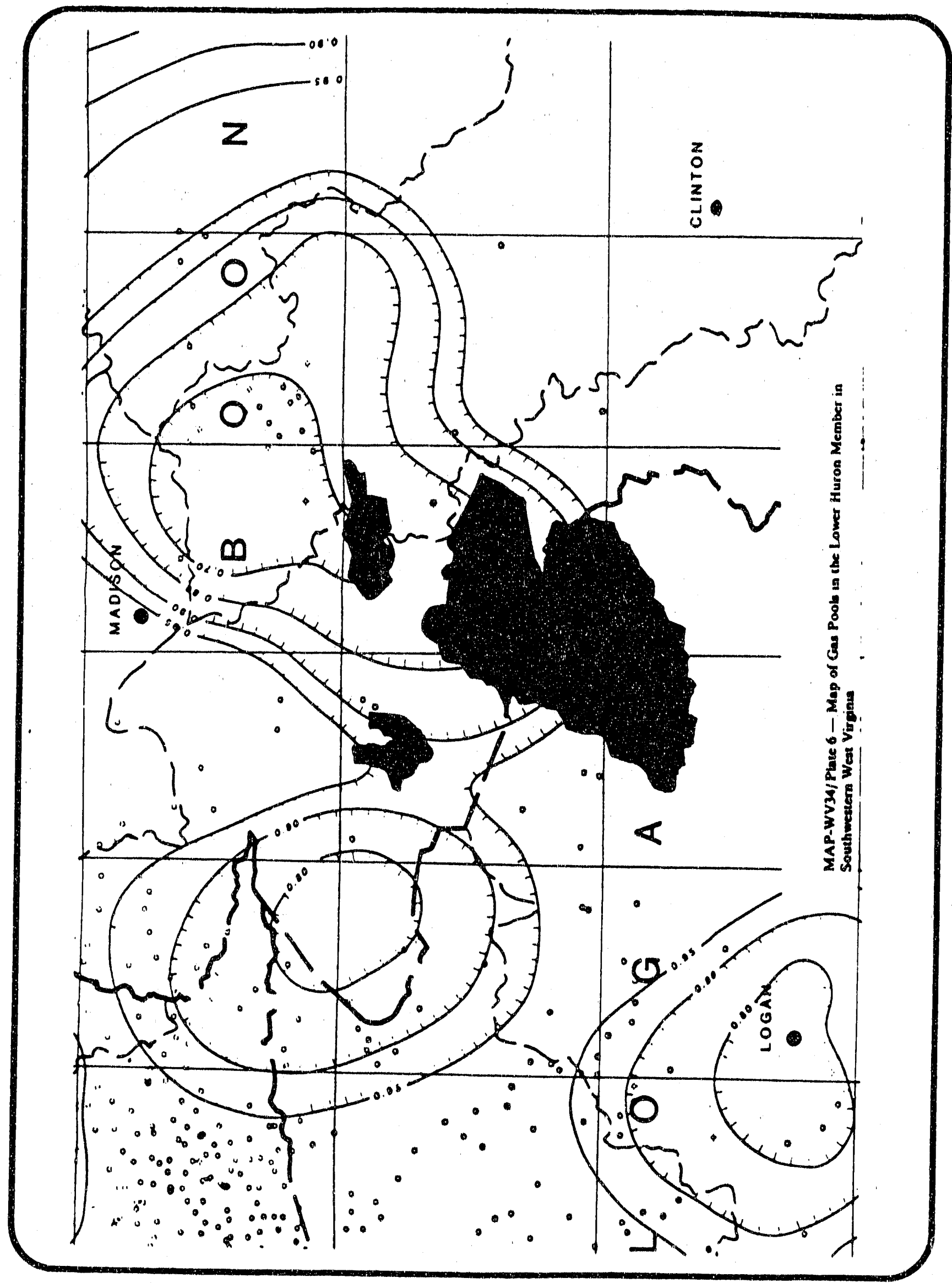

Figure 3.11 - Prospect Area 3 in Boone and Logan Counties 
NW

$0.0-S E$

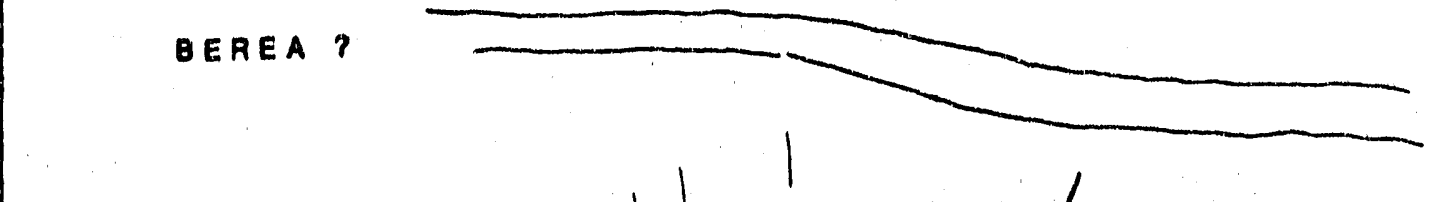

ONONDAGA

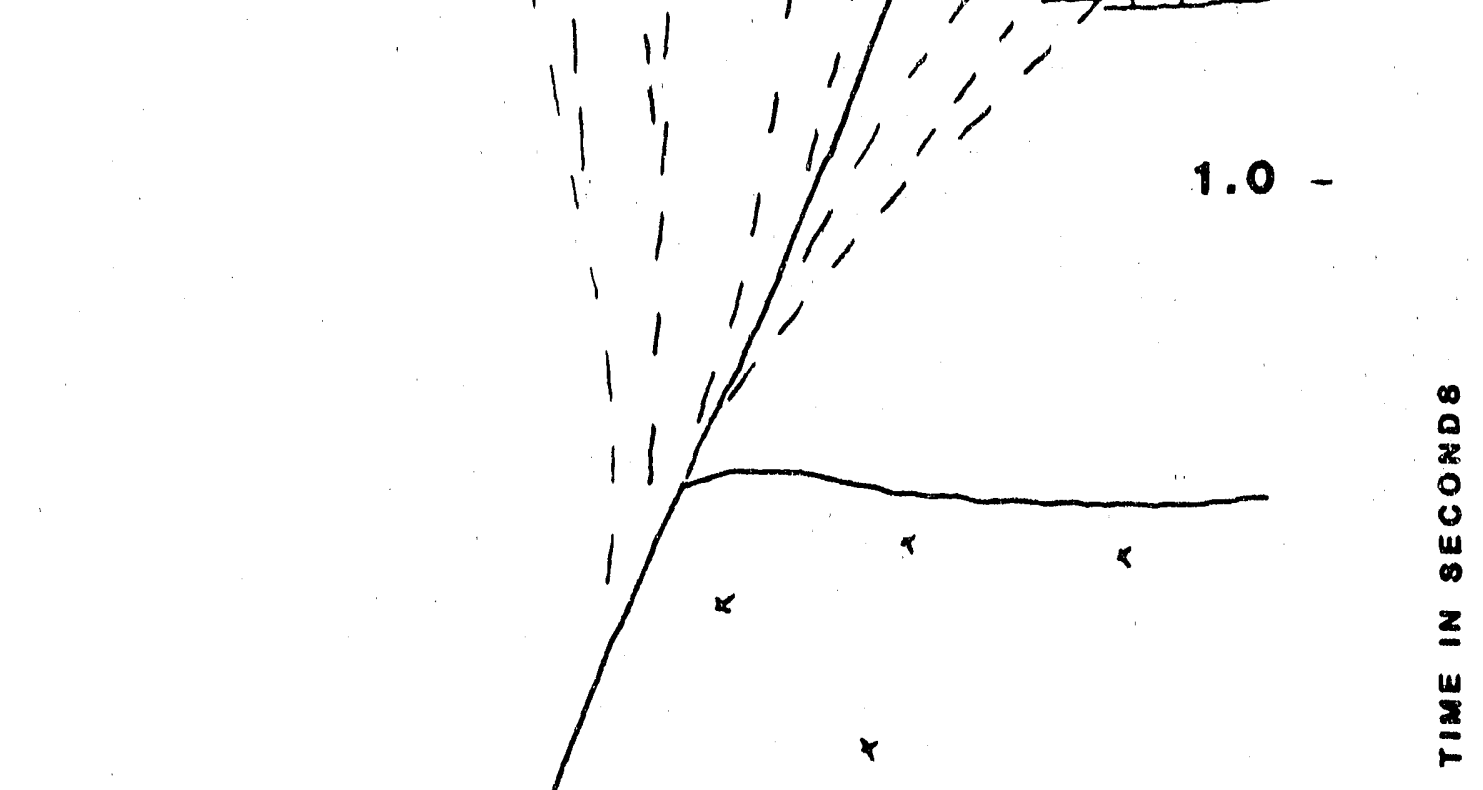

2.0

STABLE SHELF

BASEMENT

4

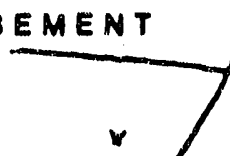

$3.0-$

Figure 3.12 - Southwestern Rome Trough Edge at Logan County 


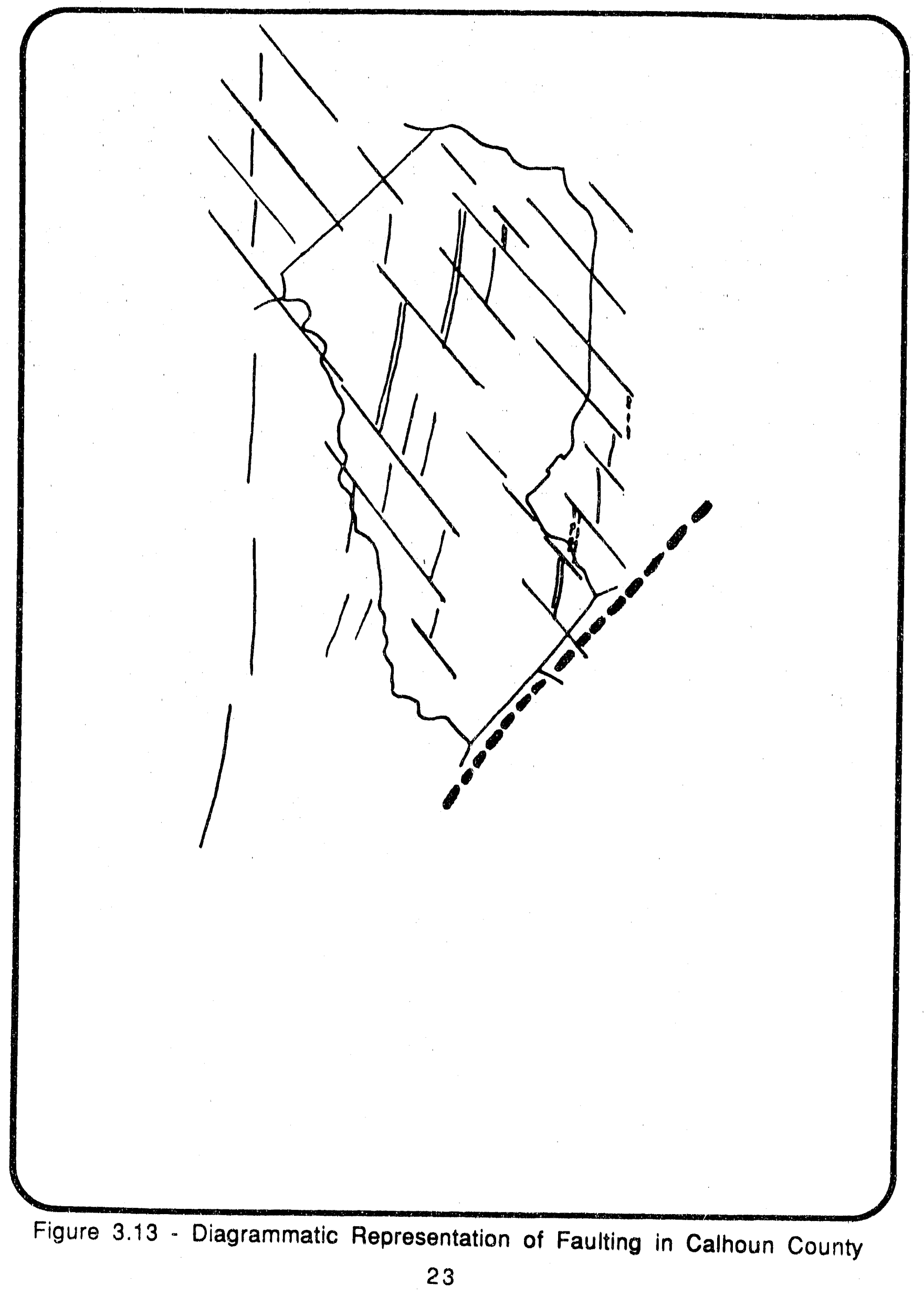




\subsubsection{The Boone-Logan County Line Area}

The Boone-Logan acreage block lay along what appears to be the most intensely deformed portion of the Rome Trough in West Virginia. Basement offsets here are the largest seen in this portion of the continent Figure 3.12). Detailed geologic study and structure mapping showed a long zone of intense deformation with extensive extensional fracturing over the Basement fault zone that had excellent potential for shale production (Figure 3.14). Production in many of the shallow wells overlying the Basement faults was found to be exceptional. The better Boone-Logan shale gas wells were greatly under-pressured, compared to theoretical models. Therefore, when the pressure data were reviewed and mapped, the Boone-Logan area was eliminated from further consideration.

\subsubsection{Southern Calhoun County}

The area that was eventually selected for the study well was in southern Calhoun County, just within the Rome Trough. The offset at the Basement level in this area was just a fraction of that found at BooneLogan, but was still measured in thousands of feet (Figure 3.15).

CNGD had a very large single leasecovering in excess of 19,000 acres in this area. This lease had been tested in the shale with a number of wells, giving good geologic and engineering data to meet the "Developmental Well" requirements of the project. Seismic maps, lineament maps, shallow structure maps, and production data were reviewed to identify the local structural history of the area and to establish the relationship between the structures and production trends. A series of production fairways was recognized and related to the complex structural history of the area.

\subsubsection{Selection of Area and Site}

Engineering and geologic data were compiled and the sites were ranked as shown in Table 3.3. The larger thickness and original gas reserves ranked Boone-Logan area higher than Sand Pidge in Calhoun/Gilmer Counties; however, projected ultimate recovery was nearly equal. Calhoun County had a much higher reservoir pressure which 


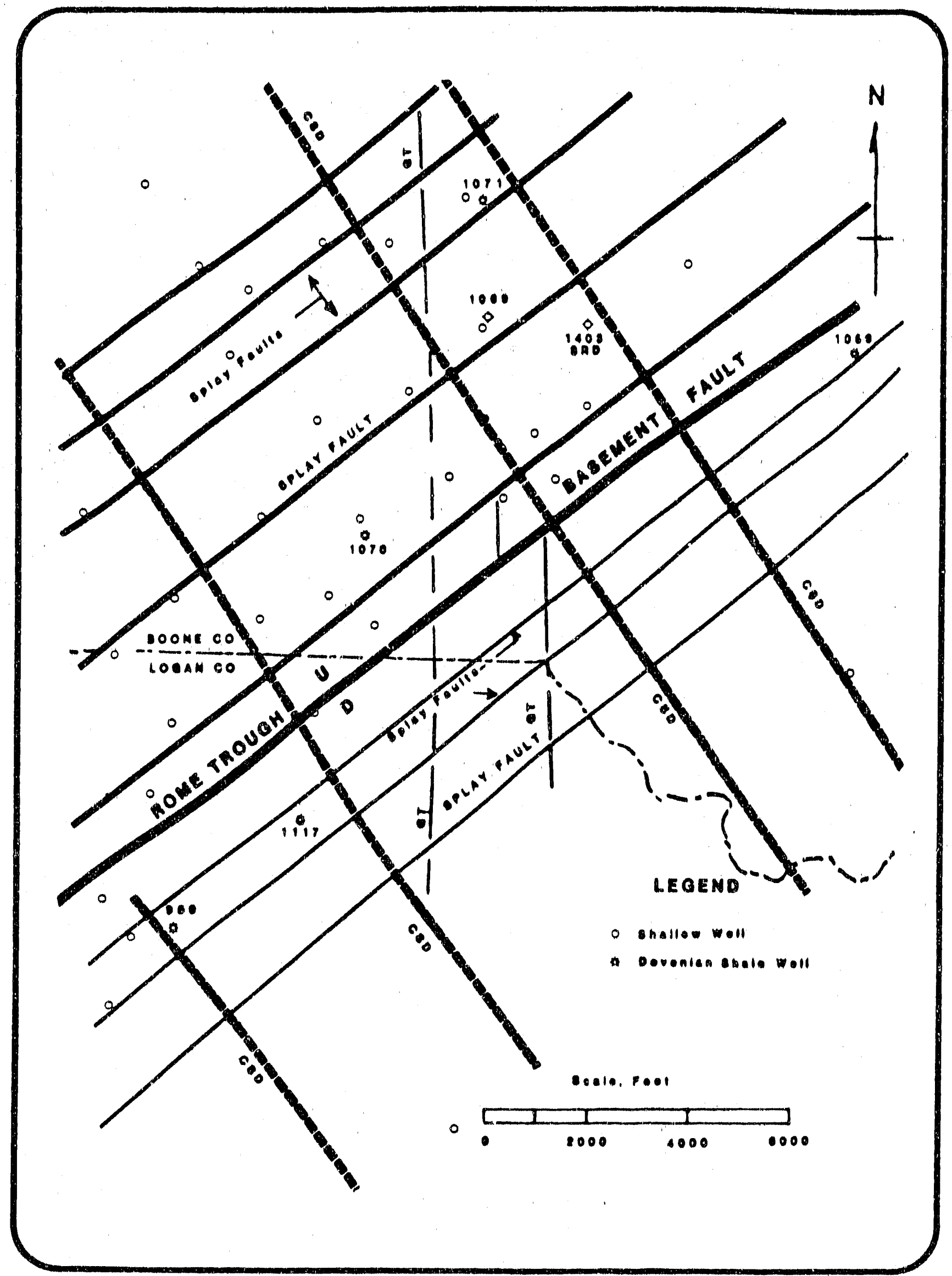

Figure 3.14 - Main Rome Trough Fault and Splay Faults at the Huron Shale Level From Seismic Control 25 


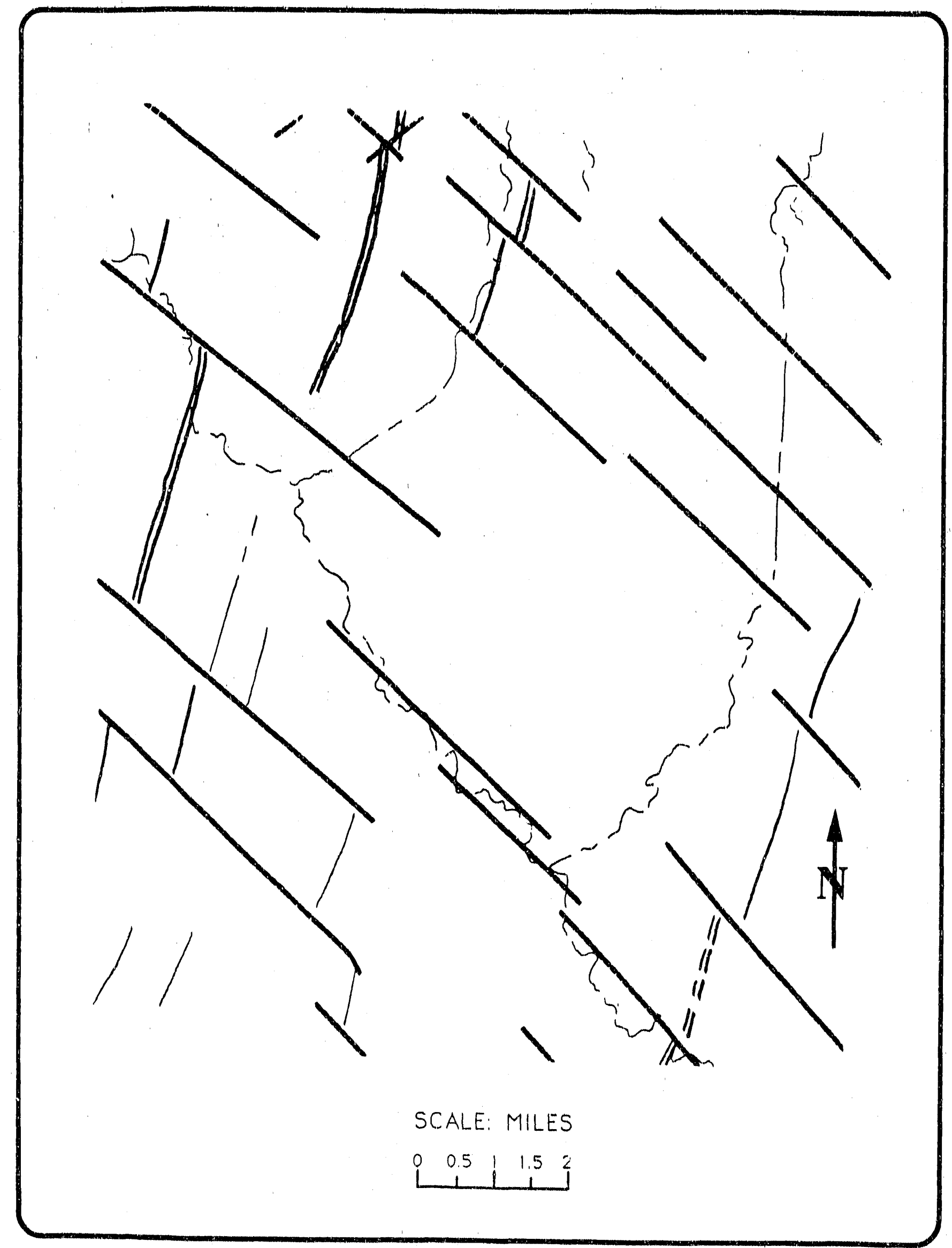

Figure 3.15 - Generalized Basement Fault Map of the Prospect Area 26 


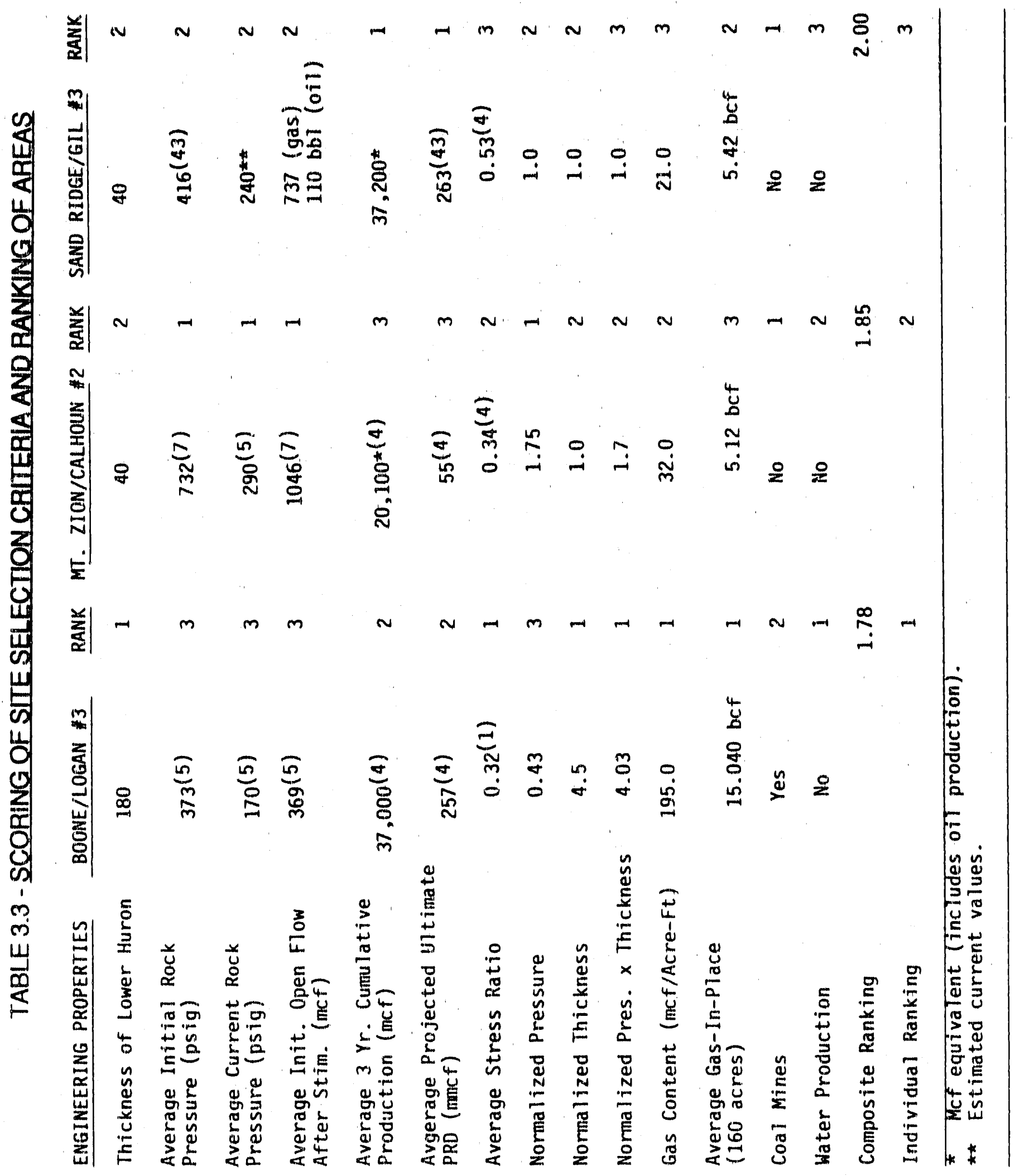


was a critical requirement; therefore, Area Three in Calhoun County was approved by DOE.

BDMESC located several high-potential well sites (Figure 3.16) that should have good fracturing in the shale section and excellent production possibilities. These locations were ranked, and wells with a higher potential for oil production were eliminated, due to the complications from oil production in a horizontal hole. BDMESC, CNGD, and DOE ultimately agreed on a site just west of the main 19,000 acre Hunter Bennett Lease. The location required additional lease negotiations with CNGD partners. Projected structure and location of the drill unit negotiated along with well location and trajectory are shown in Figure 3.17 .

\subsection{DRILLING OPERATIONS}

In accordance to the terms of the contract, two horizontal wells were drilled and completed; Cabot's Hardy HW\#1 and CNGD's Hunter Bennett \#3997.

\subsection{Hardy HW\#1 Well}

Hardy HW\#1 was spudded on November 29, 1989, and drilling operations completed on January 2, 1990. The conductor hole was drilled to 32 feet below ground level and a 20" conductor pipe was set. A 17-1/2" surface hole was drilled to 696' KB through fresh water zones and coals. Sixteen joints of $13-3 / 8^{\prime \prime}, 54.5 \# / f t, J-55$, ST\&C casing were run, set, and cemented to a depth of $668^{\prime} \mathrm{KB}\left(654^{\prime} \mathrm{GL}\right)$.

The 12-1/4" intermediate hole was drilled to a depth of 2657 '. Water flow was encountered in the Maxton sand section and the Big Injun formation, where water had been anticipated. At this point, the well was mudded up. A mud pit, mud pump, and shale shaker were rigged up.

A string of 9-5/8", 36\#/ft, J-55, ST\&C casing was run and set at $2654^{\prime} \mathrm{KB}$. The casing was cemented to surface using a total of 430 sacks of which 100 sacks of Class " $A$ " cement containing $3 \% \mathrm{CaCl}_{2}$. After waiting on cement for 12 hours, the $13-3 / 8^{\prime \prime}$ casing was cut off and 


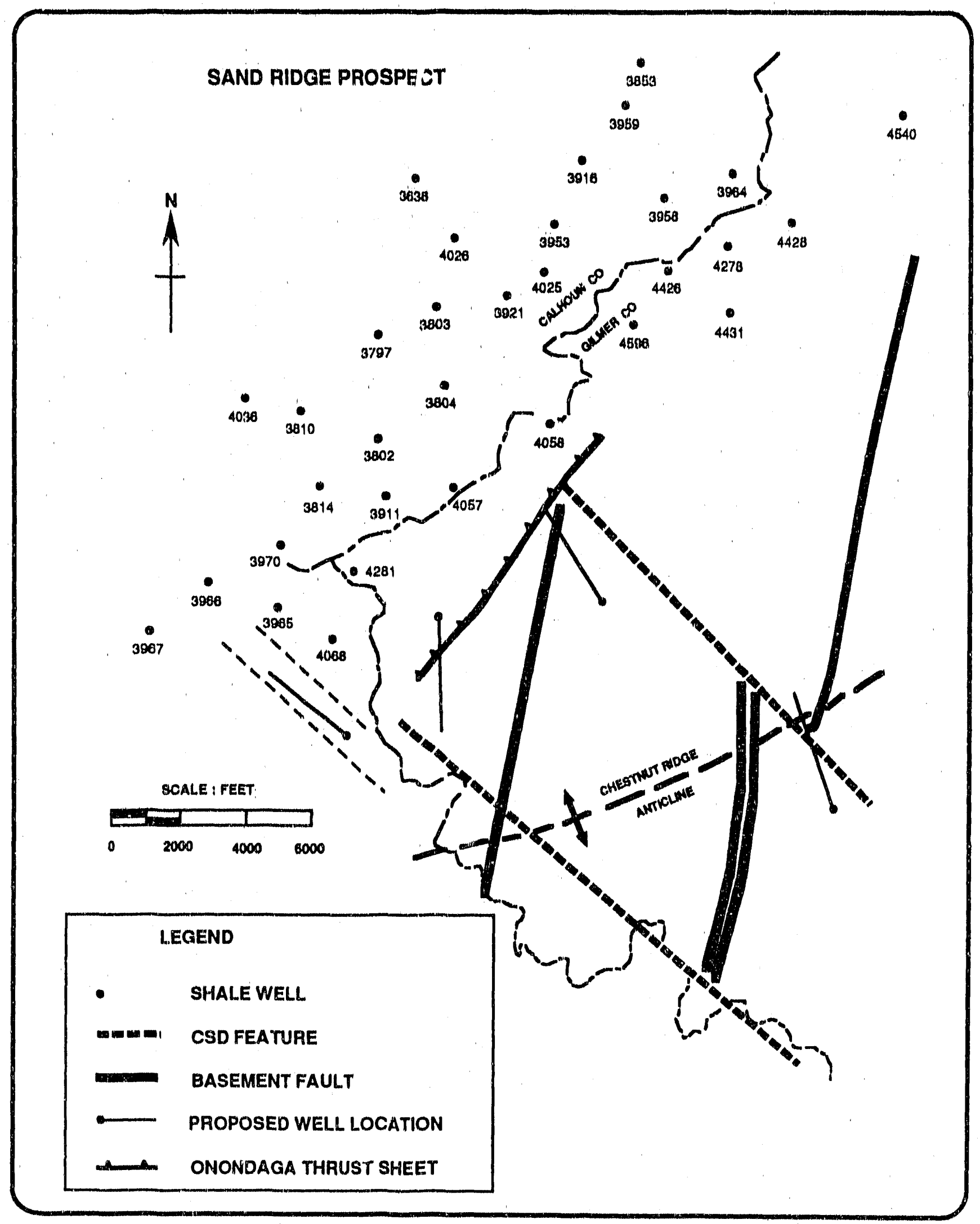

Figure 3.16 - Potential Horizontal Well Locations at Sand Ridge Prospect 

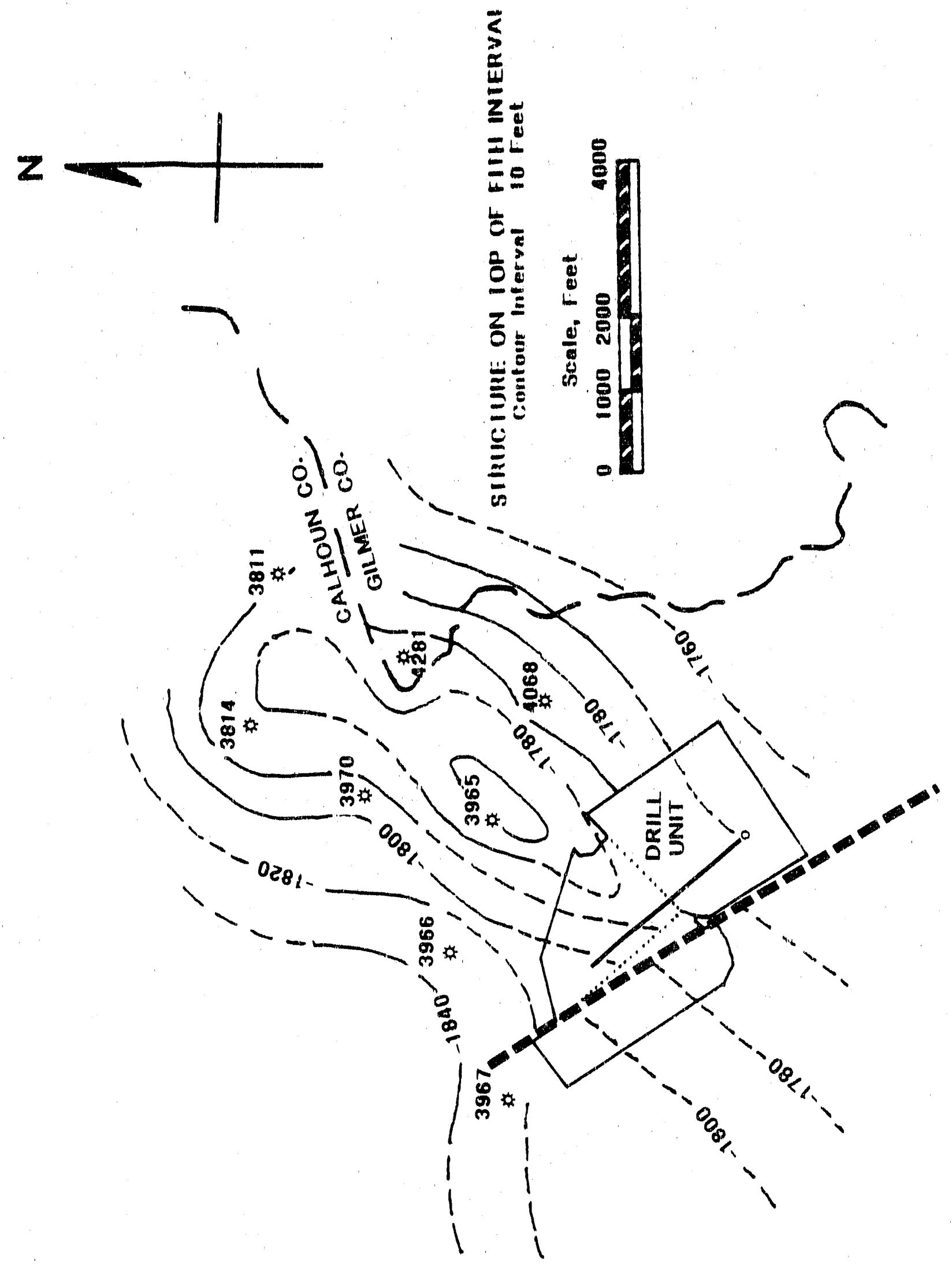

Figure 3.17 - Location Selected and Projected Structure on the Target Formation 
welded to the 9-5/8" for support. The mud system was rigged down and the air system rigged back up. The BOP's were nippled up and the casing drilled out with an 8-3/4" bit. Drilling continued, (dusting) to 3253' when a survey was taken to determine inclination and well direction. The survey showed an inclination of $1^{\circ}$ and an azimuth of $279^{\circ}$ at a depth of $3194^{\prime}$.

Based upon the Berea top, the kickoff point should have been at 3295'; however, the kick-off point was changed to 3253' to provide some margin for failure to build angle at the planned rate. The Eastman air motor was designed for a build rate of $8 \% 1100^{\prime}$ which was exactly the rate required. Because an azimuth change had to be made and the build rate from a motor will nearly always be slightly less than the design rate the kick-off point was moved up the hole by almost fifty feet. The first motor run drilled from $3253^{\prime}$ to $3487^{\prime}$ at an average penetration rate of 47 feet per hour. The build rate experienced with this motor configuration was only 5.9\%1100'. The motor was pulled from the hole and the bend was adjusted and set at the maximum angle of $1.3^{\circ}$ which according to Eastman's design should yield a build rate of $9.5 \% 100$. The motor was tripped back in the hole and drilling continued to $3603^{\prime}$ but the build rate was still only $6.3^{\circ} / 100^{\prime}$. Several configuration changes were attempted using the $8-3 / 4^{n}$ bit and bent sub set ups, but the motor was still building inclination at an average rate of $6.6 \% 1100$ ' which was still not fast enough to hit the target. The bit size was then reduced to 8-1/2" and the jets were left out of the bit. The build rate achieved in the smaller diameter hole was $8.4 \% 100$. At that rate, the well would be nearly horizontal at TVD of approximately $4100^{\prime}$ which was barely acceptable. Drilling continued to 4249' $M D$ when the motor rotated $90^{\circ}$ to the right on a connection. The motor was worked back up to high side and the well was drilled to $4324^{\prime} \mathrm{MD}$. The survey data from the steering tool indicated that the well was turning to the left and not building much inclination, which meant that either the geometry of the motor assembly in the hole had changed or the steering tool was no longer oriented properly. To be sure of correcting the problem, it was decided to change out the motor assembly. The Eastman air drilling motor was replaced by a Baker motor with a $2^{\circ}$ bent housing with no stabilizers and with the same 8-1/2" bit. The motor drilled 98 feet but problems with the steering tool prevented drilling further. Problems with the steering tool and the electromagnetic MWD 
(EMWD) continued to delay the drilling operations in the build section. At a d. pth of 4502', the three-axis steering tool failed. The tool had come apart and the motor had to be pulled to retrieve the remainder of the steering tool. The motor was run back in the hole and drilled to $4610^{\prime}$ at which point the inclination was projected to be $90^{\circ}$ with an azimuth of $340^{\circ}$. The motor was pulled and laid down and the rest of the hole was drilled with rotary assemblies. A multi-shot survey showed that the well reached $90^{\circ}$ at a measured depth of $4605^{\prime}$ (4082' TVD).

The horizontal sectic was drilled from 4610' $M D$ to $6399^{\prime} M D$ using rotary assemblies. The bottom hole assembly (BHA) was run in the hole at $4610^{\prime}$ using a 7-7/8" bit which was dressed with three 16/32" jets. This assembly drilled to a depth of $5126^{\prime}$ where survey data indicated a build rate of $0.7^{\circ} / 100^{\prime}$. The inclination was projected to be about $95^{\circ}$ at $5126^{\prime}$ MD. A $10^{\circ}$ pendulum assembly (a $10^{\prime}$ pony collar in front or the lead reamer) was run to drill the remainder of the well. After reaching a depth of 5670', the pipe would no longer fall into the hole because of excessive down drag. The drill pipe had to be rotated with the slips to get it into the hole. Hole drag also prevented taking additional surveys.

At this depth, it appeared that the $10^{\prime}$ pendulum was dropping at a rate of 2 to $2.5 \% 100$. Without new survey data and with limited options available with respect BHA's, the well was drilled to total depth. Total depth was determined by two factors: a) when predominately gray shale was being drilled and b) when no more shows were indicated by the mud logging unit. Drilling was terminated at a measured depth of 6406'.

A plot of depth versus days is shown in Figure 4.1 with the plot comparing actual and projected times. The vertical section of the well to the kick-off point took four days longer than anticipated because of an excessive water flow and stuck drill pipe. The build section required eight days to drill compared to a planned seven days.

After reaching total depth, the drill pipe was strapped out of the hole and the well was logged. Free fall logs were run first with the video camera falling to 


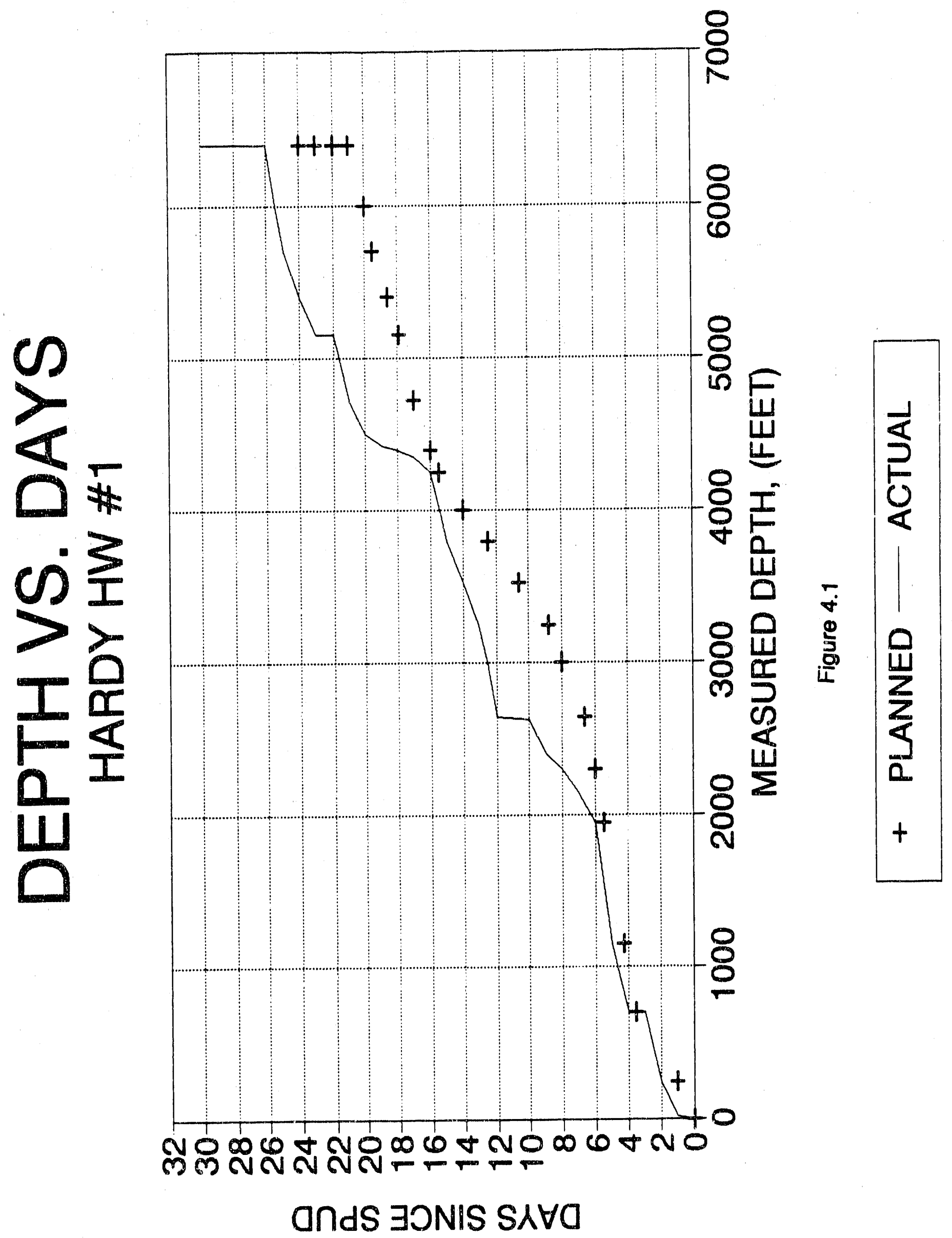


4100'. The open hole logs fell to 4325' where the inclination was $74^{\circ}$. The drill pipe conveyed video camera log was run to 4550' and was terminated because no signal was being received from the tool. The drill pipe conveyed, open hole logs were run to $6360^{\prime}$ depth.

A multi-shot survey was run indicating that the wellbore entered the target interval at a measured depth of 4178' and dropped out of the target at MD of 6198'. A plot of the planned versus actual wellbore path is exhibited in Figures 4.2 and 4.3.

After laying down the drill pipe, 140 joints of $4-1 / 2^{n}, 10 / 5 \# / f t, K-$ 55, ST\&C casing were run in the hole. The casing contained five external casing packers and four port collars. The casing tally and detailed drilling operation information are summarized in the BDM/Cabot/DOE final report.

\subsection{Hunter Bennett \#3997 Well}

Drilling operations commenced on November 9, 1990, and completed on December 11, 1990. Operations were suspended between November 14, 1990 and November 23, 1990 for the Thanksgiving holidays. Total days on location were 24 days which was the same as the estimated time of drilling. A plot of the actual and planned depth versus time in days is exhibited in Figure 4.4.

The vertical portion of the well to the kick-off point took five days. Twenty-inch conductor casing was set at five feet below ground level. A $17-1 / 2^{\text {" }}$ surface hole was drilled to $289^{\prime} \mathrm{KB}$ through the fresh water zones. Six joints of $13-3 / 8^{\prime \prime}, 37 \# / f t$ casing was run and set at $268.5^{\prime} \mathrm{KB}$. The casing was cemented with 540 sacks neat cement followed by 100 sacks cement with $3 \% \mathrm{CaCl}_{2}$. Drilling continued with an $8-3 / 4^{\mathrm{N}}$ bit and air as the drilling fluid to the kick-off point of $2165^{\circ}$.

The build section, from $2165^{\prime}$ to $3280^{\prime}$, required eight days to drill compared to a planned six days. Penetration rates were lower than anticipated and one reaming run was required.

Initially the plan was to run the Baker motors and the bend set at two degrees without a stabilizer but the stabilizers shipped with the 


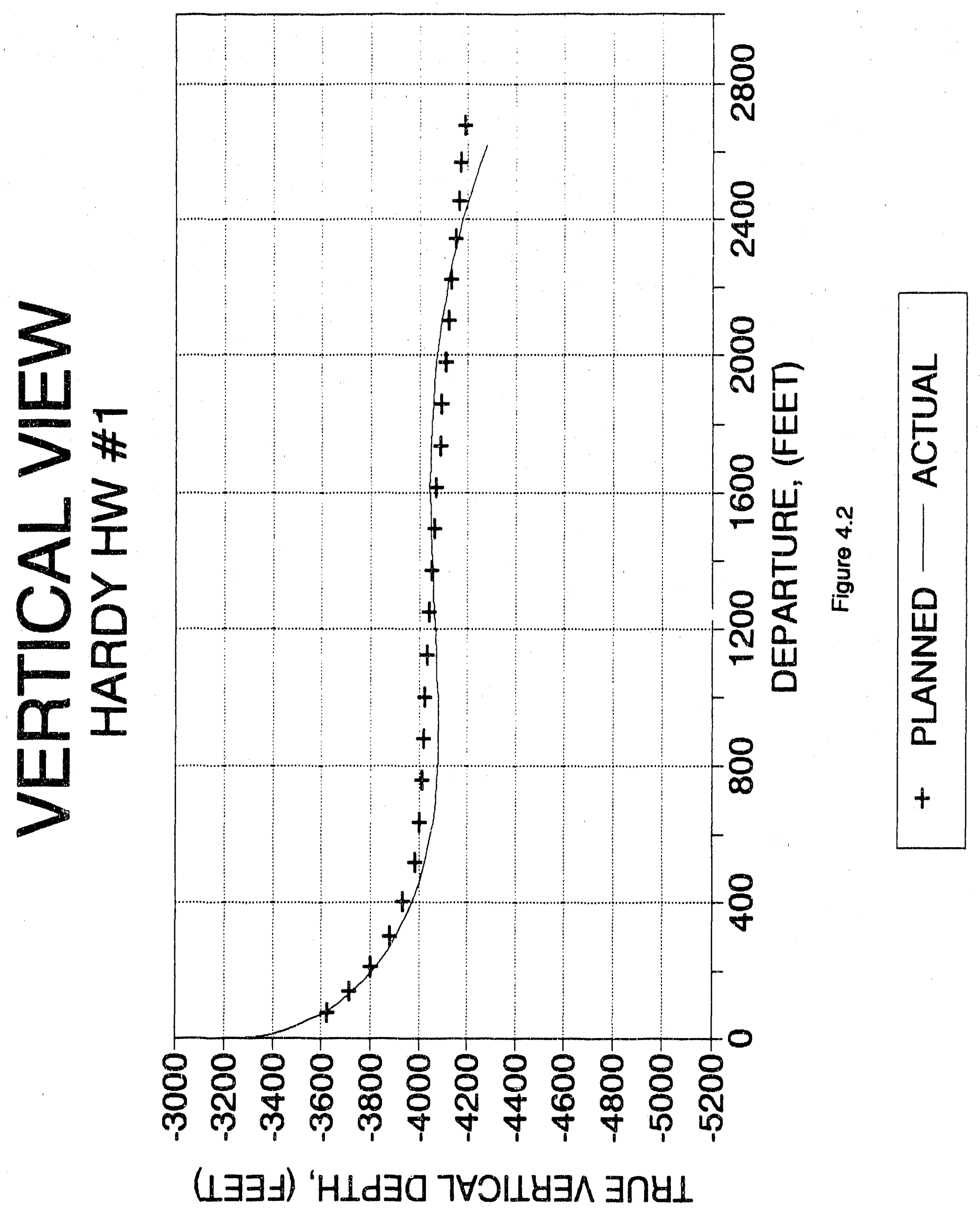




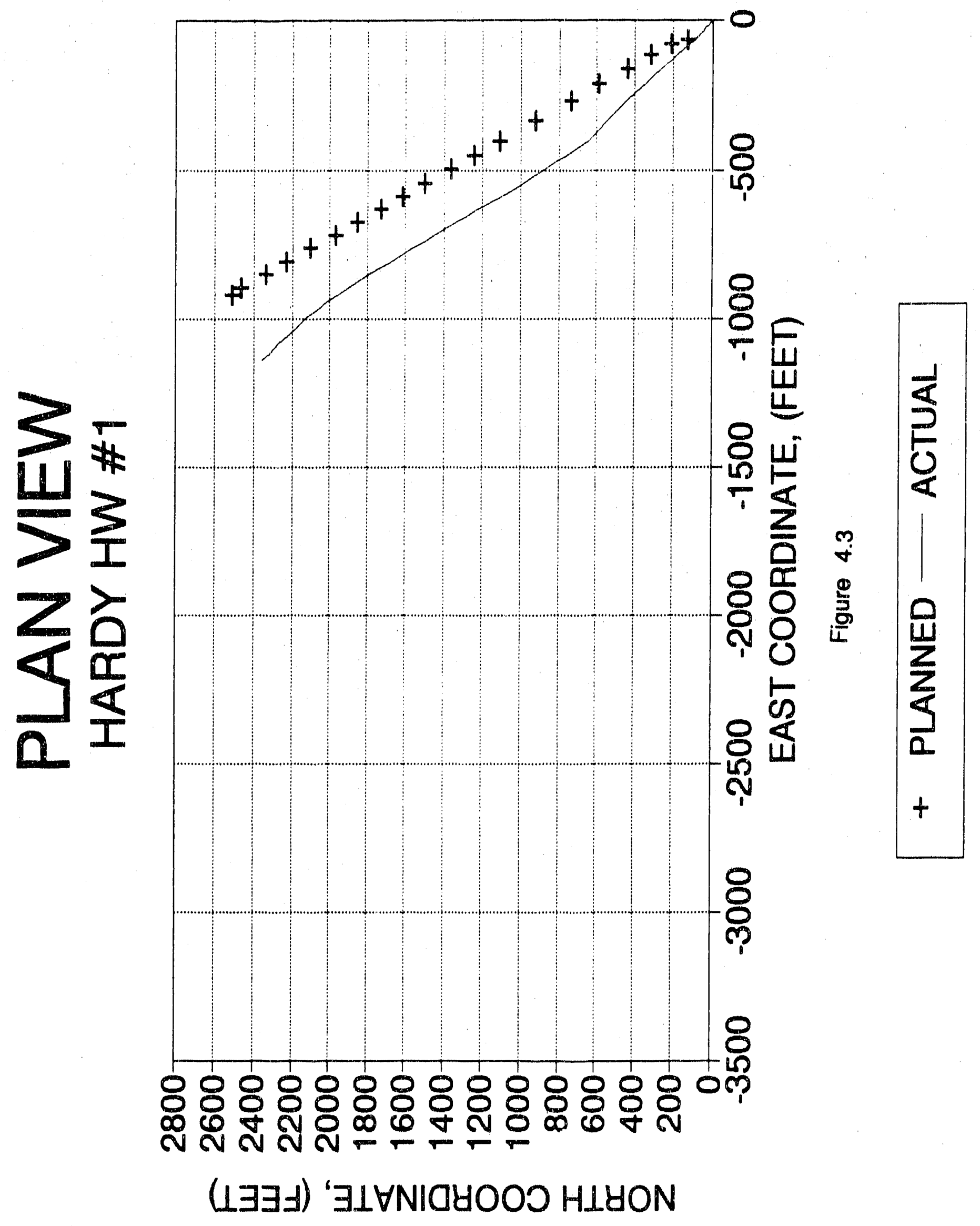




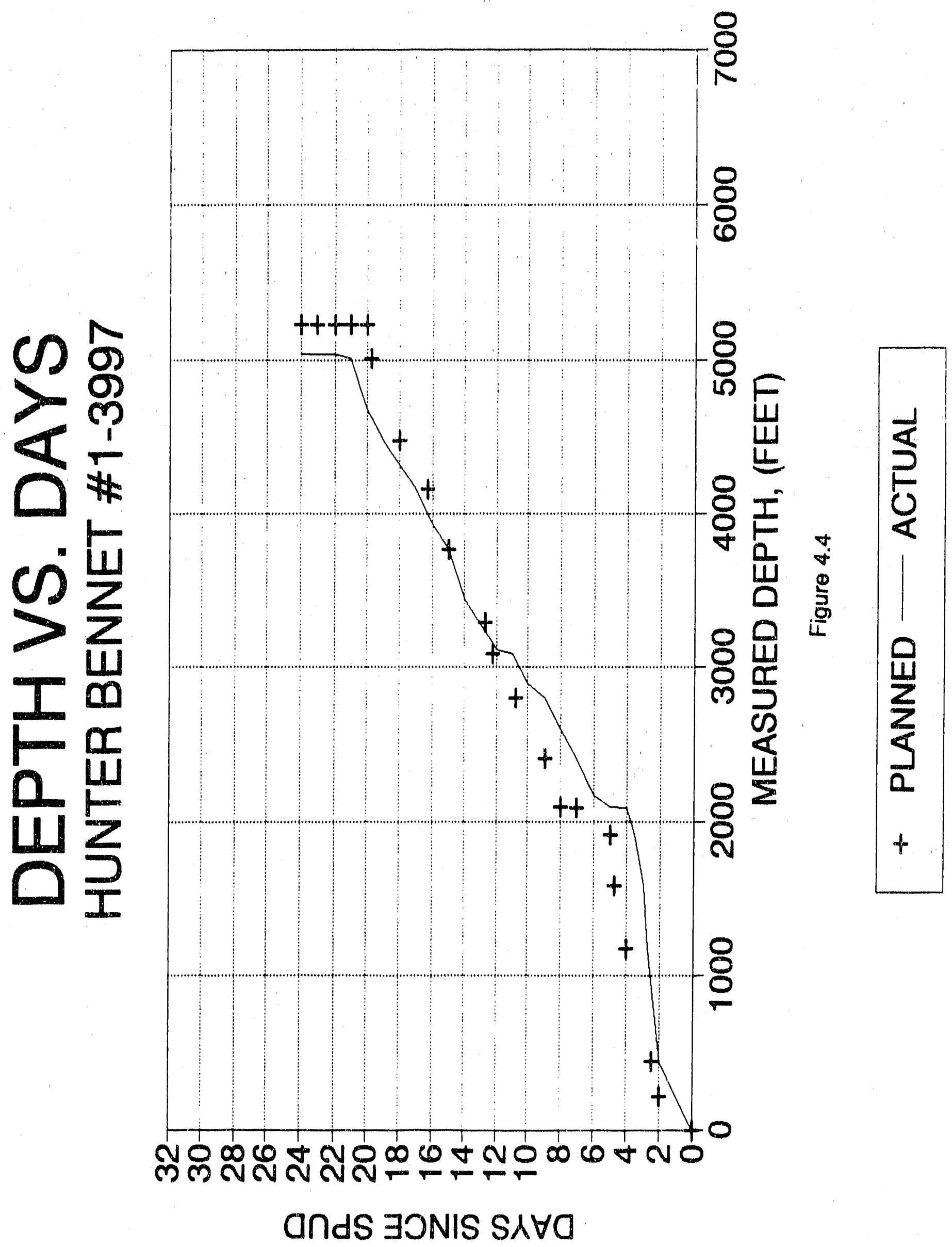


motors could not be removed in the field. With the stabilizer on the motor, the build rate was executed to be less predictable and it would not be possible to drill an 8-1/2" hole. Two non-magnetic drill collars were placed on top of the motor and three 14/32" jets were placed in the bit to increase steering tool life. A steering tool was run through a side entry sub to orient the motor. The first motor run drilled from $2165^{\prime}$ to $2598^{\prime}$. The motor was building inclination at an average rate of $10.1 \% 1100$. A short tangent section was planned at about $55^{\circ}$ to compensate for the higher build rate. The motor quit drilling at a measured depth of $2598^{\prime}$ and an estimated inclination of $46^{\circ}$. Examination of the bottom-hole assembly indicated that the motor had quit drilling because of hole cleaning problems.

Bottom hole assembly \#2 was a rotating assembly design to ream the build section and drill the tangent section. The well reamed easily and the assembly drilled from 2598' to $2773^{\prime}$. The assembly dropped inclination at a rate of $0.45^{\circ} / 100^{\circ}$. The average penetration rate for the rotary assembly was $24.1 \mathrm{ft} / \mathrm{hr}$.

A second motor run (bottom-hole assembly \#3) drilled from 2773' to 3117'. The average penetration rate for this motor run was $8.65 \mathrm{ft} / \mathrm{hr}$, and the build rate was over $12 \% 1100^{\prime}$. At this rate, the well would have been horizontal above the target zone so the motor was turned left and then right to control the inclination angle. At 3117', the motor quit drilling and the assembly was pulled from the hole. Bottom-hole assembly \#4 was run to ream the hole since drilling could not continue with an 8-1/2" bit. The bit stopped reaming at 3081 ' and acted like it was trying to sidetrack the hole. With considerable effort, the directional driller was able to get the bit into the old hole and reaming continued to bottom.

The third motor run (bottom-hole assembly \#5) drilled from $3117^{\prime}$ to $3280^{\prime}$ at an average penetration rate of $13.6 \mathrm{ft} / \mathrm{hr}$ and an average build rate of $10.3^{\circ} / 100^{\prime}$. When the motor was pulled, it was projected that the inclination on bottom was $88^{\circ}$ and the azimuth was $317^{\circ}$ compared to the last survey at $3231^{\prime}$ which indicated an inclination of $83.6^{\circ}$ and an azimuth of $312^{\circ}$. 
The horizontal section was drilled from $3280^{\prime}$ to $5013^{\prime}$ and required elght days to complete.

The first horizontal rotary assembly run (bottom-hole assembly \#6) was similar to bottom-hole assembly \#2 which had been used to drill the tangent section. That assembly had dropped inclination at a rate of $0.45 \% 100$ '; therefore, bottom-hole-assembly \#6 was modifled slightly to keep it from dropping as much inclination. This BHA actually built and when the wellbore approached the top of the target interval, the BHA was changed to a dropping assembly. Bottom-hole assembly \#7 was designed to drop inclination at a rate of $2.5^{\circ} / 100^{\prime}$, but a survey run at $3820^{\prime}$ showed that the assembly was still building inclination. The wellbore had climbed above the target interval top of 2846' TVD, so the inclination had to be dropped back down to less than $85^{\circ}$ to drill through the target interval at 2911' TVD.

Bottom-hole assembly \#8, a 30-foot pendulum assembly, was run in the hole at 3846' MD to drop the inclination. The first two surveys taken at $3927^{\prime}$ and $4136^{\prime}$ showed drop rates of $2.10^{\circ} / 100^{\prime}$ and $2.39 \% 100^{\circ}$ respectively, low for a 30 -foot pendulum in a horizontal well. Drilling continued with the pendulum assembly until the projected survey on bottom was $84^{\circ}$ at a depth of $4335^{\prime}$. At this point the wellbore was back within the target interval.

Bottom hole assembly \#9, a short packed hole assembly, was run to maintain the $84^{\circ}$ inclination of through the target interval and was used to drill to $4665^{\circ}$. A survey at $4534^{\prime}$ showed an inclination of $85^{\circ}$ and a build rate of $0.81 \% 100$. With the packed assembly building inclination, the wellbore would not drop all the way through the horizontal interval and a dropping assembly had to be run to finish drilling the well. Bottomhole assembly \#10 was run in the hole at 4662 ' with a projected drop rate of $2 \% 100^{\prime}$. This assembly drilled to $5013^{\prime}$ where it would no longer fall into the well. No surveys were taken in this interval since a multi-shot survey was to be run at the end of the well. A plot of the planned versus actual wellbore path can be found in Figures 4.5 and 4.6. 


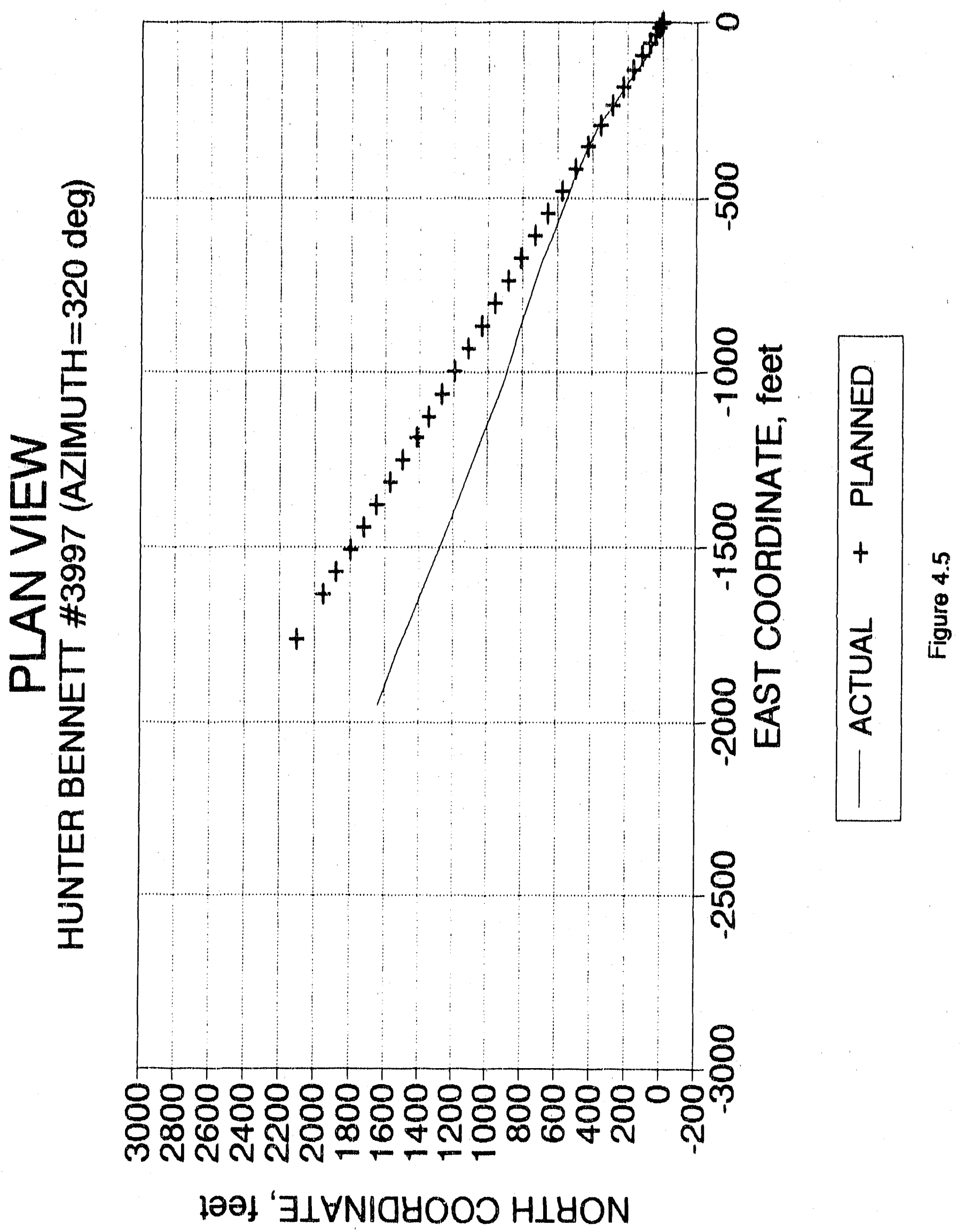

40 


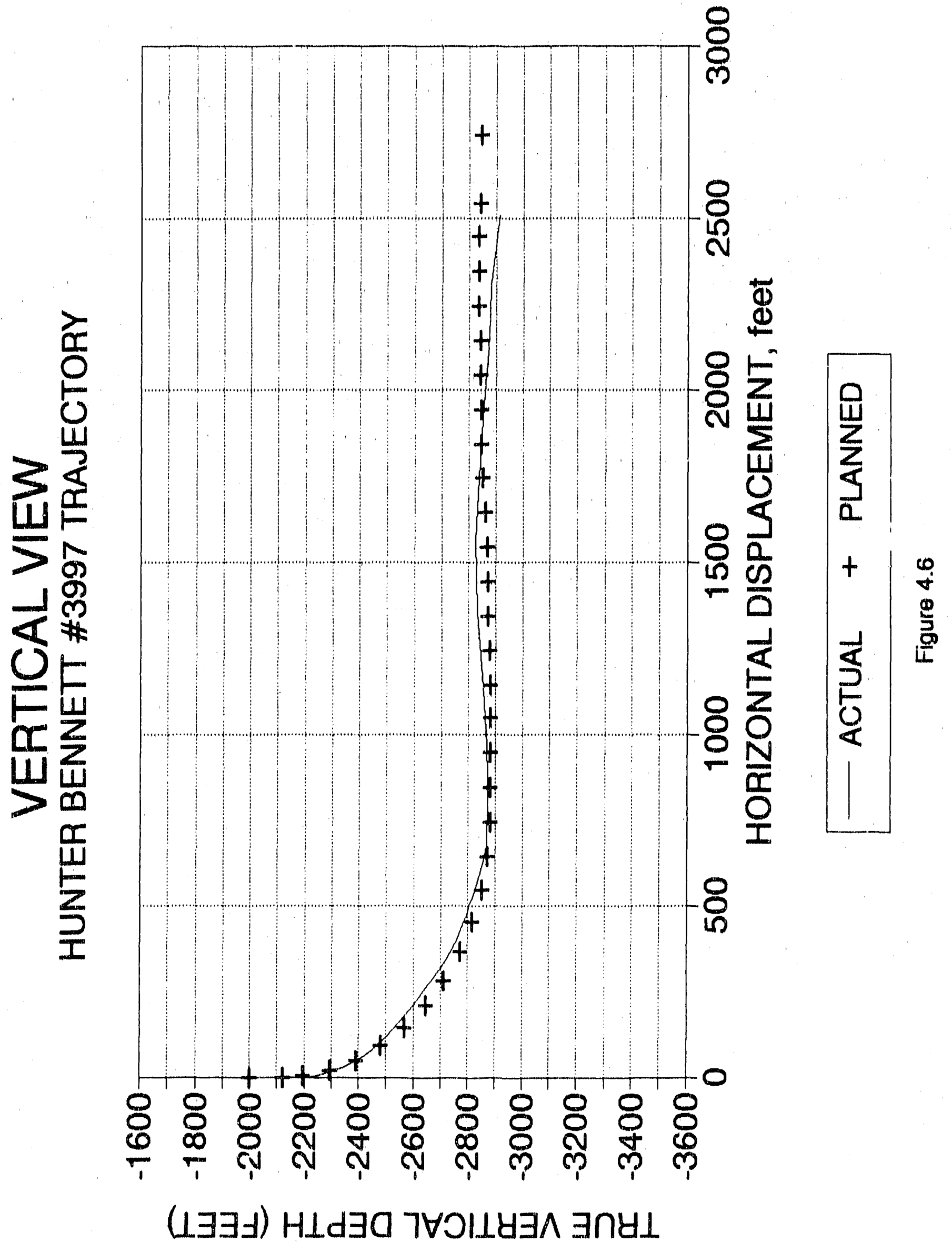




\subsection{LOGGING OPERATIONS}

Logging was planned to identify key stratigraphic units used in the location of the kick-off point, and in the determination of hydrocarbon gases present in the target formation. Logging was also used to determine the points where external casing packers were to be placed in the casing string. Hydrocarbon mud logging was conducted during drilling operations to provide the primary information on gas shows, and information on lithology via drilling time logs.

This section summarizes the procedures and results of conventional geophysical logs and hydrocarbon mud logs for the two horizontal wells; Hardy \#1 and Hunter Bennett \#3997.

\subsection{Hardy HW\#1 Well}

Hydrocarbon mud logging for Hardy \#1 was initiated at a depth of 800 feet. A complete record of shallow and deeper sandstones, limestones, coals, shales was obtained. These data were used in locating the intervals where external casing packers were located in the casing string. A detailed analysis of the mud log for Hardy \#1 is summarized in the Hardy HW\#1 horizontal well report.

Free fall logs were obtained down to a depth of 4327 feet $\left(74^{\circ}\right.$ inclination. The logging suite consisted of gamma ray, compensated density, temperature and differential temperature, and caliper logs. The logs revealed the Berea sandstone, a key marker bed at a depth of 2667' $(G L)$, and the top of the Huron shale at a measured depth of $3767^{\prime}(G L)$.

The inclined and horizontal sections of the well were logged by attaching the logging sonde to the front end of the drill string and pushing the tools through the open wellbore. Logging operations started at $3850^{\circ}$ and continued to a total depth of 6360'. While running the drill string and logging tools into the well, the log was recorded in 60 -foot sections, the length of two joints of drill pipe. Depths were correlated by comparison with strapping of each joint of drill pipe as it was run in the hole. Logging was also attempted while pulling the drill pipe out of the well, but slack left in the wireline cable looped around the drillpipe and could not be 
pulled out. As a result, these logs were not scaled properly and were not useable.

A true vertical depth (TVD) log was constructed using data from the multishot survey. This TVD log is used to correlate the Hardy HW\#1 with nearby vertical wells. Figure 5.1 is a presentation of the TVD log of the well and the target interval.

\subsection{Hunter Bennett \#3997 Well}

Mud logging of HB\#3997 was initiated at a depth of 1700 feet to obtain a good sample description of the rocks through the Big Lime and Big Injun sections for correlation with the projected tops in the area. Gas shows and the measured depths where they were encountered aresummarized in Appendix $E$ of $\mathrm{HB} \# 3997$ horizontal well final report. Figure 5.2 exhibits the location and intensity of gas shows along the length of the inclined borehole.

Free fall logs were run to a depth of 2969 feet, which corresponds to a wellbore inclination of approximately 66 degrees. Gamma ray, compensated density, caliper and temperature logs were run in the open hole section from 2969 to 2090 feet where the $9-5 / 8^{\prime \prime}$ casing is set.

The inclined and horizontal sections of the wellbore were logged by attaching the logging sonde to the front end of the drill string and pushing the tools through the open wellbore. Drill pipe conveyed logs were run from 2969 to 4981 feet. Shortly after starting the logging run, the density log failed and the drill string was tripped out to change the logging tool. The logs run in the inclined and horizontal sections were gamma ray, temperature, and compensated density.

\subsection{MOTOR PERFORMANCE AND BOTTOM HOLE ASSEMBLIES}

Motor performance during drilling of the inclined section of the well is extremely important and can have considerable effect on the overall economics of the drilling operation. 


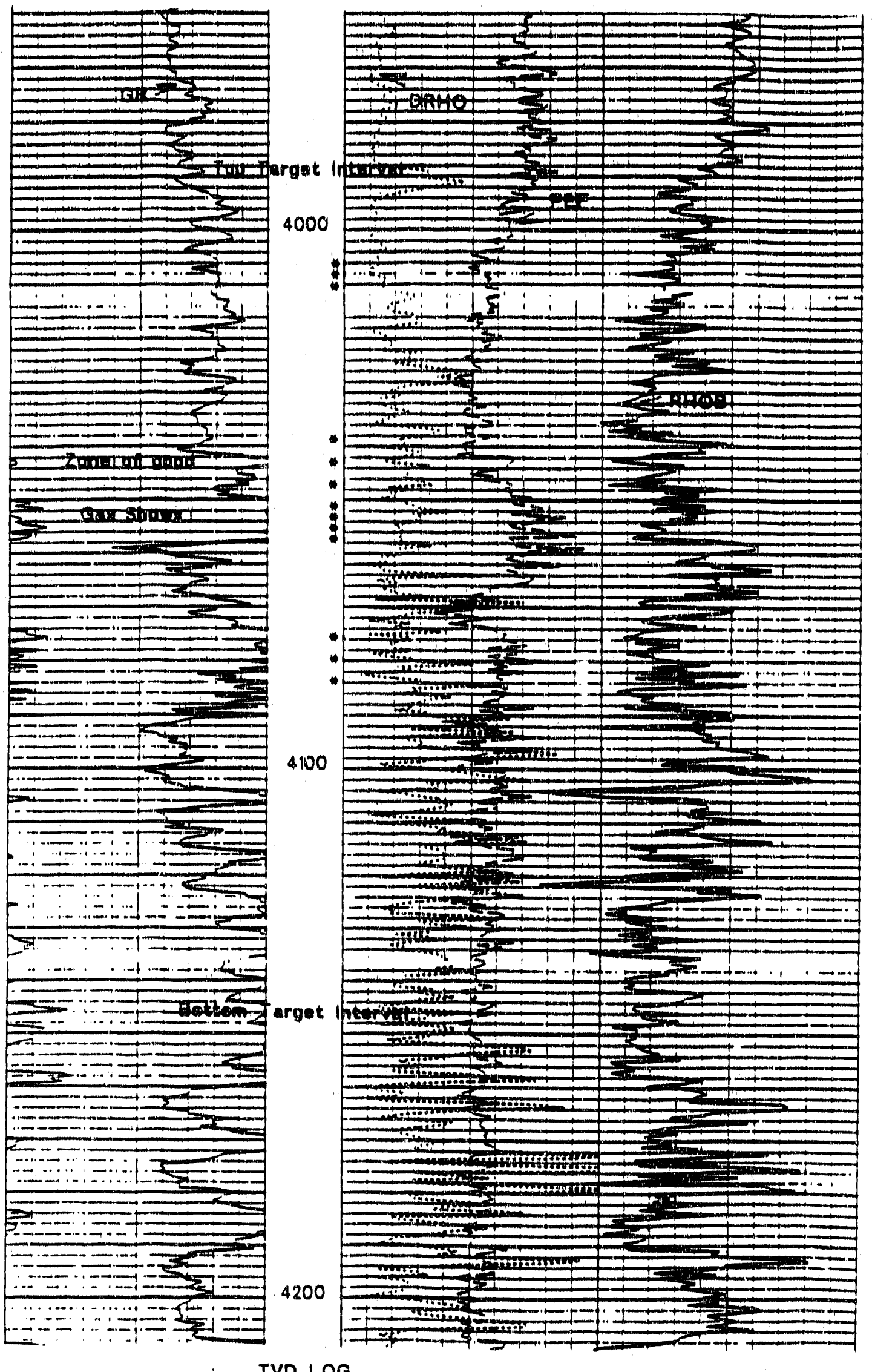

TVD LOG

Figure 5.1 - True vertical depth presentation of well logs of the Hardy HW\#1 well with gas shows 
(udd 000 L) SMOHS SVD

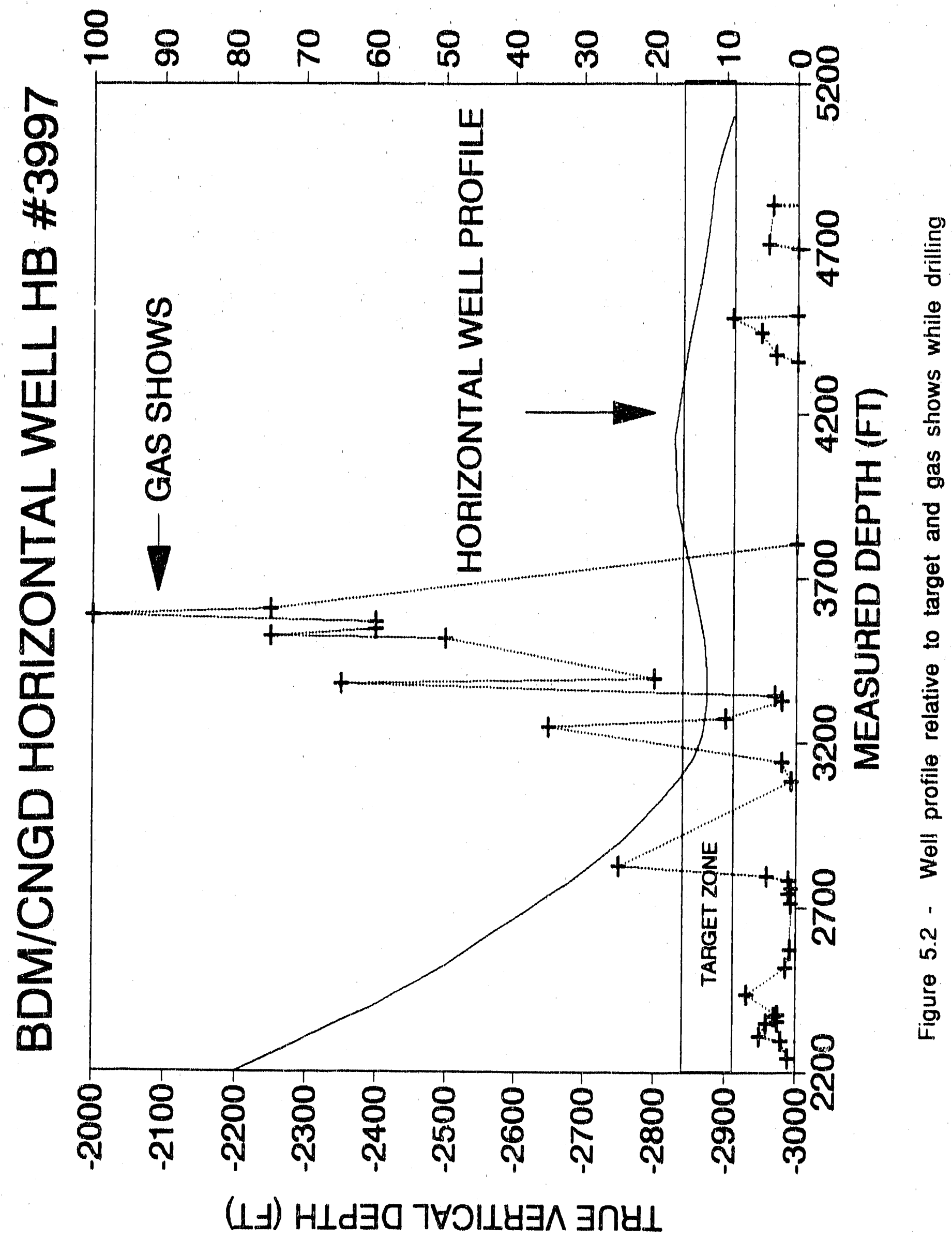


During the drilling of Hardy HW\#1, two motors were tested to determine which motor would provide the best economics for the drilling operation (1) the Eastman Christensen motor which had been designed to build angle at a rate of $9.5 \% / 100^{\prime}$, and (2) the Baker Hughes Drilling Systems adjustable bent housing motor.

The angle build section of the Hunter Bennett \#3997 was drilled using two Baker motors with adjustable bent housing. Each motor had an 8$5 / 8^{\prime \prime}$ stabilizer between the bit and the bend. It was not intended to run motors with stabilizers, however, the stabilizers could not be removed in the field.

\subsection{Hardy HW\#1 Well}

\subsubsection{Angle Build Section}

The first motor to be run at kick off was the Eastman Mach IAD which is an air drilling motor. The motor drilled from 3253 feet to 4324 feet in four separate runs.

The first run was from $3253^{\prime}$ to '3487' $\left(234^{\prime}\right)$ in five hours. The motor was then pulled to change the configuration because it was not building fast enough. The average rate of penetration was $47 \mathrm{ft} / \mathrm{hr}$. The motor was run with an air rate of $2000 \mathrm{scfm}$ and generated an average dogleg severity of $5.9 \% / 100^{\prime}$.

Run number two was from $3487^{\prime}$ to $3603^{\prime}$ (116') in 2.75 hours. The motor was pulled because it achieved a build rate of only $5.6 \% 100^{\prime}$ compared to the designed build rate of $9.5^{\circ} / 100^{\circ}$. The average penetration rate for this motor was $42 \mathrm{ft} / \mathrm{hr}$.

On the third motor run, a $1.5^{\circ}$ bent sub was placed on top of the Eastman motor leaving the bend in the motor set at $1.3^{\circ}$. Eastman could not predict the build rate with their computer program. This motor run drilled from $3603^{\prime}$ to $3817^{\prime}\left(214^{\prime}\right)$ in 6.75 hours. The average penetration rate was $32 \mathrm{ft} / \mathrm{hr}$, and the average build rate was $7 \% / 100$, still not high enough. The motor was then pulled and the hole size was reduced to 8 $1 / 2^{n}$. 
The fourth motor run drilled from $3817^{\prime}$ to $4324^{\prime}$ (507') in 10.75 hours. The average penetration rate was $47 \mathrm{ft} / \mathrm{hr}$ and the average build rate was $8.4 \% / 100$, not enough to hit the targeted TVD of 4010 feet at the desired angle of inclination. The motor was pulled to retrieve the steering tool and was not rerun. The average overall penetration rate of all Eastman motors ivas 42 feet per hour.

The Baker Hughes Drilling Systems Adjustable Bent Housing Motor was run with no stabilizers and with the bend set at the maximum of 2 degrees. Four separate runs were made with the Baker motor, drilling from 4324' to $4610^{\prime}$; a total of $370^{\prime}$. The motor also drilled one side track of about 103 feet.

The first run using the Baker motor, run \#5, drilled from 4324' to $4374^{\prime}\left(50^{\prime}\right)$ in 1.25 hours. The average penetration rate was $40 \mathrm{ft} / \mathrm{hr}$. The motor was pulled because of a problem with the steering tool.

The second run, run \#6, drilled from $4374^{\prime}$ to $4422^{\prime}\left(48^{\prime}\right)$ in 1 hour. The average penetration rate was $48 \mathrm{ft} / \mathrm{hr}$ and the motor was again pulled because of steering tool problems.

The third run, with the Baker motor, run \#7, sidetracked the well at 4338 feet and drilled to 4502 feet when the steering tool again failed. The motor drilled 164 feet in 4.25 hours with an average penetration rate of $39 \mathrm{ft} / \mathrm{hr}$.

The remainder of the build section was drilled with the fourth Baker motor run, run \#8, which drilled from $4502^{\prime}$ to $4610^{\prime}$ (108') in 3.25 hours at an average penetration rate of $33 \mathrm{ft} / \mathrm{hr}$. Table 6.1 compares the two motors during their eight motor runs in the angle build section. For a more detailed analysis of the motor runs during the angle build section refer to Section 7.2 of the Hardy HW\#1 Final Report.

\subsubsection{Herizontal Section}

Two rotary directional drilling assemblies were used to drill the horizontal section of the well from 4610 feet to total depth. 
Table 6.1 Comparison of Rates of Penetration of Motors During Angle Building Drilling of Hardy HW⿰三丨 1

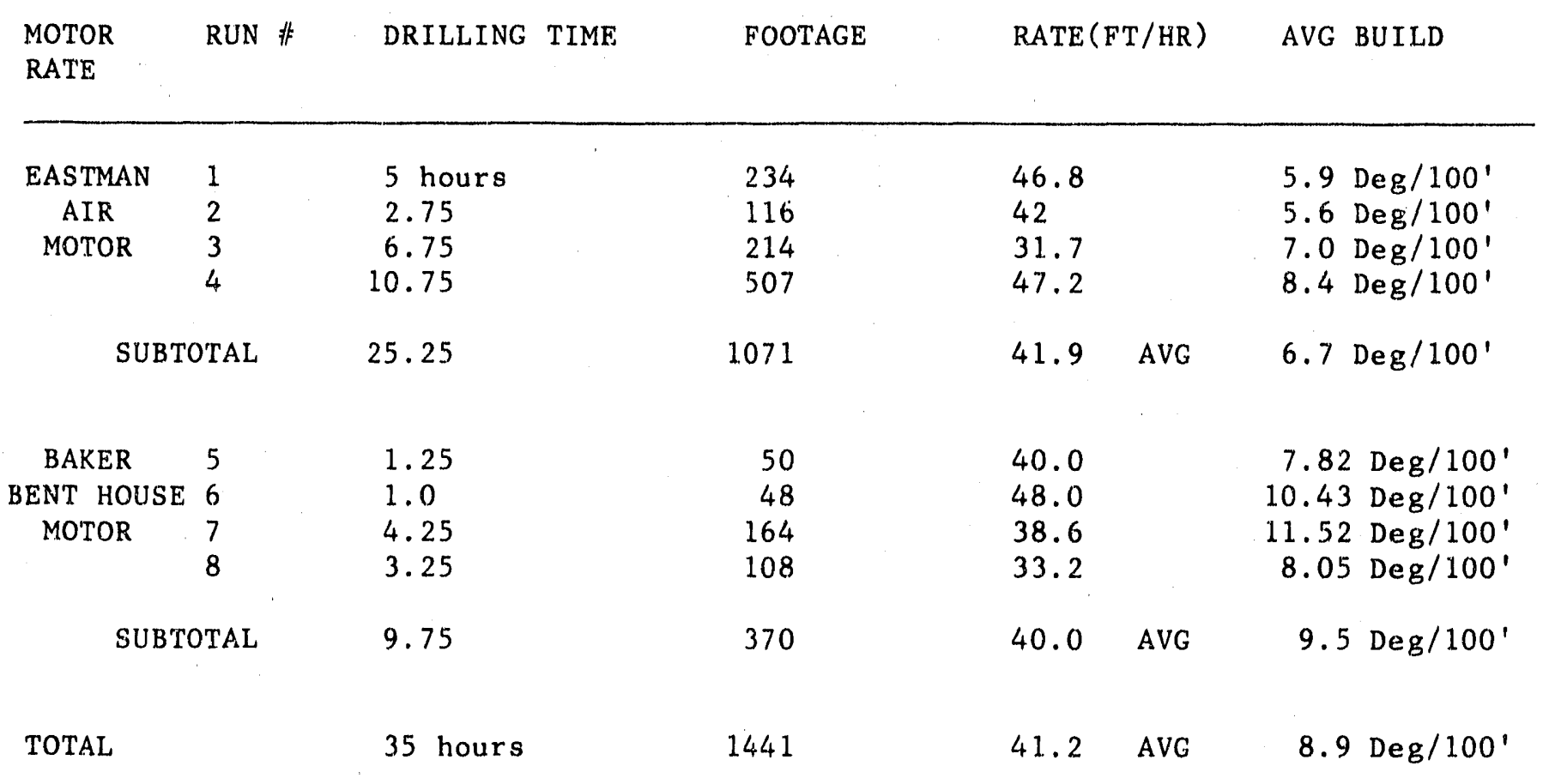


The first assembly, BHA\#6, consisted of a 7-7/8" bit, float sub, 3-point reamer, $\mathrm{X}-\mathrm{O}$ sub, and two monels. This assembly drilled from $4610^{\prime}$ to $5126^{\prime}$ and built inclination at a rate of $0.7 \% / 100$ '. The inclination at $5126^{\prime}$ was projected to be $95^{\circ}$, and the wellbore needed to drop through the rest of the target interval.

Bottom hole assembly \#7 was designed to drop inclination at about 1 to $1.5 \% 100$. Unfortunately, it would not go into the sidetracked hole.

Bottom hole assembly \#8 which consisted of a 7-7/8" bit, bit sub, short drill collar, 3-point reamer, X-O sub, float sub, and two monel drill collars drilled from $5126^{\prime}$ to $5763^{\prime}$. One slight modification was made in the assembly at a depth of 5763'. To help reduce drag going into the hole, one of the two monels was eliminated and is indicated as BHA \#9.

The average drop rates for BHA\#8 and BHA\#9 were 2.34\% 100 ' and $2.75 \% 100^{\prime}$ respectively. Drill collars were placed at the top of the build section to provide the strength necessary to keep the drill string from buckling in the vertical section of the hole. The collars were also used to help push the pipe into the hole on trips and connections. The configurations of the different assemblies are summarized in Appendix B of the Hardy HW\#1 Final Report.

\subsection{Hunter Bennett \#3997 Well}

\subsubsection{Anale Build Section}

Three motor runs were required to drill the build section using Baker motors. The first motor run was terminated because of a hole cleaning problem, the second motor run was terminated because of a bit gauge problem, while the third motor run finished the build section.

The first motor run drilled from $2165^{\prime}$ to $2598^{\prime}\left(433^{\prime}\right)$ in 42 drilling hours. The average penetration rate was $10.3 \mathrm{ft} / \mathrm{hr}$. The motor 
housing bend was set at 2 degrees producing an average build rate of $10.7^{\circ} / 100^{\prime}$.

At 2598', the motor quit drilling and was pulled from the hole. Three hours prior to tripping, the well had quit dusting. The penetration rate had slowed three feet per hour indicating hole-cleaning problems. problems. The motor appeared to be in good condition when checked at the surface. Since this motor had 46.5 hours on it and only half the build section had been drilled, the motor was laid down and not used again.

The hole-cleaning problem was determined to be the result of not enough cuttings being generated to absorb the oil being injected into the drill pipe for motor lubrication. The hole was wet with lube oil and a rotary assembly had to be run to clean and dry out the well. Therefore, it was decided to drill the tangent section at that point.

Bottom-hole assembly \#2 (30' building assembly) was run to ream the build curve and drill the tangent section. The well reamed easily and the assembly drilled from 2598' to $2773^{\circ}$. The assembly dropped inclination at a rate of $0.45 \% 100$. The average penetration rate for the rotary assembly was 24.1 feet per hour.

The end of the tangent section was based upon finishing the build section with an average build rate of 9.5\%/100'. Based upon the observed build rate of the first motor run, the bend in the second motor was reduced to 1.75 degrees to achieve a build rate of $9.5 \% 100$. Also, a softer formation bit was run to improve penetration rates. Three 16/32" jets were placed in the bit to reduce air pressure from 390 psi, which was too high for continued operation of the compressor system, to $300 \mathrm{psi}$.

The second motor drilled from $2773^{\prime}$ to $3280^{\prime}$ in two separate runs. The first run drilled from $2773^{\prime}$ to $3117^{\prime}\left(344^{\prime}\right)$ in 39.75 hours for an average penetration rate of $8.65 \mathrm{ft} / \mathrm{hr}$. This motor run was terminated when the motor would not drill. The second run drilled from 3117' to $3280^{\prime}$ in 12 hours for an average penetration rate of 13.58 feet per hour. The motor was pulled because the build curve section was complete. The second motor run had the bend set at 1.75 degrees and produced an average dogleg severity of $11.33^{\circ} / 100^{\prime}$. This dogleg severity was greater than 
that of the first motor run even though the bend was set 0.25 degrees lower. Total drilling and circulating time for the second motor was 53 hours with no failures.

\subsubsection{Horizontal Section}

BHA\#6 was the first rotary assembly run in the horizontal section and drilled from $3280^{\prime}$ to $3544^{\prime}$. The intention was for BHA\#6 to be a holding assembly that would maintain inclination at 88 degrees. BHA\#6 drilled from $3280^{\prime}$ to 3544'. Initially, the assembly built inclination at a rate $1 \% 100$ with a $2 \% 100$ ' left walk tendency. The next survey, however, showed a build rate of 5.05\%/100', indicating some strong formation tendencies controlling the rapid angle build.

The next assembly to be run was BHA \#7 which drilled form $3544^{\prime}$ to 3846 '. This assembly, designed to drop angle at a rate of $2.5^{\circ} / 100^{\prime}$, actually built inclination at a rate of $0.25 \% 100$, with little or no tendency to walk. Obviously, the formation tendencies were substantial and would require a stronger pendulum assembly to counteract the formation. Analysis of subsea top of the target formation showed change in structure which is most likely related to faulting. Revised interpretation of the structure is presented in Figure 6.1 for comparison with Figure 3.17. This points out the tendency to walk west and updip by the bit.

BHA\#8, a 30-foot pendulum assembly, drilled from $3846^{\prime}$ to $4335^{\prime}$, and dropped the angle of inclination at an average rate of $2.4 \% / 100$.

BHA\#9 was run to hold the inclination near $84^{\circ}$. BHA\#9 drilled from $4335^{\prime}$ to $4665^{\prime}$ and it built inclination at a rate of $0.81 \% / 100^{\prime}$, with a right-handed walk. Drilling continued until the projected inclination was $86^{\circ}$ at the bottom. At this point another pendulum assembly was required to drop the well through the target interval. BHA\#10 drilled from 4665' to 5013'. No surveys were run to check the drop rate of this assembly but it was less than $2 \% 100$ ' because the open hole logs suggesting that the wellbore did not drop out of the target interval. To reach the bottom of the target interval a drop rate of $2 \% / 100$ ' would have been required. 


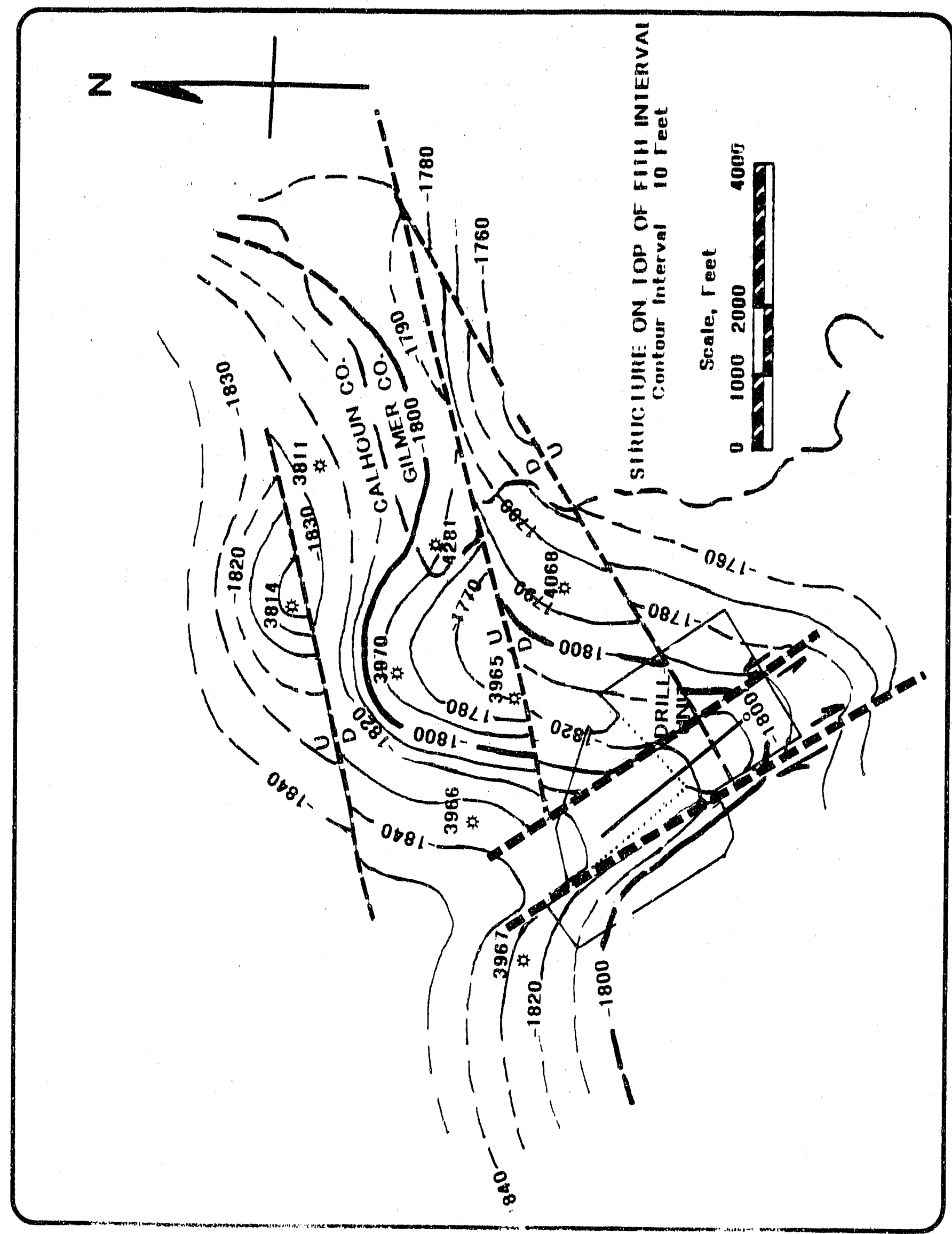

Figure 6.1 - Revised Structure Inti rpretation of or $11: 3 . t$ 
A detalled description of the different bottom hole assemblies and their configurations are summarized in Appendix $B$ of the CNGD Final Report.

\subsection{DIRECTIONAL CONTROL OPERATIONS}

In drilling to the Hardy HW\#1 well, steering tool failure was a costly and time consuming problem. Smith International initially brought four, two axis probes to the location. The first probe operated without any problem from kickoff point to around $3900^{\prime}$ when it falled after about 16-1/2 drilling hours. The second probe was then run and drilled 1.5 hours before it was pulled; not due to fallure but due to the fact that the ton face reading was bouncing around and it became difficult to tell which way the motor was pointing. The third probe was run inside a fiberglass case (instead of steel) to reduce the vibration on the tool. Problems were encountered after about. 5 hours with this probe but drilling continued for another hour at which time the surveys indicated the well was turning left. The tool was pulled out, the probe was repaired, and then run back. Drilling continued for one half hour but tool readings were bouncing around too much to get any good information from the tool. The fourth probe was run and drilling continued, but it, too, was pulled because the tool readings were bouncing around.

By the time the 4th two-axis probe falled, the wellbore inclination was over $70^{\circ}$ and a three-axis probe was required. Eastman's steering tool which had a three-axis probe was brought on location. The three-axis probe performed much better than the two-axis probes. The three-axis probe readings also bounced around but not enough to halt drilling operations. The steering tool again failed at $4502^{\prime}$, was pulled and repaired, and rerun. Drilling continued to 4610' where the desired inclination and direction had been obtained.

The Electromagnetic Measurement-While-Drilling (EMWD) tool was used to test the tool when the wireline steering tools had failed and while waiting on replacement probes. The EMWD failed to transmit signals to the surface due to lack of signal strength caused by a mismatch between the tool and formation impedance. 
While the Hardy HW\#1 was plagued with steering tool problems, the $H B \# 3997$ horizontal well steering operations were considered acceptable. There were no failures of the three-axis probes but three fallures occurred due to wireline connectors and electronic components.

\subsection{ANALYSIS OF DRILLING OPERATIONS}

Hardy HW\#1 and HB\#3997 were planned to be drilled in the most economic manner to obtain data for analyzing the economics of slant/horizontal drilling the Devonian Shales.

Hardy HW\#1 was drilled in thirty days compared to twenty-five days needed to complete HB\#3997.

The major sucress during the drilling operations of Hardy HW\#1 was the increase in the rate of penetration during the angle building phase of the operation compared to the previous air-drilled horizontal well. The biggest problem during this operation was the steering tool failures. This was attributed to the steering tools not having been adequately hardened for alr-drilling operations. The result was four or five additional days of daywork and repair costs.

By the time HB\#3997 was drilled, a year after Hardy HW\#1, the failure rate of the steering tools was much lower. Failures with the steering tools were not attributed to the probes but rather to the wireline connectors and electronic components.

Mud logging operations were successful during the drilling of each of the horizontal wells. The gas show data were used in designing the final casing completion configuration in each well.

Conventional geophysical logging operations continued to be difficult and fraught with numerous problems. These problems make it difficult to justify the cost of geophysical logging operations in relation to the amount of useful data acquired, particularly when logging a Devonian Shale horizon. 
Video camera logs, normally a key $\log$ in an air-drilled horizontal well because of the information that can be obtained about natural fracture orientation, and spacing was a failure during Hardy $\mathrm{HW \# 1}$ drilling operations. Video camera logging was not attempted on the HB\#3997 horizontal well.

\subsection{COMPLETION OPERATIONS}

The completion designs of the Hardy HW\#1 and HB\#3997 wells were based largely on the results of the successful completion of the previous DOE-sponsored horizontal well in Wayne County, West Virginia (BDM/RET\#1). The BDM/RET\#1 well had been successfully completed with a 4-1/2" casing liner with 7 different zones being isolated from each other by inflatable casing packers. Access to each zone was provided by two port collars which could be opened and closed using special tools. This system allowed testing, production, and stimulation of individual zones or group of zones as necessary.

One of the purposes for the Hardy HW\#1 and HB\#3997 wells was to replicate the previous BDM/RET\#1 test, but to do so using drilling and completion technology more representative of industry practices for a purely commercial well.

\subsection{Hardy HW\#1 Well}

The completion design for the Hardy HW\#1 well was limited to the identification of four zones for appropriate stimulations. Figure 9.1 shows each of the four zones on the wellbore schematic and Figure 9.2 shows where the zones occur with respect to the true-vertical depth (TVD) log of the well. The best gas "shows" were at 4004-4010 feet TVD and 4050-4058 feet TVD. Both Zone 1 and Zone 2 of the horizontal wellbore penetrated the lower interval of good shows. Zone 4 penetrated both intervals of good shows. Zone 3 did not penetrate either of the two best intervals but did penetrate an interval which had gas shows at 4.0754081 feet TVD. 


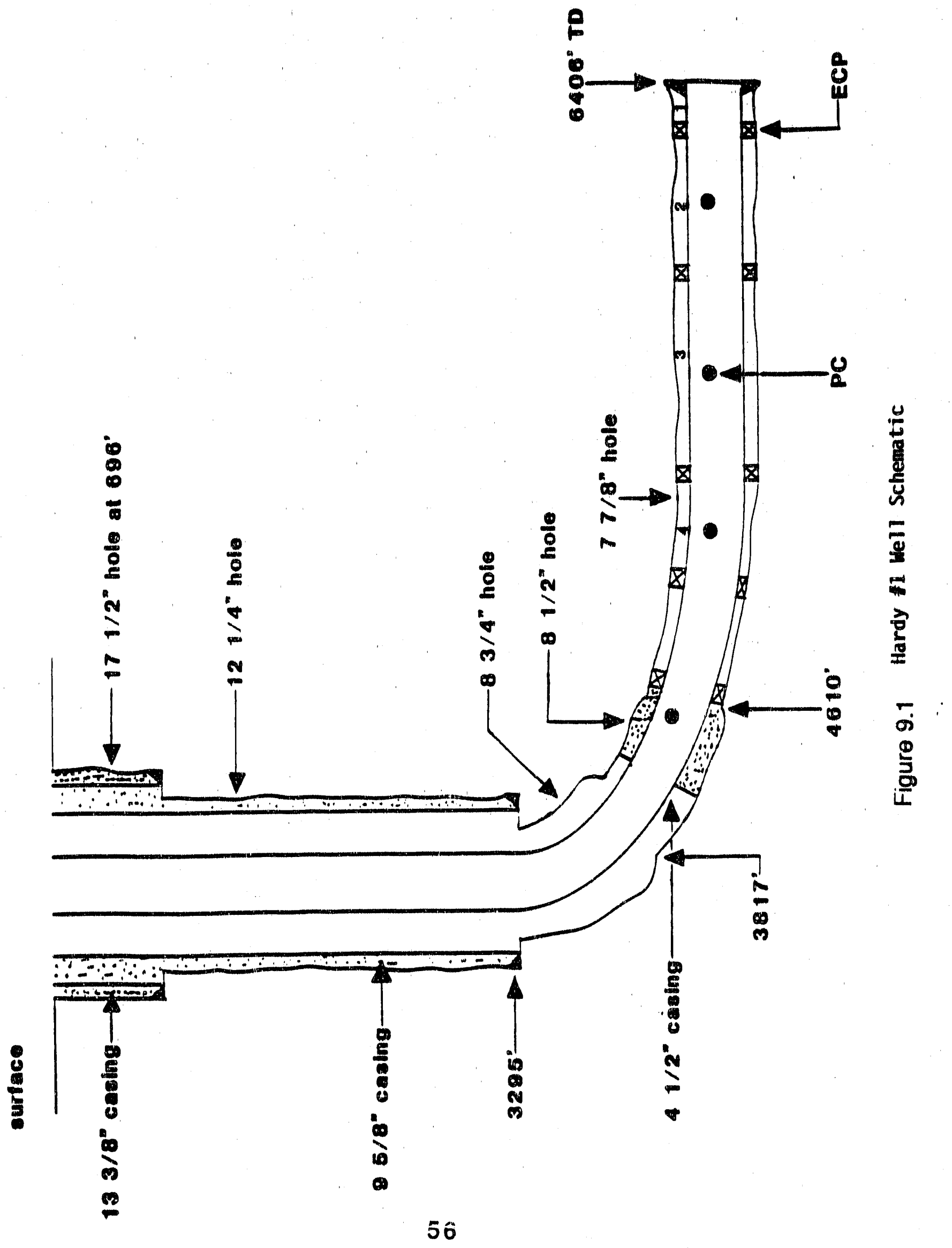


(peje|nગeo pdłou ) 'SMOHS S

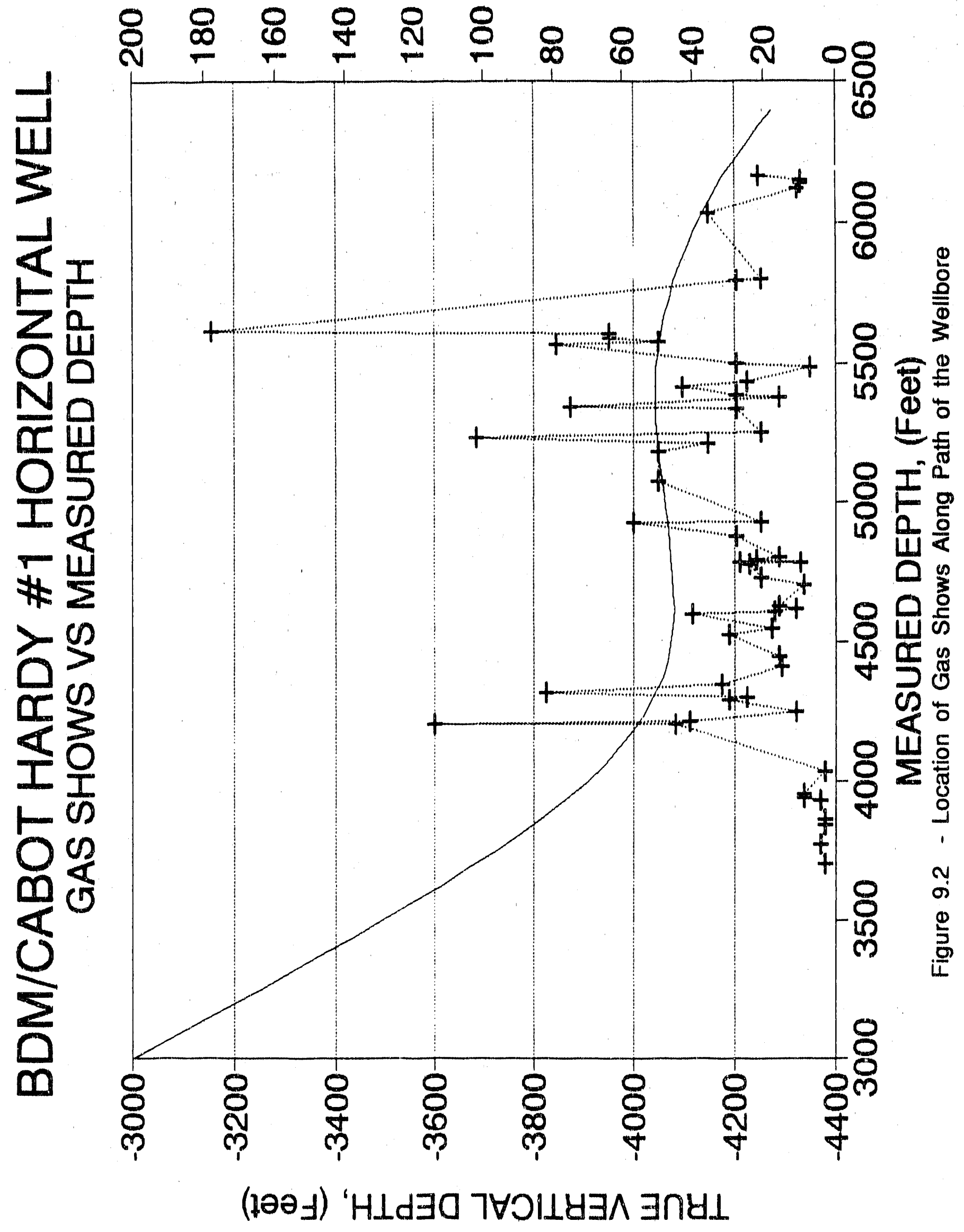


In order to isolate the four zones for individual stimulation, the well was cased with $4-1 / 2^{n}, 10.5 \# / f t, J-55$, ST\&C casing. The size, weight, and grade of the casing were designed to meet stimulation requirements based on hydraulic fracture treatments on nearby vertical wells. Five casing packers were placed in the casing string at measured depths of $6014,5515,4765,4390$, and 4106 feet. This design utilized three port collars which were placed in Zones 1,2, and 3 (the lower zone numbers indicate zones farthest from the wellhead). Zone 4 was left without a port collar since it was in a position where it could be conventionally perforated using wireline equipment. A fourth "spare" port collar was placed above the shallowest casing packer for use in cementing the casing in that part of the hole.

To inflate the casing packers it was decided to first inflate and test the uppermost packer, (Packer \#5), which would be supporting the cement to be placed above the producing zones as a permanent waterbarrier. After two attempts, Packer \#5 was successfully inflated and tested. The casing above packer \#5 was cemented via access to port collar \#4. The remaining packers were then individually inflated and tested. Although the basic completion method for this well was essentially open-hole with a liner, one section of the casing was cemented in place. The casing immediately above the uppermost casing packer was cemented from approximately 4057 feet to 3500 feet measured depth with 130 sacks of Class A cement. Cement was pumped through the "spare" port collar. For a detailed description and analysis of the completion design refer to Section 10.0 of the Hardy HW\#1 Final Report.

\subsection{Hunter Bennett \#3997 Well}

HB\#3997 well was successfully completed with a 5-1/2" casing liner with five different zones isolated from each other by inflatable casing packers. A total of six casing packers were placed in the casing string at measured depths of 4575,4179,3826, 3474, 3160, and 3109 feet. A total of nine port collars were placed along the horizontal section with two port collars placed in Zones 2, 3, 4, and 5 and a port collar placed above the shallowest casing packer (ECP\#6) for use in cementing the casing in that part of the hole. Zone 1 was left without 
port collars and without a casing string (i.e. open hole completion, see Flgure 9.3).

The size, weight, and grade of the casing, 5-1/2" OD, 17.0 $/ 2^{\mu} \mathrm{ft}$, J-55, ST\&C; respectively, were designed to meet the stimulation requirements. Based on hydraulio fracture treatments (nitrogen treatments) in nearby vertical wells, the average breakdown pressure and average Instantaneous Shut-In Pressure (ISIP) was estimated at 2400 and 900 psig, respectively.

The External Casing Packers (ECP's) were inflated from bottom to top using $\mathrm{KCl}$ water and nitrogen. A retrievable bridge plug (RBP) was used to isolate Zone 1 from the rest of the wellbore. The RBP was first tested using nitrogen, then the hole was loaded with $\mathrm{KCl}$ water after the nitrogen was released. The RBP was set at 4558 feet, nitrogen was then pumped down hole to inflate ECP \#1. 2-3/8" tubing was used to set and inflate the RBP and ECP's respectively. After inflating and testing ECP \#1, pressure on the tubing was released and the RBP was moved up hole to start inflating and testing ECP \#2. Similar procedure was followed to Inflate and test ECP \#2, \#3, \#4, and \#5. A detailed inflating and testing procedure is summarized in Section 10.0 of the CNGD HB\#3997 well final report. The casing immediately above the uppermost casing packer was cemented from 2245 feet to 3118 feet measured depth using 235 sacks of 50/50 POZ cement. Cementing operations were conducted by pumping the cement through a port collar set immediately above the uppermost ECP (ECP\#6). The cement was overflushed with water and then the hole was acid cleaned.

\subsection{STIMULATION}

The purpose of stimulation operations is to improve the productivity of the well to the point where commercial productior: can be achieved and sustained.

The Hardy HW\#1 was stimulated with 80-quality foam and 20-40 mesh sand as the proppant in Zones 1 and 2 . Zones 3 and 4 were stimulated as a single zone using straight nitrogen as the working fluid. Only Zone 1 was stimulated as originally planneu. The stimulation 


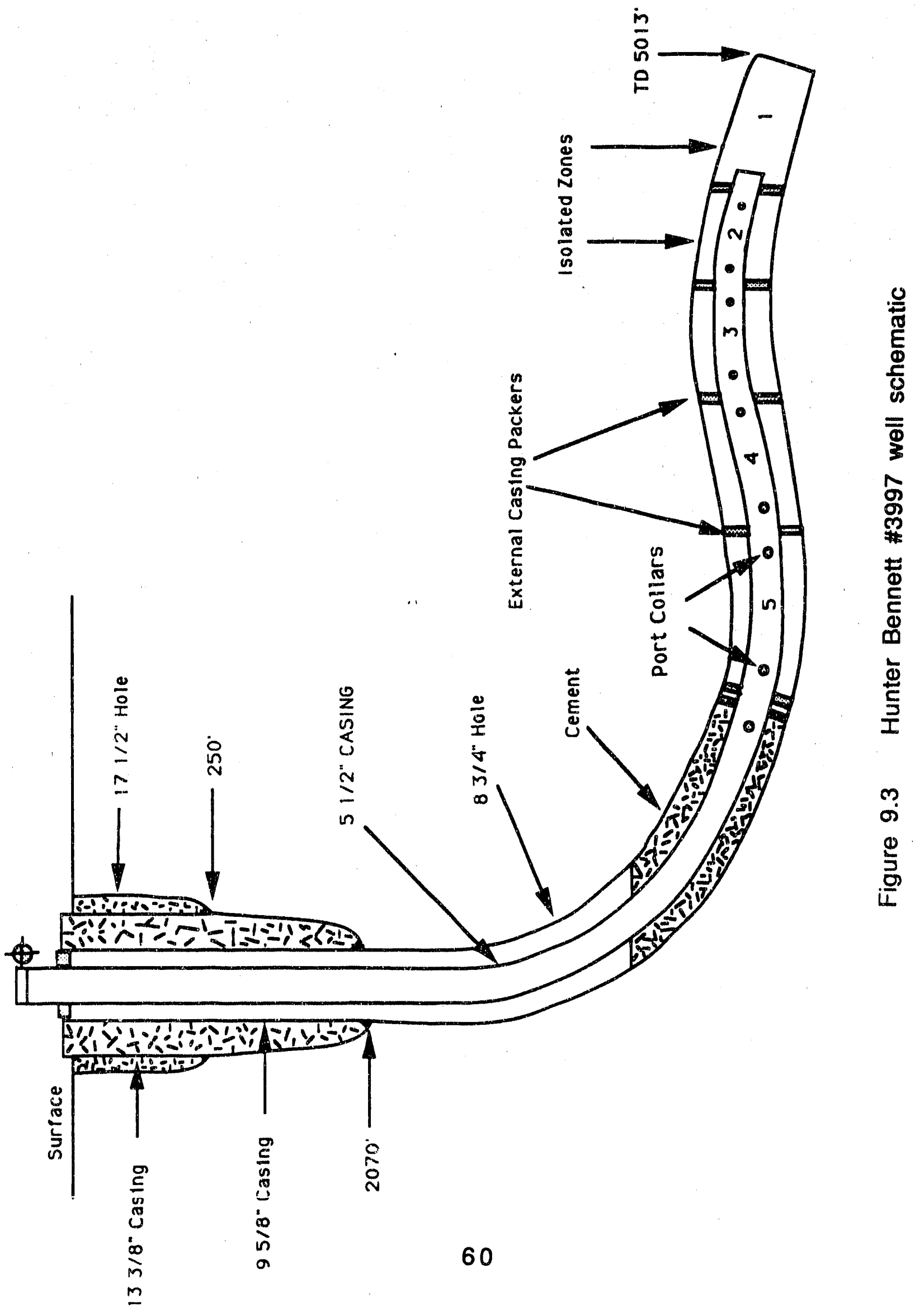


treatments for Zones 2, 3, and 4 had to be modified in the field in order to obtain at least partial success.

The Hunter Bennett \#3997 horizontal well was stimulated in Zones 1 and 2 using nitrogen as the working fluid.

\subsection{Hardy HW\#1 Well}

The initial stimulation designs for the Hardy HW\#1 well were based primarily on the favorable results of the stimulation conducted on the BDM/RET\#1 well in Wayne County, West Virginia. Because of the ease with which the Wayne County stimulations had been executed, the stimulations for the Hardy HW\#1 were very similar except that much higher rates were planned for the Hardy well. Table 10.1 summarizes the stimulations originally planned and those which were actually performed on each zone.

Zone \#1 was expected to have the highest treating pressure of all zones since it was the farthest from the wellhead. However, Zone 1 was found to have the lowest treating pressure and was the only zone for which design rates and volumes were achieved. The actual closure pressure based on the breakdown of the formation with nitrogen was about 1200 psig (Figure 10.1). Although the nitrogen breakdown indicated a closure stress of 1200 psig or about 400 psi less than predicted, analysis of the shut-in period after stimulation indicated that closure stress had increased to approximately $1650 \mathrm{psi}$ (Figure 10.2). Therefore, the lowerthan-expected treating pressure was due largely to less total friction than predicted. A total of $140,000 \mathrm{lbs}$ of $20-40$ mesh sand was pumped in the formation. Following the treatment, the well was flowed back gradually through chokes ranging from 0.25 -inch to a full 2-inch opening. The ga: open flow after being open eight hours on the fourth day of flow back was measured at $292 \mathrm{mcf} / \mathrm{day}$.

The overall plan for Zone 2 was to close the port collar to Zone 1, open the port collar to Zone 2, and then to stimulate Zone 2 with a foam frac treatment similar to, but proportionately larger than Zone 1. After a series of unsuccessful attempts to close the port collar to Zone 1, an inflatable packer was placed in the casing between Zone 1 and 2. Initial 


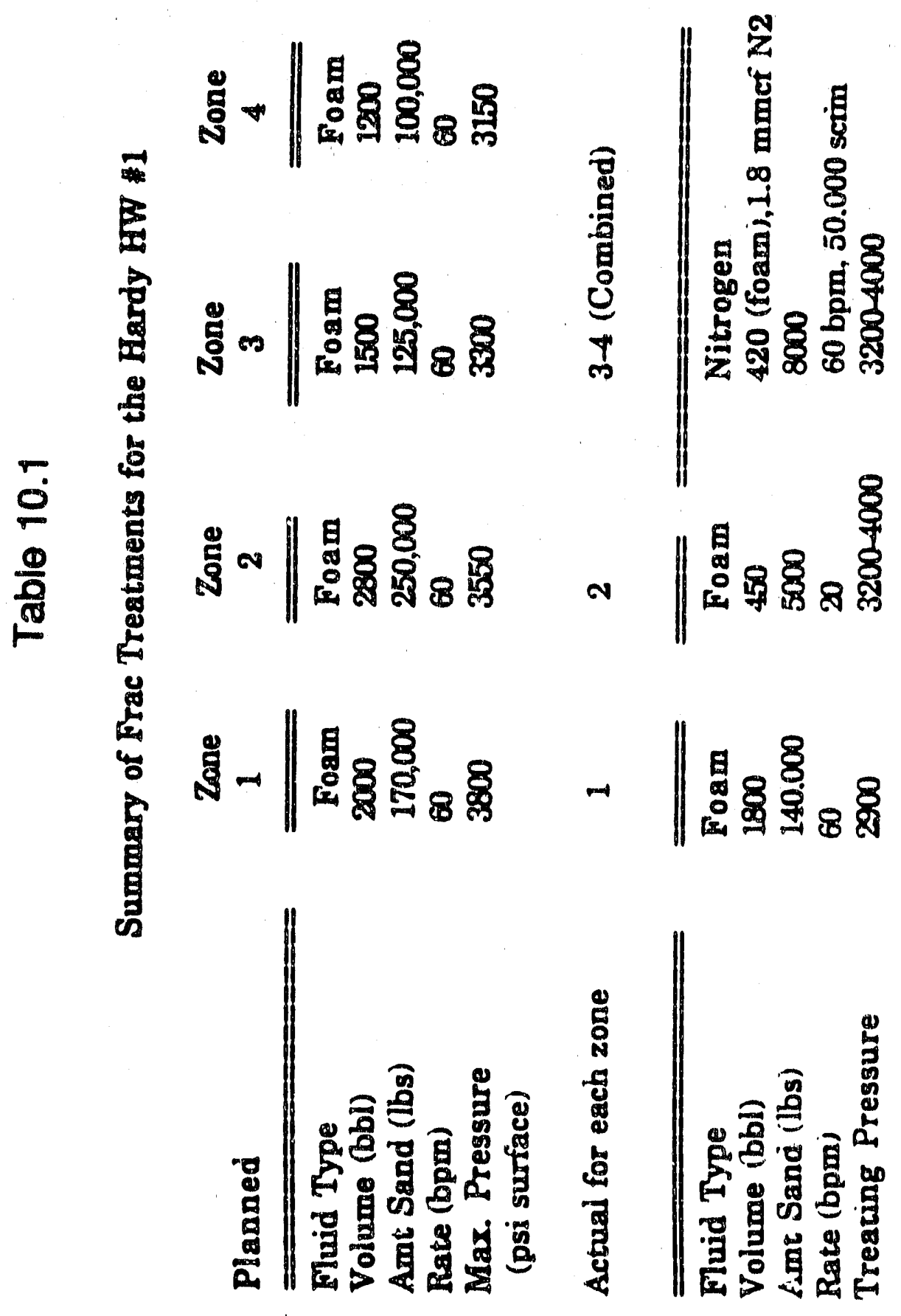




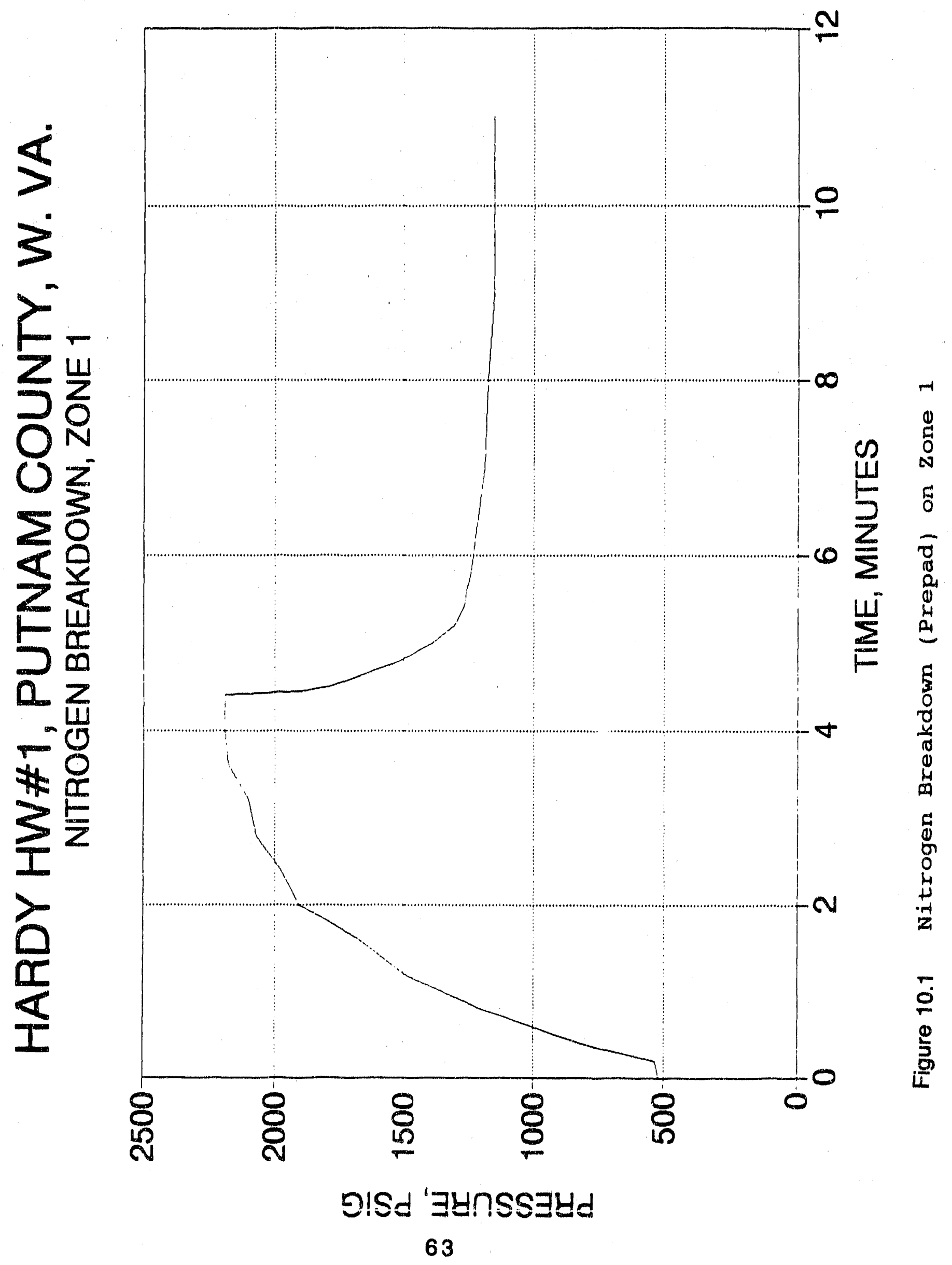




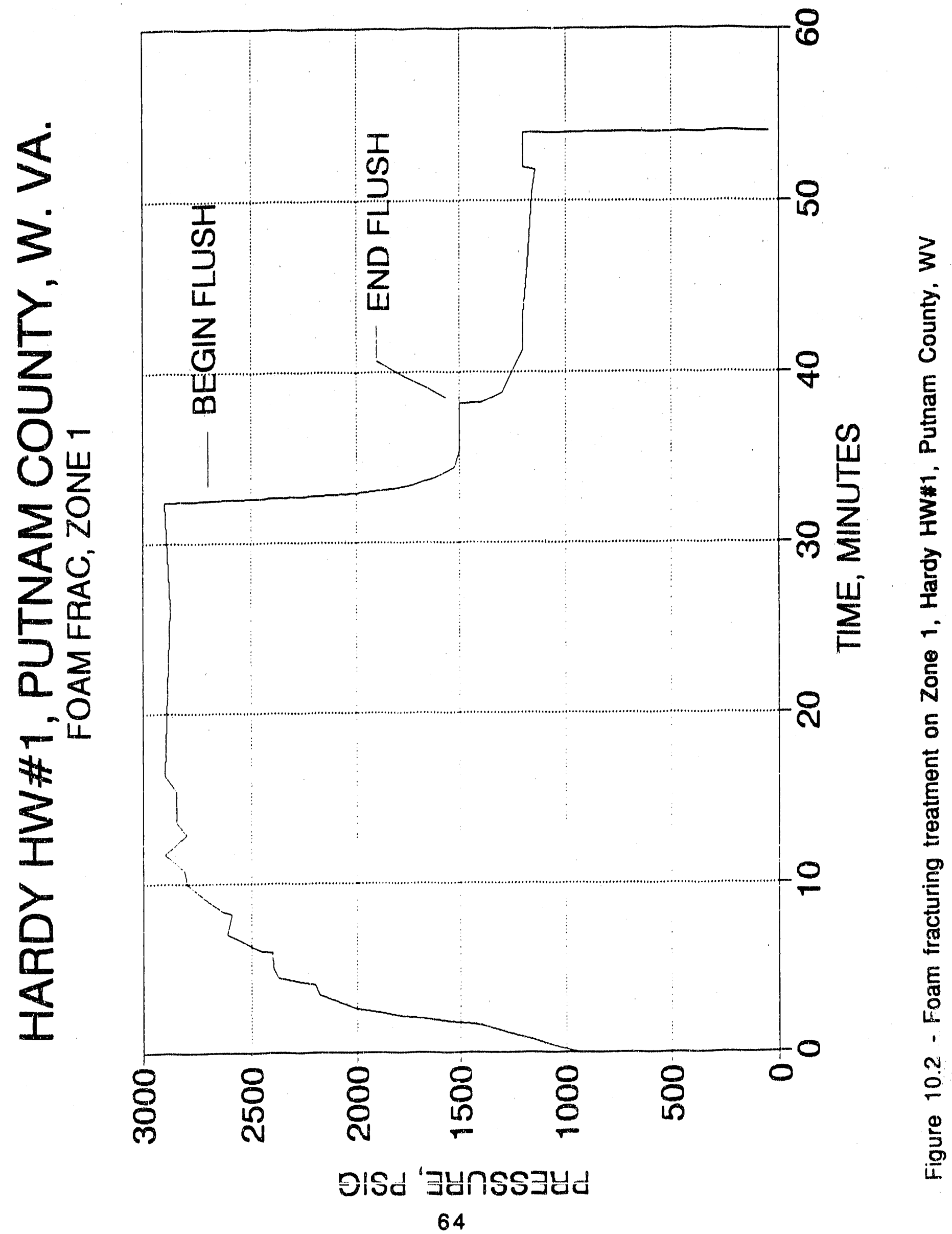


attempts to set the packer by inflating it with nitrogen failed and the packer was then set by inflating it with water. The port collar to Zone 2 was then opened so that the zone could be accessed for stimulation.

The first attempt to stimulate Zone 2 failed as pressures approached the limit of the casing (see Section 11.3 Hardy HW\#1 Final Report). On the day following the initial breakdown, a second breakdown or nitrogen "pre-pad" was injected into the formation. Injection rates were similar to the initial breakdown, but the pressure response was somewhat different (Figure 10.3). The pressure climbed to nearly 3100 psig during injection of the pre-pad before leveling off compared to 2300 psig the previous day.

After the nitrogen pre-pad was injected; a 50-barrel foam pad was injected at three rates increasing stepwise from $20 \mathrm{bpm}$ to $40 \mathrm{bpm}$ and $60 \mathrm{bpm}$. Figure 10.4 shows the pressure response that resulted from the foam pad injection. As shown in Figure 10.4, the injection pressure quickly grew to over $4000 \mathrm{psig}$, shutting down the frac job before any sand-laden foam could be injected.

Because of the apparent increase in frictional losses associated with this zone compared to Zone 1, it was believed possible that the retrievable packer had shifted after the initial breakdown and had partially blocked the port collar. The packer was retrieved and replaced by a new packer. In addition, the casing adjacent to Zone 2 was perforated with thirty 0.47 -inch holes to assure access to the formation and to minimize friction losses within the casing system. At this point a final attempt was made at fracing Zone 2. Pressure associated with the nitrogen prepad injection are shown in Figure 10.5. The pressure response was typical of previous attempts, with the maximum pressure reaching over $3250 \mathrm{psig}$ at an injection rate of $33 \mathrm{mcfm}$. Figure 10.6 illustrates the predictable results at injection rates of 60,40 , and $20 \mathrm{bpm}$ of 80 quality foam. The job "sanded off" at approximately 17 minutes into the job while injecting a foam slurry at $20 \mathrm{bpm}$ with $1.5 \mathrm{lb} /$ gallon of $20 / 40$ sand.

During the several attempts to frac Zone 2, various hypotheses were proposed to explain the peculiar behavior of the zone. These hypotheses 


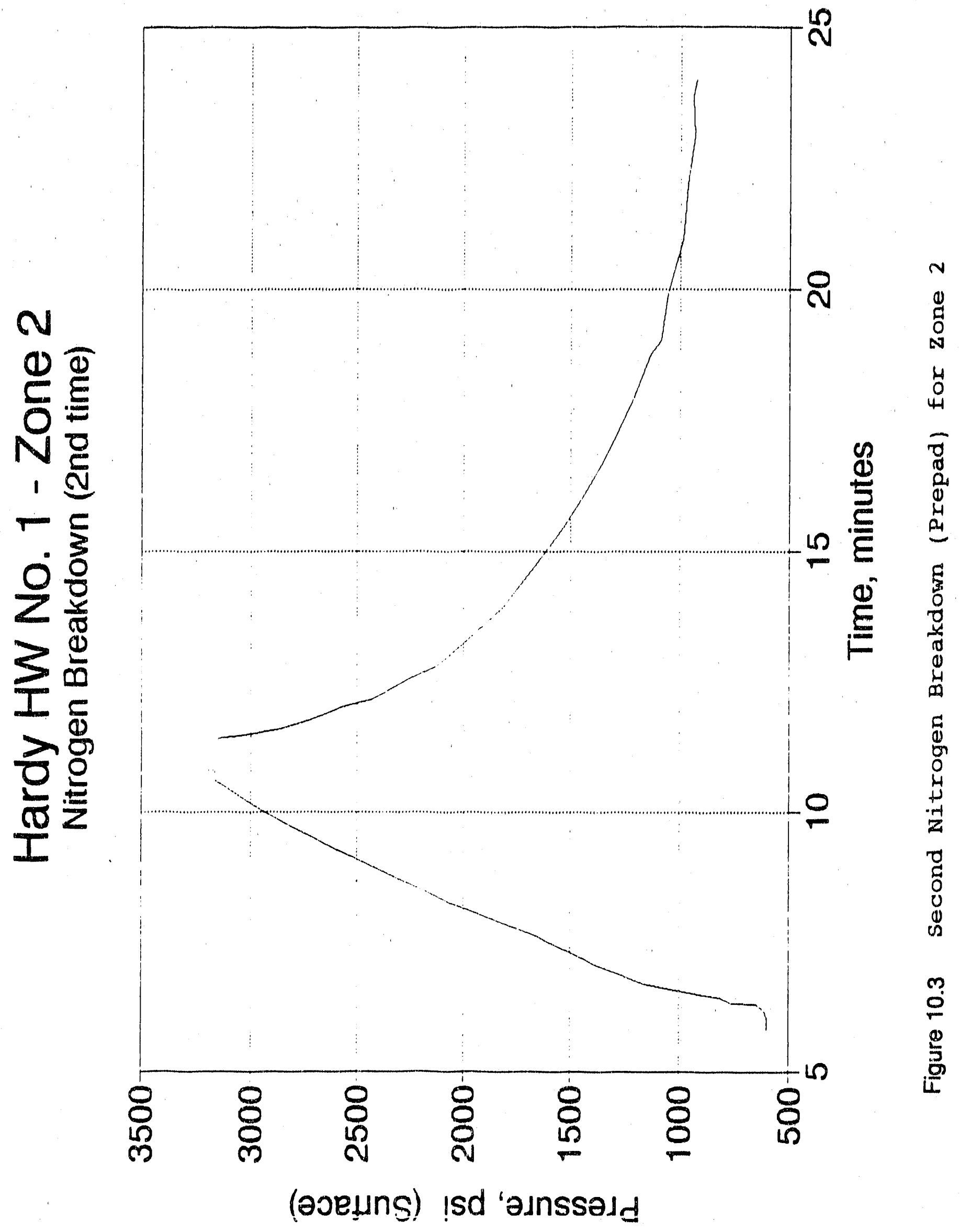




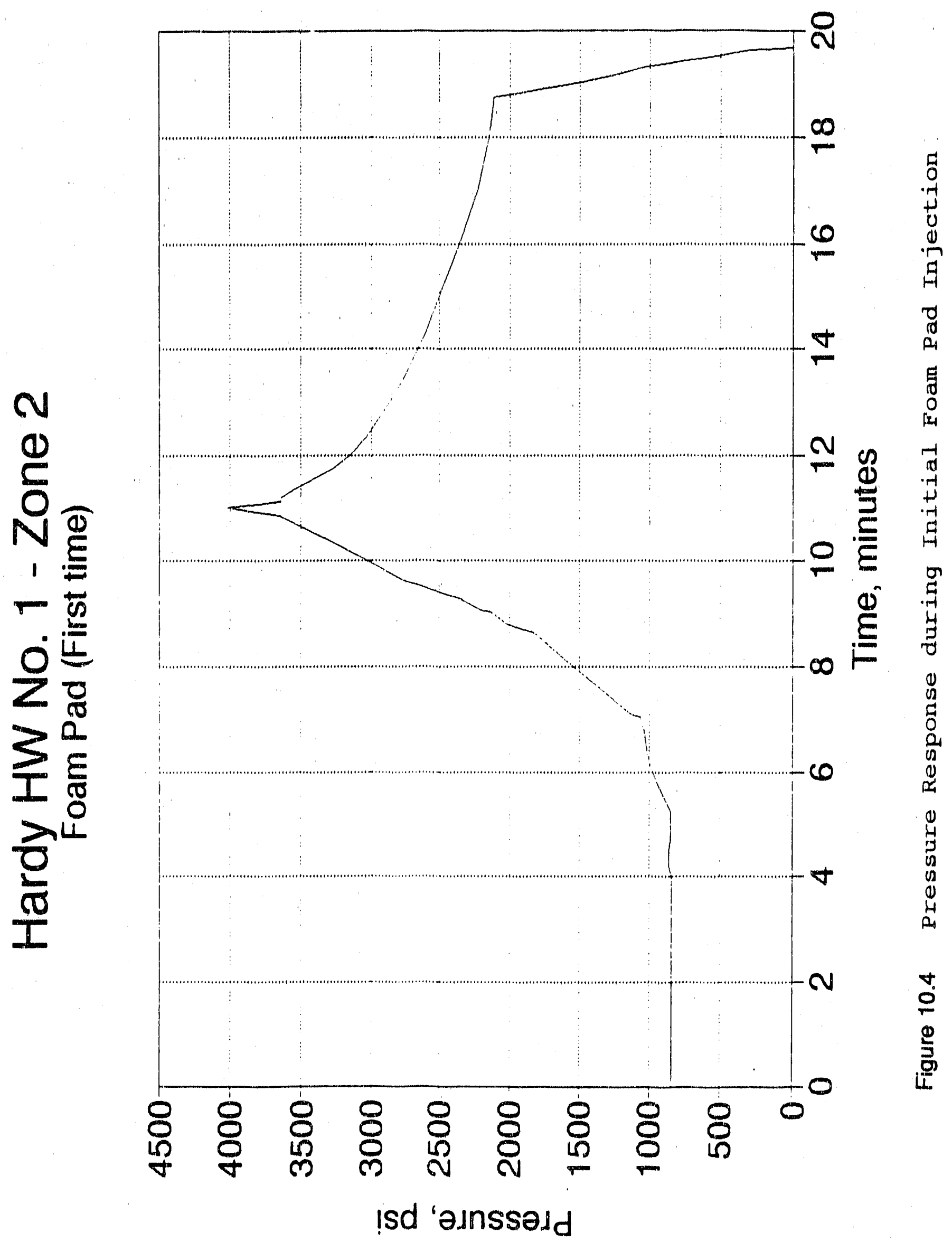




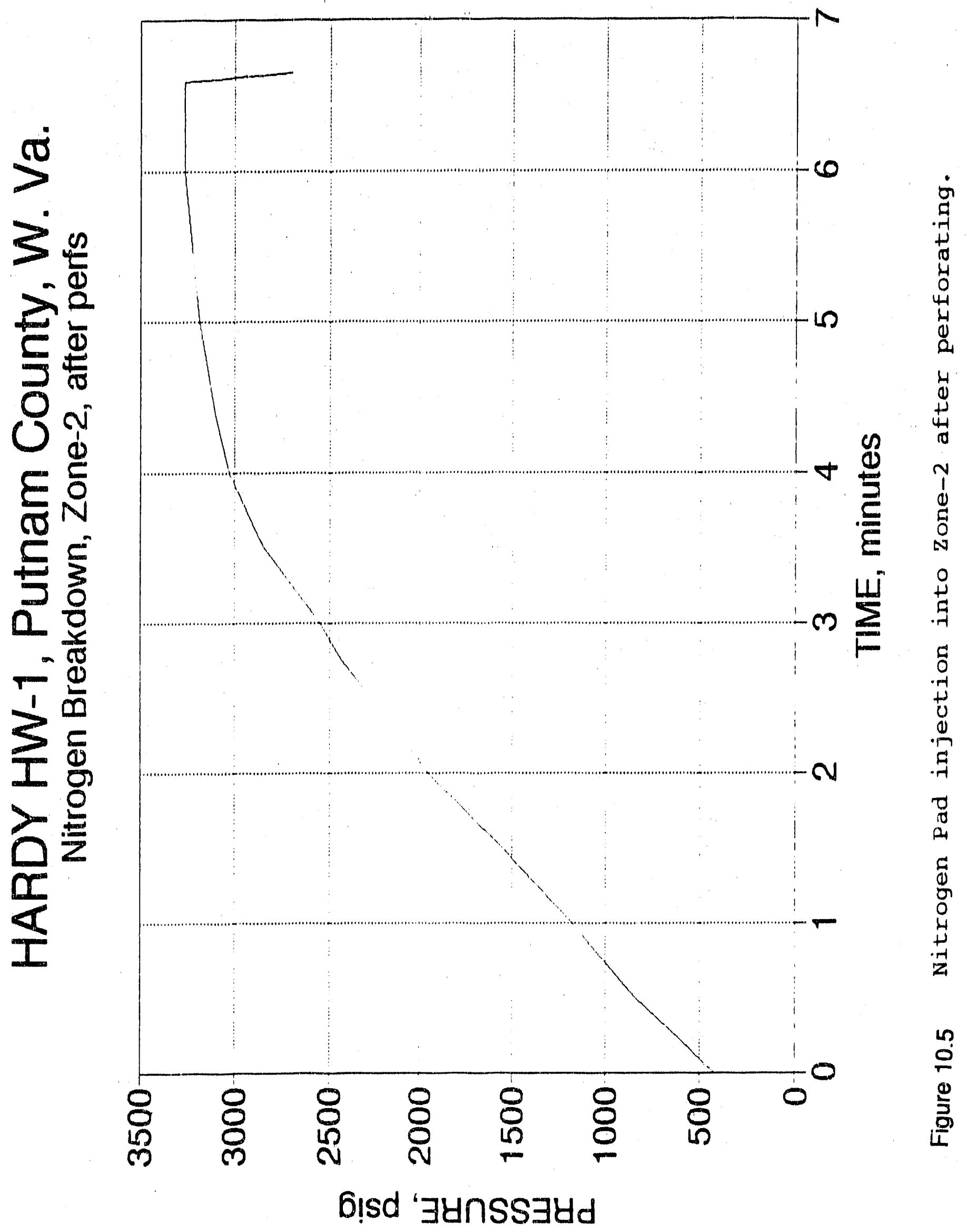




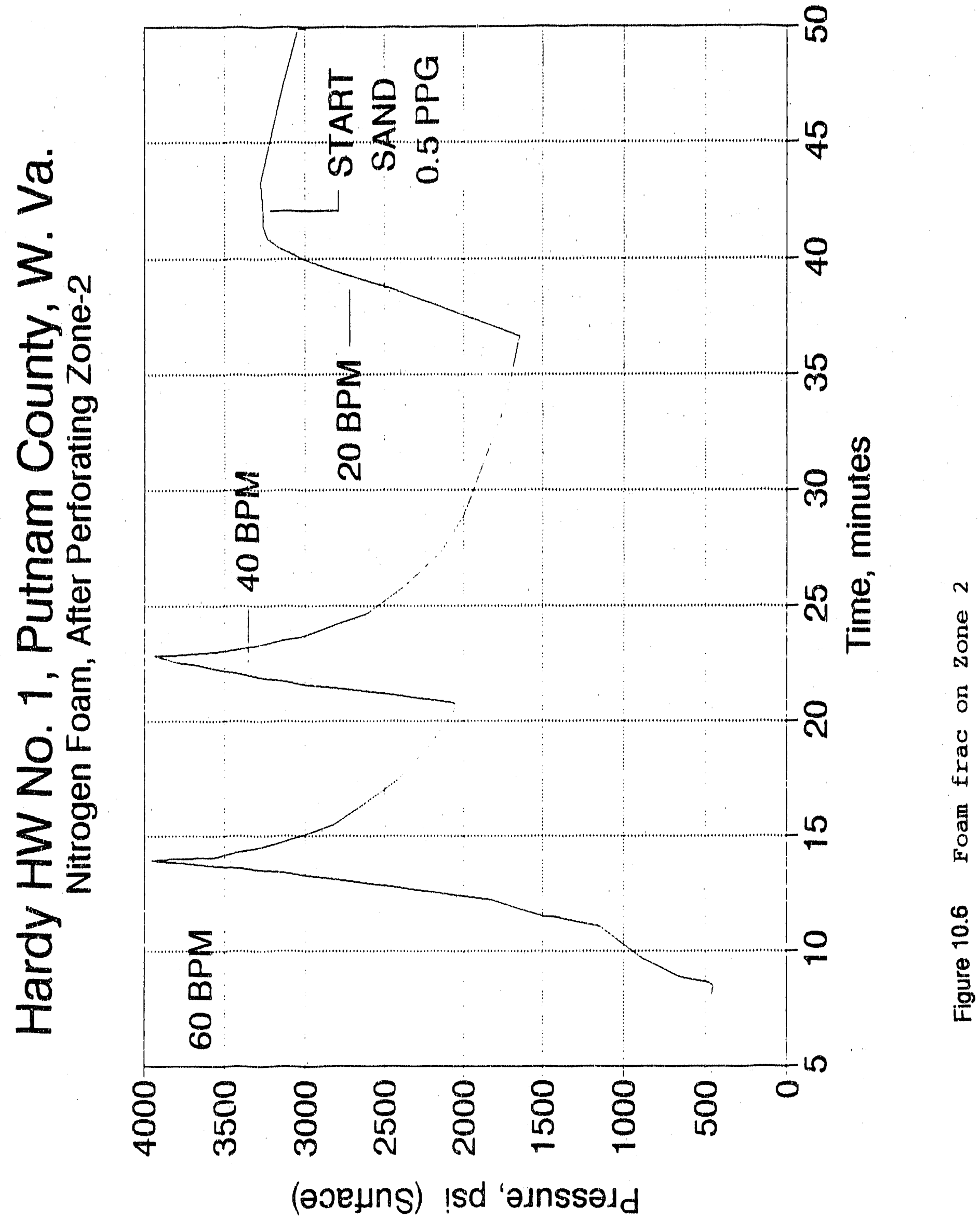


ranged from downhole equipment problems to pre-stressing of the formation by the preceding frac treatment on Zone 1 . Suggested explanations included the following:

1. Blockage of port collar by retrievable packer

2. Closed or partially closed port collar

3. Mud, sand, or rubble behind the casing

4. Zone 2 fractures filled by sand when Zone 1 was fraced.

5. Stress build-up in formation by prior frac in Zone 1.

6. Too many natural fractures to inflate for the avallable rate.

7. Interval too long for effective stimulation.

Initially, the first three suggested explanations appeared to have the most merit; however, after careful examination of the data, the latter two appear to be closer to the answer.

To initiate a fracture in shale in a horizontal wellbore in a plane other than one containing the wellbore itself, there must be pre-existing natural fractures. Otherwise, the shale is so uniformly impermeable that it would be impossible for fluids to break out of the wellbore without flrst initiating a longitudinal fracture along the wellbore. The same problem exists with a uniformly permeable formation where the frac fluid enters the formation on a uniform front along the length of the horizontal wellbore. Since no differential stresses are created parallel to the wellbore except at the very ends of the injection zone, it is nearly impossible to create a fracture that is perpendicular to the wellbore, regardless of the minimum stress orientation. A situation similar to this very well may have existed in Zone 2.

Analyses of the problems associated with fracing Zone 2 refer to Section 11.4 in the Hardy HW\#1 Final Report.

After the extreme difficulty and cost growth encountered in fracing Zone 2, plans for the stimulation of Zones 3 and 4 were modified to reduce costs of the final stimulation treatments. Therefore, Zones 3 and 4 were combined and stimulated as a single zone (Zone 3-4). 
Zone 3-4 was perforated with 42 holes between measured depths of 4207 and 4476 feet. Ten of the holes were in Zone 3 between 4430 and 4476 feet, MD, and 32 holes were in Zone 4 between 4207 and 4370 feet, MD. Zone 3-4 was then stimulated with an 80-quality sandladen foam. Figure 10.7 shows the pressure response during the stimulation of zone 3-4. Sand concentration reached a maximum of 1.5 lb/gal into the fracture(s) before "screening out". This screen-out occurred while foam was being pumped at $60 \mathrm{bpm}$ compared to a screenout at $20 \mathrm{bpm}$ in Zone 2. Prior to the screen-out in Zone 3-4, nitrogen breakdown and pre-pads of $134 \mathrm{mcf}$ and $135 \mathrm{mcf}$ had been injected at $35,000 \mathrm{scfm}$ and $1900 \mathrm{psi}$ (surface).

After partial clean-up of fluids from the first attempt to foam frac Zone 3-4, a second attempt was made with no sand injection. Very quickly, after the arrival of the 80-quality foam at the formation face, the injection pressure rose to $3700 \mathrm{psi}$ and the treatment was halted (Figure 10.8). The foam was allowed to flow back from the well and the treatment was continued using only nitrogen. The final stimulation of Zone 3-4 consisted of $2867 \mathrm{mscf}$ of nitrogen injected at an average rate of $50,000 \mathrm{scfm}$. The treating pressure ranged from 2850 to $3400 \mathrm{psi}$ with the highest pressure being recorded within the first four minutes after restart of the treatment with nitrogen. Unlike the problems associated with fracing Zone 2, the problem of fracing Zone 3-4 appeared to be more conventional screen-out.

\subsection{Hunter Bennett \#3997 Well}

Based on previous experience with stimulating the Fifth sand in vertical wells in the area of interest and because of the problems likely to be encountered during clean-up, BDMESC recommended the use of all nitrogen gas fluid as the stimulating fluid. The procedures and recommendations to frac Zones 1 and 2 are summarized in Section 11.2 of the CNGD Final Report.

After all of the external casing packers (ECP's) were inflated with $2 \% \mathrm{KCl}$ water, all of the port collars were closed leaving Zone 1 as the only zone opened to measure pressure and gas flow prior to the stimulation operations. The well was shut-in for a ten day period and 


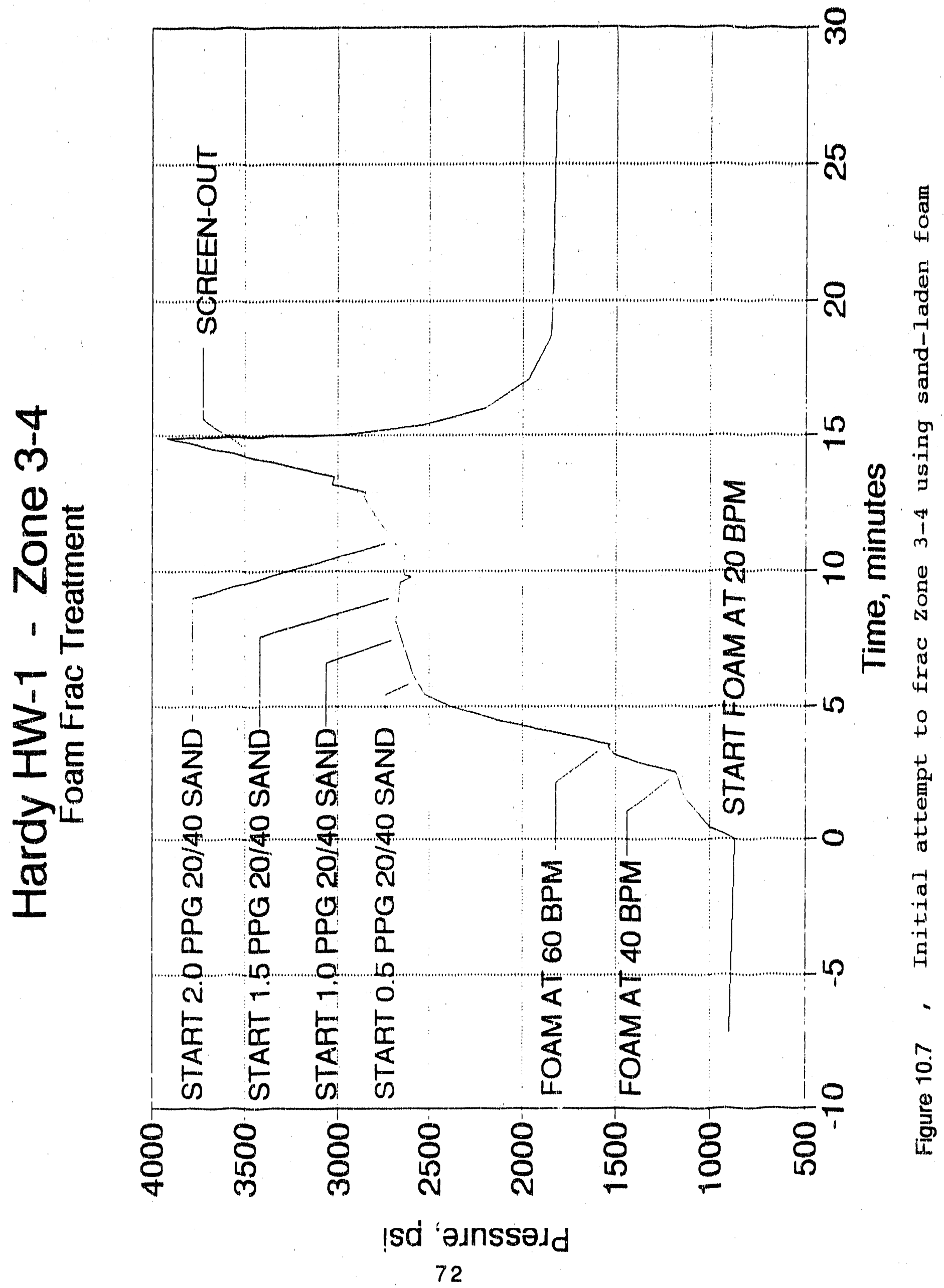




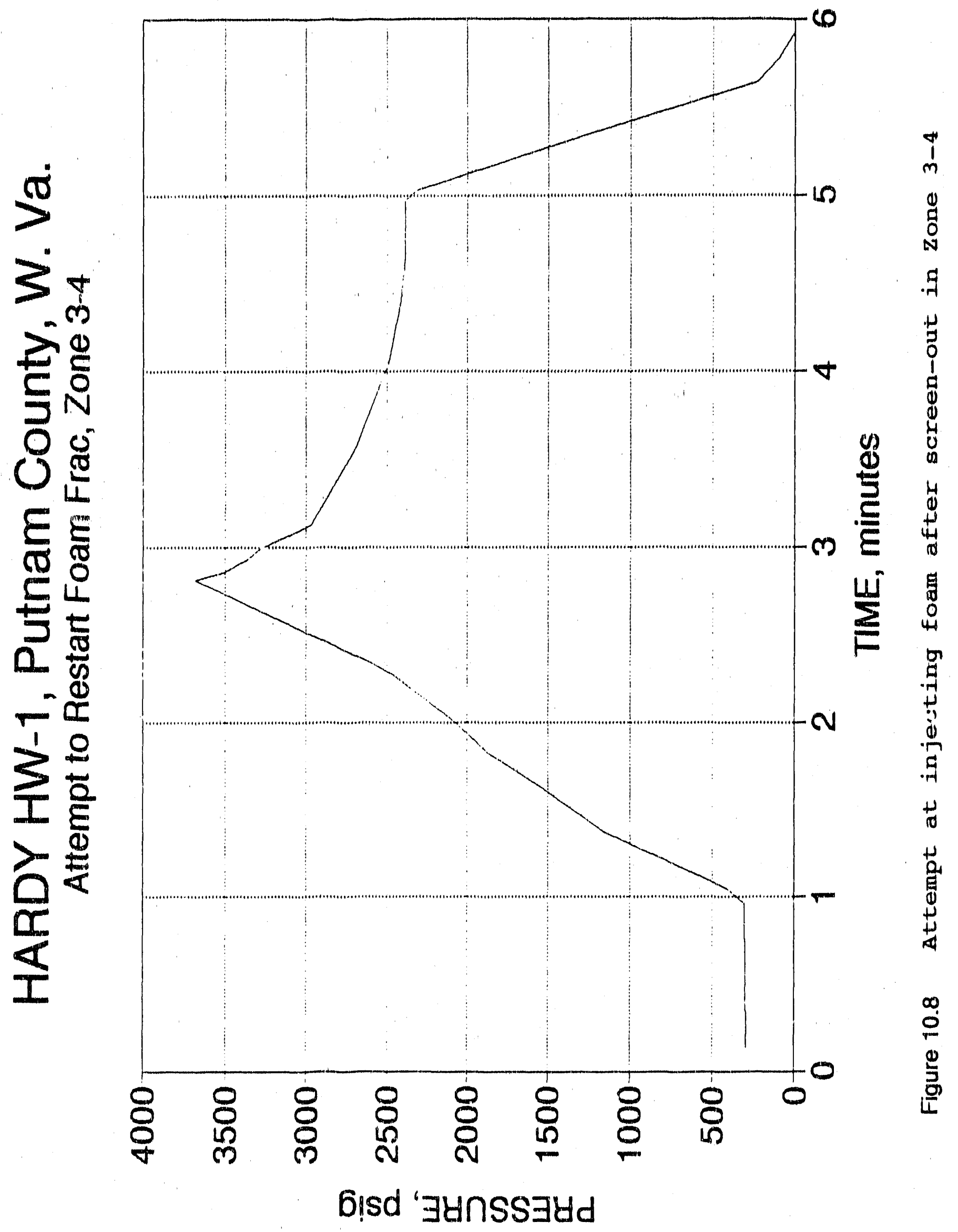


tested at a six psig pressure and recorded a gas flow rate of less than 2 mcfd. The well was actually shut-in for a period of six months before stimulation operations were initiated and Zone 1 built pressure to only 38 psig during this period. The zone was producing practically no gas prior to stimulation.

Zone 1 was stimulated on September 16, 1991. The stimulation was initiated by pumping nitrogen at a rate of $20,000 \mathrm{scfm}$ which was then was doubled to 40,000 scfm until breakdown occurred. Pumping was shut down for five minutes to watch the pressure fall off to obtain is an indication of the leak-off rate of nitrogen to the formation. Pumping resumed and injection rate continued to increase until the pressure reached 3950 psig. The programmed injection rate of 70,000 scfm was reached at a pressure of 3870 psig. The ISIP, 5 minutes SIP, 10 minutes SIP, and 15 minutes SIP were recorded at 2857, 1751, 1462, and 1288 psig respectivelw. The average treating pressure was 3842 psig at an average injection rate of $68,330 \mathrm{scfm}$. A plot of pressure versus time during the frac job is presented in Figure 10.9.

Following the frac job, the well was opened to flow back through a series of chokes and was flowing at a rate of 491 mcfd after 72 hours of continuous open flow. After 11 days of flowback, the well was flowing at a rate of 210 mcfd.

Prior to stimulating Zone 2, an ECP integrity test was conducted by setting a retrievable bridge plug below the first port collar and opening the port collar and examining the reservoir pressure in Zone 2. The pressure recorded in Zone 2 was 450 psig while the pressure recorded in Zone 1 was $550 \mathrm{psig}$. This pressure differential indicated that the ECP had held during the stimulation of Zone 1.

On October 9, 1991, Zone 2 was stimulated by pumping 1.5 mmcf of nitrogen at an average injection rate of 88,800 scfm reaching a maximum rate of $93,100 \mathrm{scfm}$. The formation broke down at approximately $3000 \mathrm{psig}$ and the average treating pressure was $3600 \mathrm{psig}$. A plot of pressure versus time for the frac job is shown in Figure 10.10. 


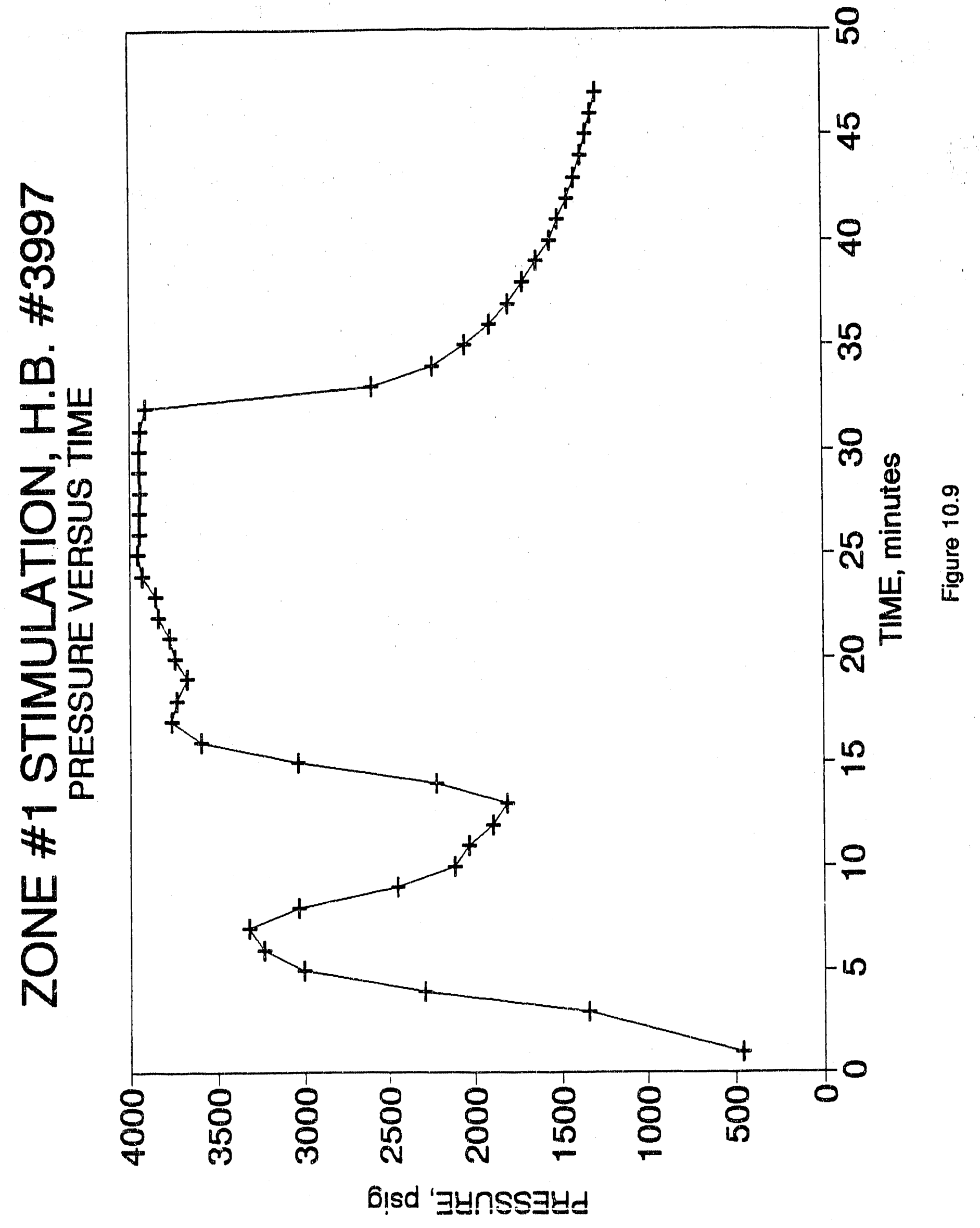




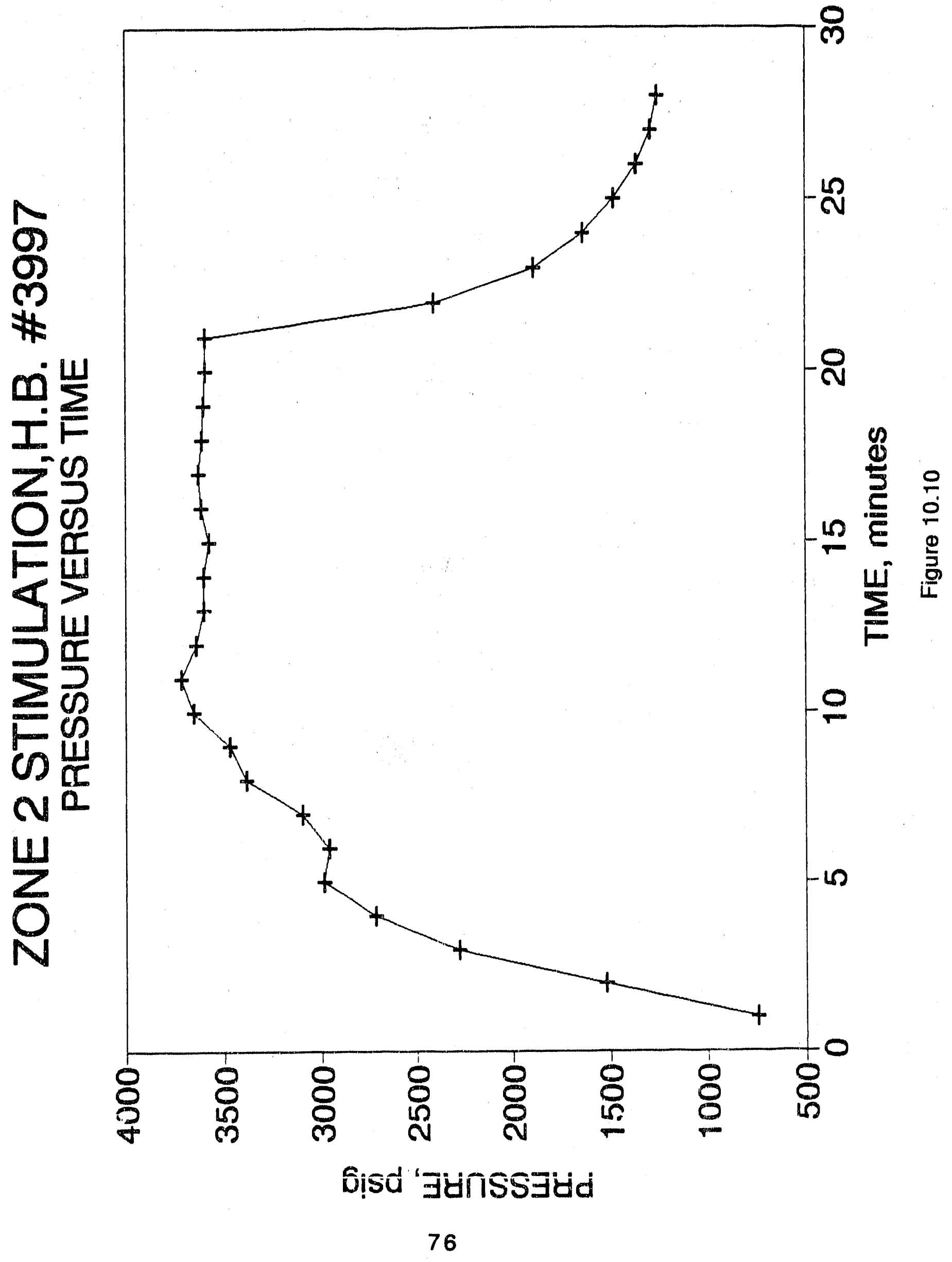


By the time flowback was initiated, approximately twenty minutes after the frac job, the pressure had declined to 920 psig. The rapid decline in pressure was interpreted to mean that a significant fracture system had been created during the stimulation. The well was left to flow continuously to clean up as rapidly as possible in order to insure cleanup before shutting in for a pressure buildup and drawdown test.

Results of the stimulation of Zone 1 indicated, through the significant gas production, that a fracture was generated, establishing communication between the wellbore and the reservoir. In Zone 2 the average treating pressure of $3600 \mathrm{psig}$ was 200 psi lower than that of Zone 1 while the average injection rate of 88,000 scfm was 20,000 scfm higher than the rate for Zone 1 , indicating a better communication with the reservoir and/or a better developed fracture system associated with Zone 2 than with Zone 1.

\subsection{WEL TESTING OPERATIONS}

Well testing operations were conducted on both the Hardy HW\#1 well and Hunter Bennett \#3997 well. A more detailed well testing procedure which included pre- and post-stimulation pressure buildup and drawdown testing were conducted on Hardy HW\#1. The following two sections summarize the procedures and results of well testing operations conducted on both wells.

\subsection{Hardy HW\#1 Well}

On January 26, 1990, an eleven day pre-stimulation pressure buildup test was initiated using downhole electronic pressure measuring services. In addition, surface pressure data were recorded using pressure chart recorders. Because of time constraints and the cost associated with testing each zone separately, BDMESC and DOE/METC elected to test the Hardy HW\#1 well when all the zones were in communication in order to arrive at general reservoir parameter values. A detailed pre-stimulation well testing procedure and data analysis are summarized in Section 12.1.1 of the Hardy HW\#1 Final Report. 
Table 11.1 lists input values used in the pre-stimulation data analysis. RHM techniques, Horner's plot and type curves generated for horizontal wells were used for analyzing the Hardy HW\#1 well prestimulation data. Table 11.2 summarizes the results of the prestimulation analysis using the aforementioned techniques. Type curve analysis using pressure buildup data indicated an effective horizontal wellbore length of 900 feet and a vertical to horizontal permeability ratio of $4: 1$. Figures $11.1,11.2,11.3$ exhibit the different pressure-time buildup data generated as a result of the various analysis techniques.

Following the stimulation of Hardy HW\#1, a fourteen day pressure buildup test was conducted where surface pressure values were measured and converted to bottom hole conditions. It is important to note that, as in the case of the pre-stimulation tests, the pressure buildup test was performed when all zones were in communication.

Similar analysis procedures were conducted on the poststimulation time-pressure data to that used for the pre-stimulation data. Type curves and Horner's technique were used for the analysis. Results of the pressure buildup data analysis are summarized in Table 11.3. Figures 11.4 and 11.5 represent plots of time-pressure data using Horner and type curve techniques respectively.

Following the post-stimulation pressure buildup test, the well was placed in line. A constant flow rate of 100 mcfd was attempted while the well's pressure was monitored at that rate. During the first six days there was fluctuation in the production rate due to freezing at the wellhead. The average production rate for the first six days was 61 mcfd. After the sixth day the production rate leveled at 100 mcfd. Figure 11.6 illustrates the relationship between the flow rates, well pressures and cumulative production with time. Using the drawdown data, a two-rate analysis test was implemented in order to provide information about the formation capacity and apparent skin. Results of the drawdown data analysis indicated an effective formation capacity of $0.52 \mathrm{md}-\mathrm{ft}$, an effective horizontal wellbore length of 1000 feet, and a vertical to horizontal permeability ratio of 4 to 1 . A detailed analysis of the drawdown data using the two-rate technique is presented in Section 12.2 of the Hardy HW\#1 Final Report. 
Table 11.1 3ASIC RESERVOIR AND WELL DATA

Input Values:

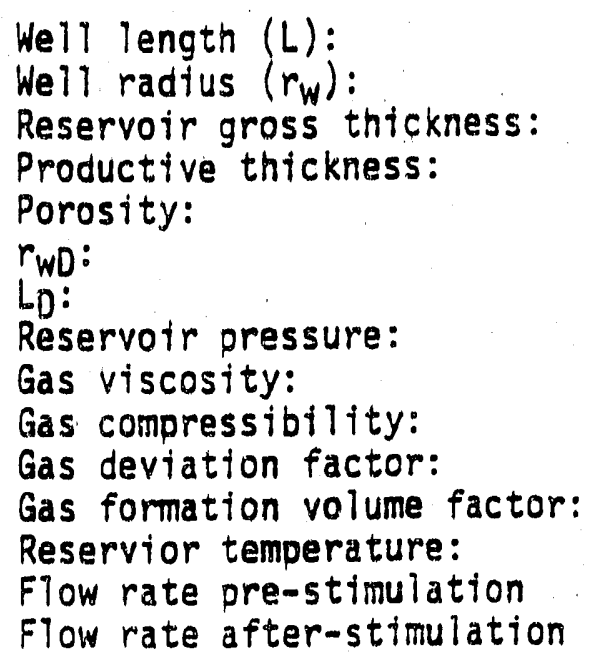

$r_{W D}$ :

LD:

Reservoir pressure:

Gas viscosity:

Gas compressibility:

Gas deviation factor:

Gas formation volume factor:

Reservior temperature:

Flow rate pre-stimulation

Flow rate after-stimulation

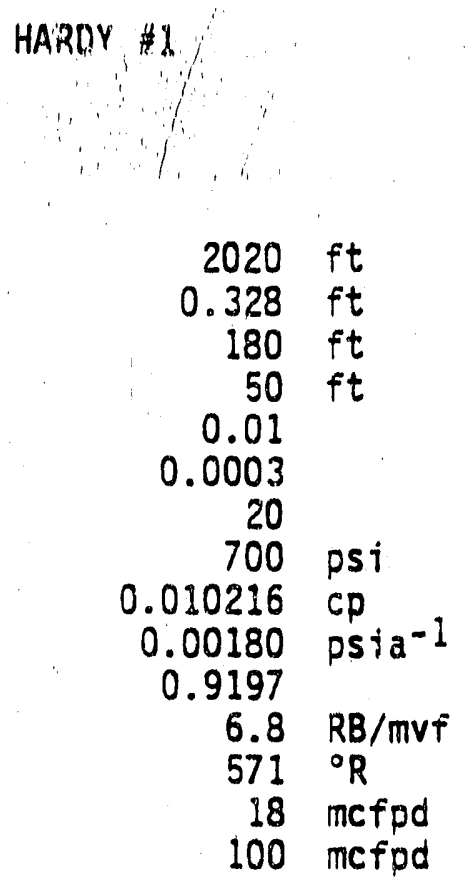



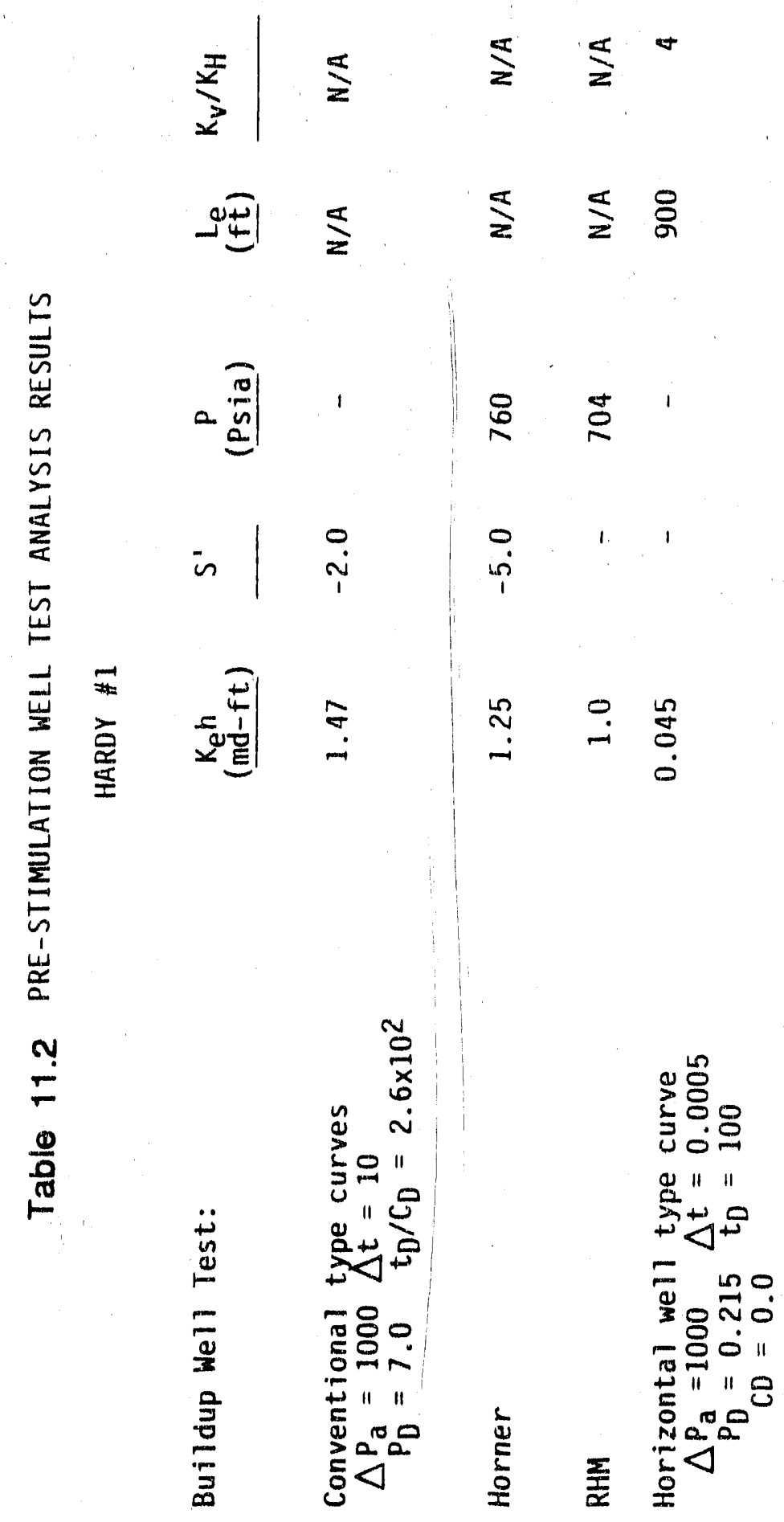


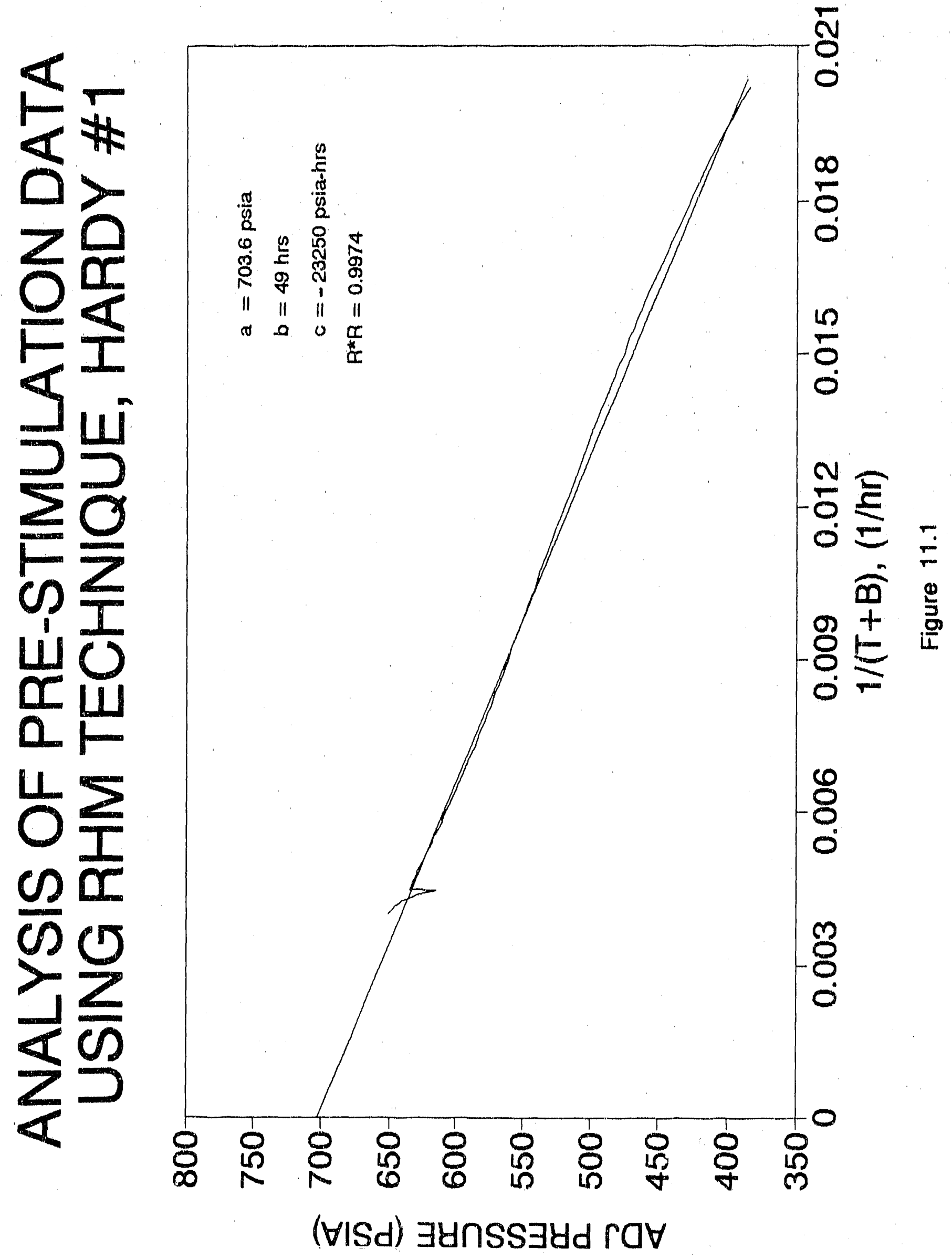




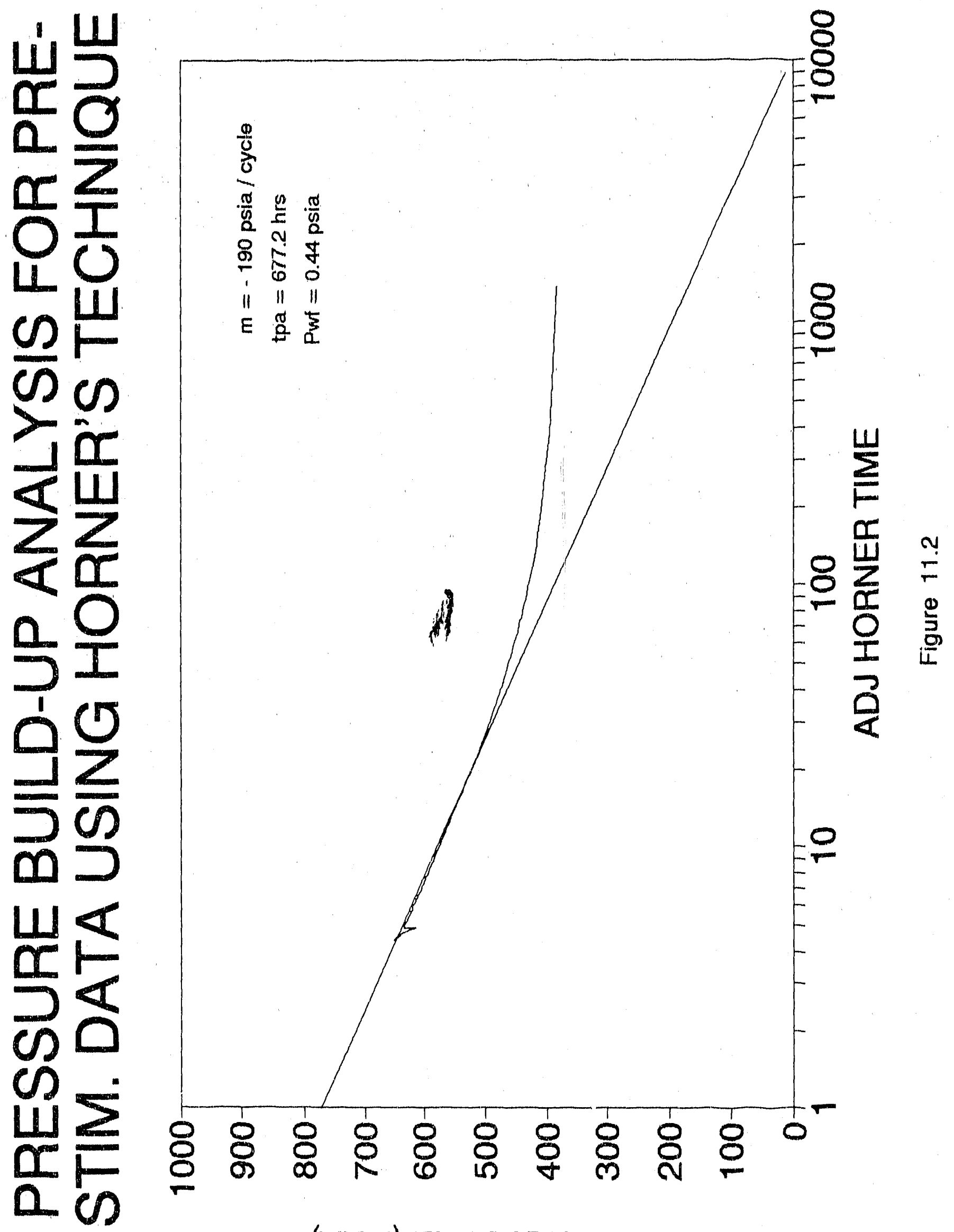

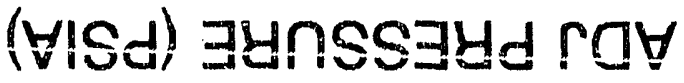

$$
\begin{aligned}
& 82
\end{aligned}
$$




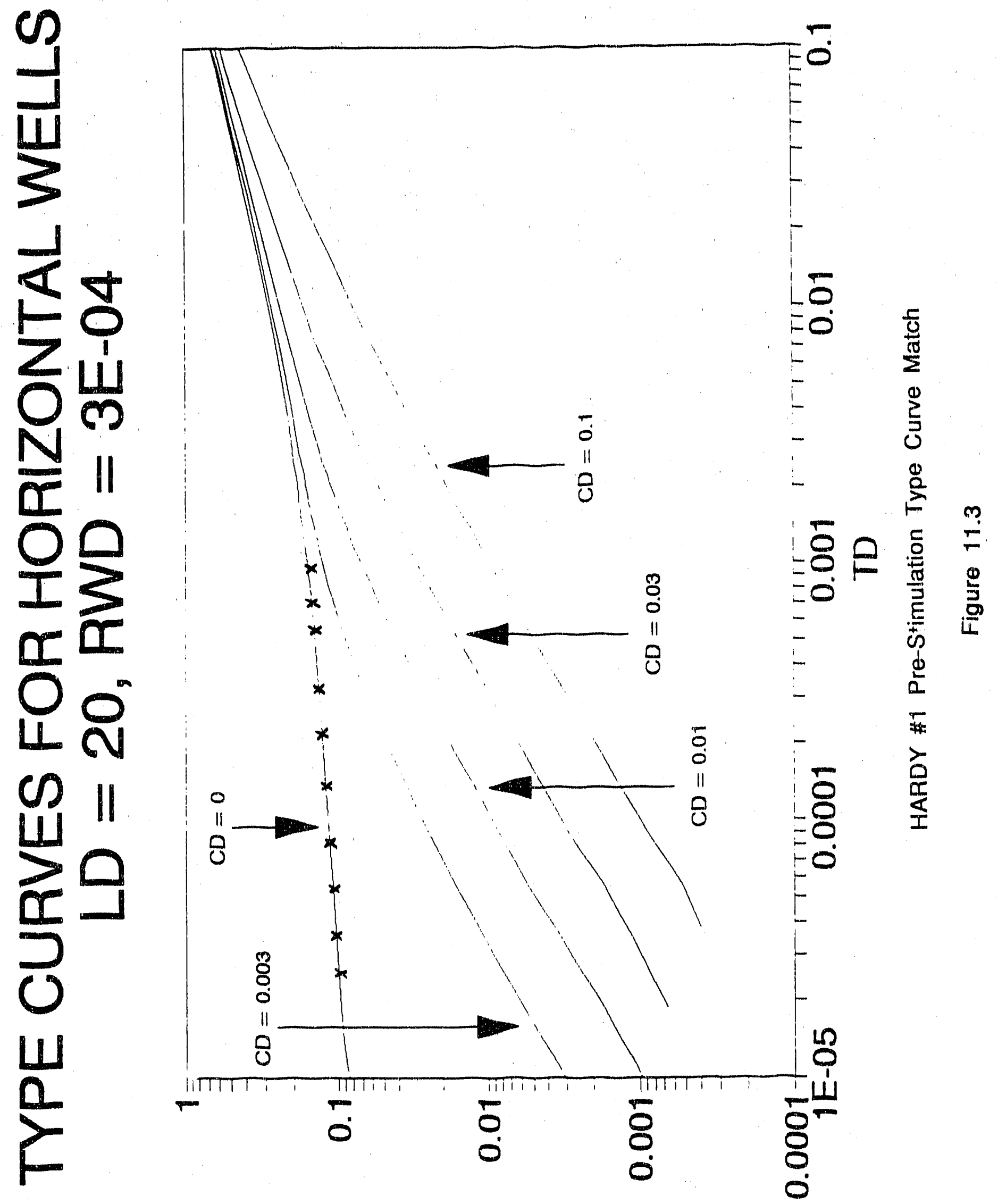

ad 


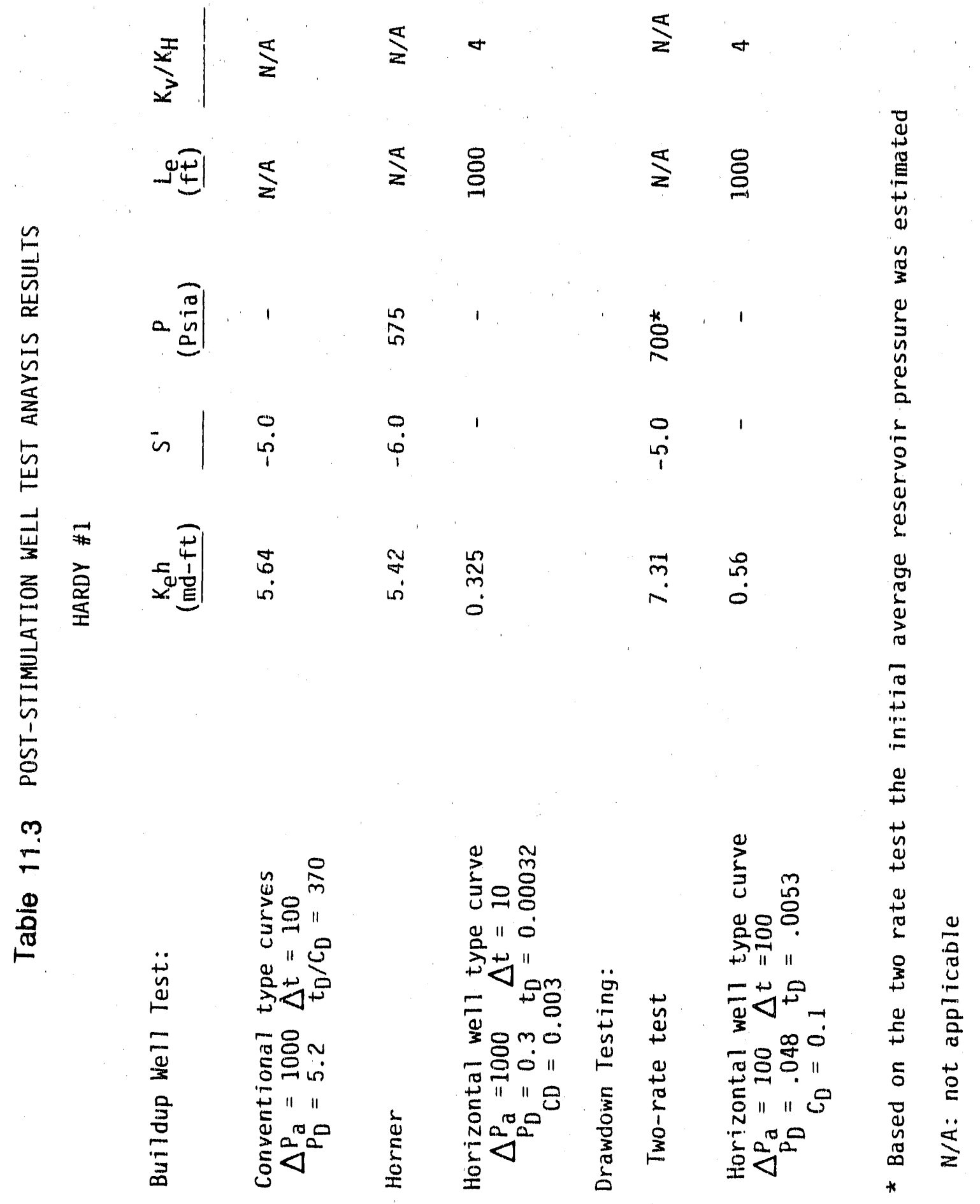




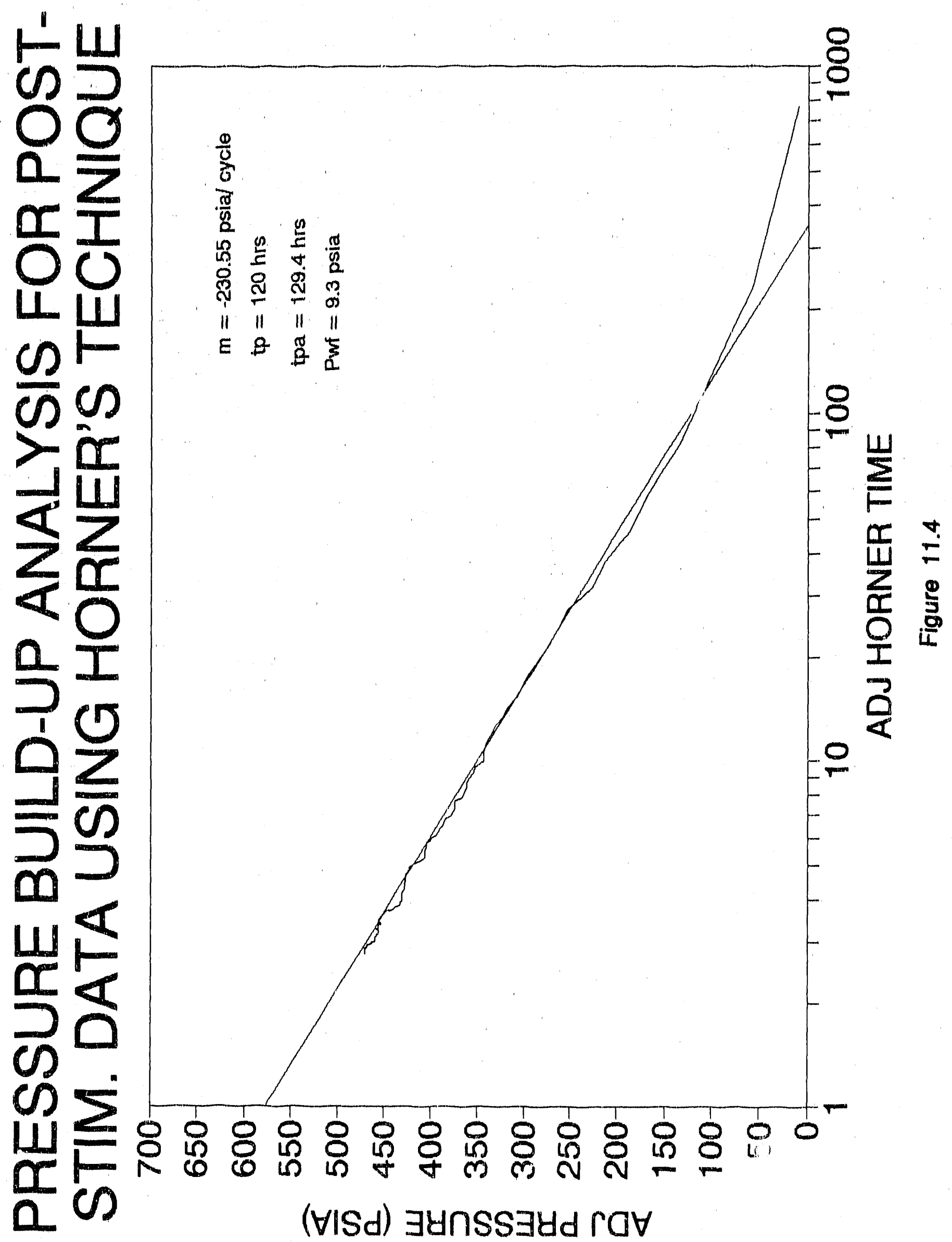




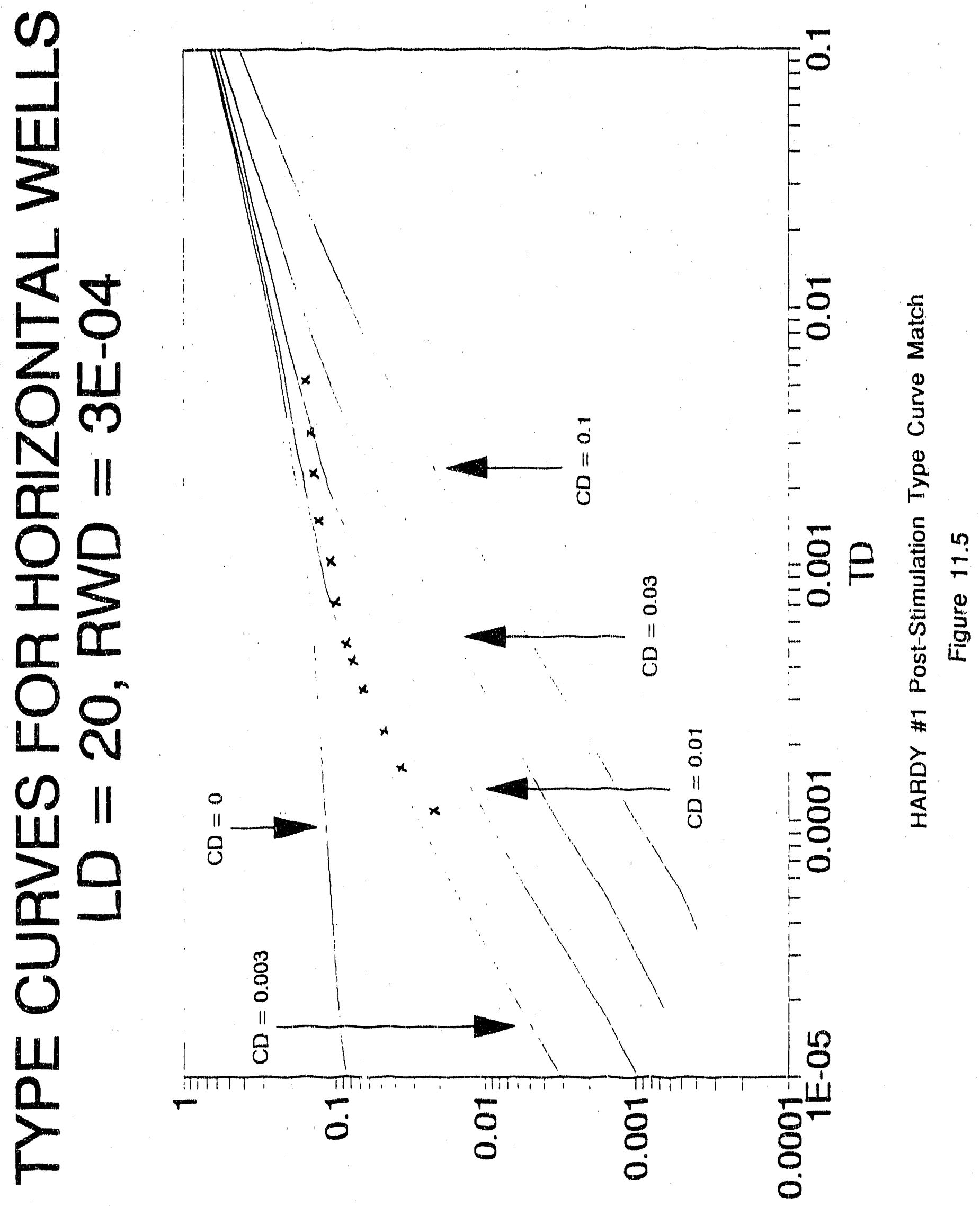


$\exists O W \exists \wedge \mid \perp \forall 7 \cap W \cap \supset$

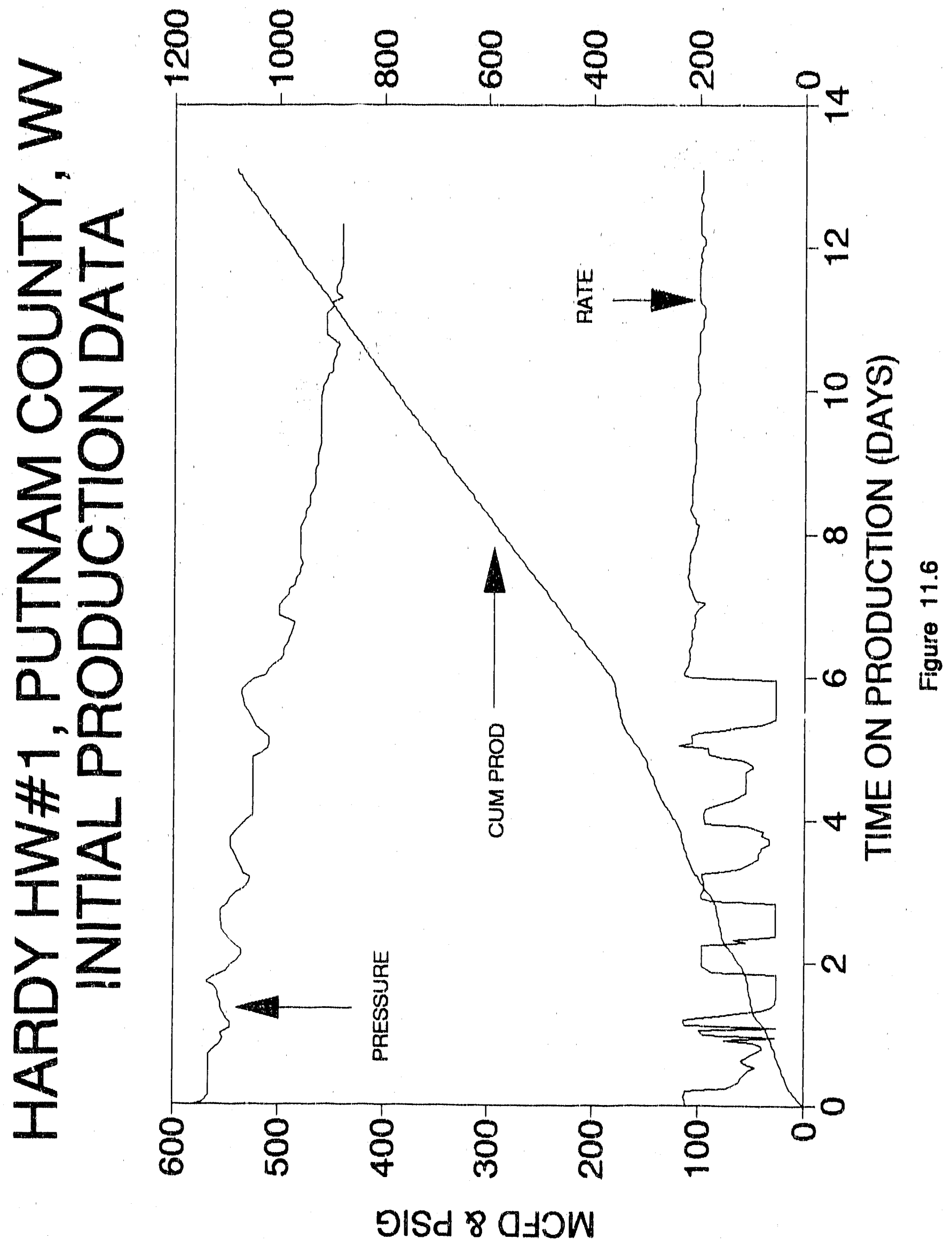


When comparing pre- and post-stimulation results it was apparent that there was an improvement in the well's productivity due to stimulation.

Using Horner's technique a comparison of pre- and poststimulation, primarily through an improvement in effective formation capacity (Kh). This improvement in Kh-value presumes an improvement in effective reservoir thickness. results indicated an improvement ratio of 4.5 compared to an improvement ratio of 7.0 when using horizontal well type curve analysis technique.

\subsection{Hunter Bennett \# 3997 Well}

The initial open flow potential was gauged at 80 mcfd after reaching TD.

Twenty four hours after stimulation of Zone 1 , the gas flow was measured at 520 mcfd and was estimated to carry at least 60 percent nitrogen. Ten days later the gas from Zone 1 gauged a flow rate of 200 mcfd with a low percentage of nitrogen content.

A seven day pressure buildup and drawdown test was agreed to by the well operator to determine the effect of stimulation on Zone 1 and measure the various reservoir parameters. Also this test would help determine the pre-frac reservoir conditions of Zone 2. An RTTS packer was set in the 5-1/2" casing to isolate Zone 1 after opening port collal \#1 in Zone 2. The intent was to conduct a pressure buildup on Zone 1 via the tubing, and a drawdown test of Zone 2 via the annular space. Initially the packer seemed to be holding, but a few days later the packer starteu leaking and both zones had stabilized at 450 psig.

BDMESC conducted a pressure pulse test with the RTTS packer in place to determine if the packer had failed. The results presented in Figure 11.7 showed an almost instantaneous pressure response during the drawdown stage indicating that the RTTS packer was no longer set properly and was leaking. 


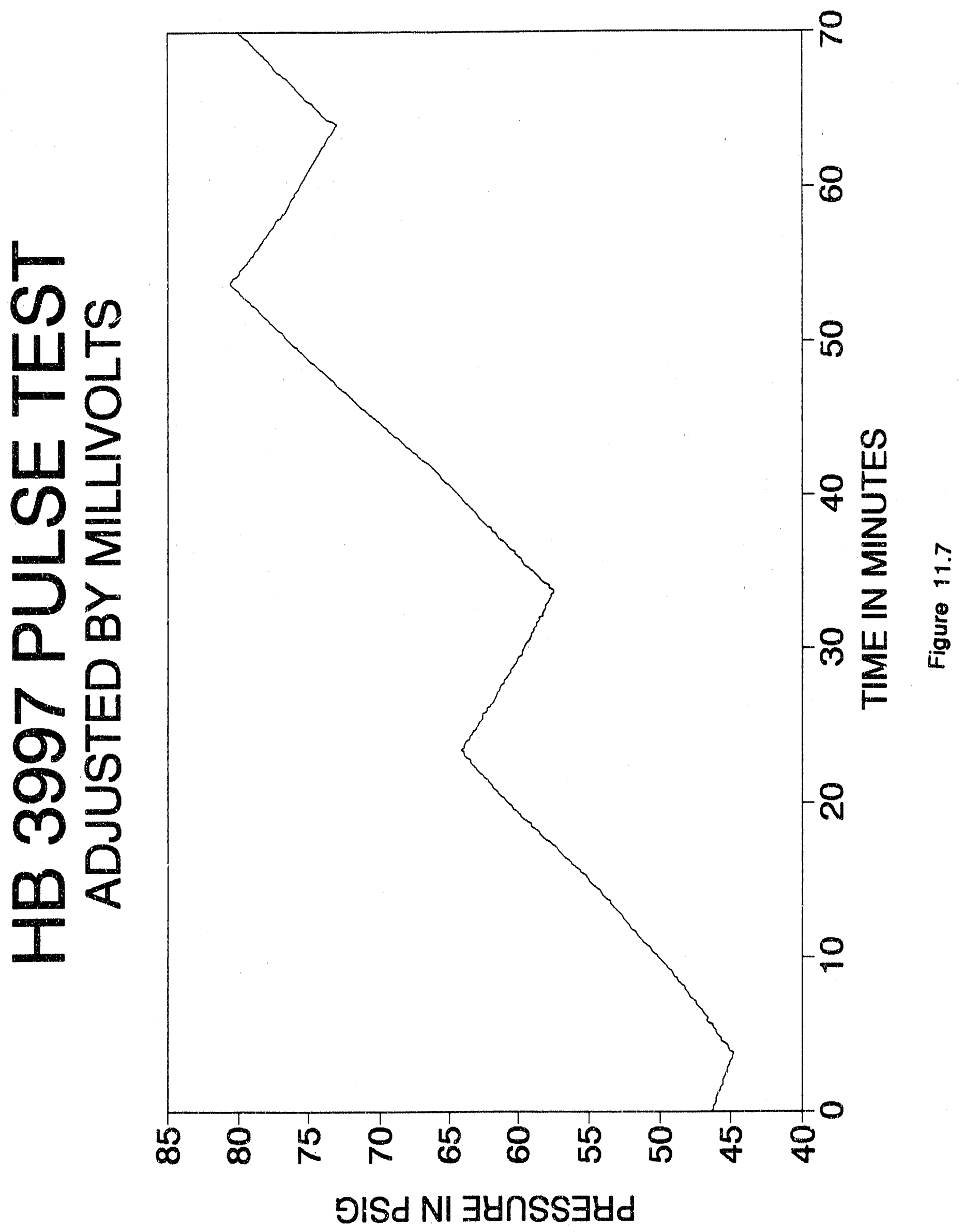


Following the stimulation of Zone 2 the well flowed back for seven days and then was shut-in for a seven day pressure build-up test. Zone 2 built up pressure to $375 \mathrm{psig}$ in six hours and stabilized at 560 psig in 148 hours. Pre-stimulation buildup indicated a pressure value of 450 psig after 6400 hours of shut-in time.

\subsection{ECONOMIC ANALYSIS}

\subsection{Introduction}

This economic analyses estimates the economic viability of two horizontal wells (BDM/Cabot and BDM/CNGD) as compared with an average Devonian Shale vertical well drilled to a depth of about 3,000 feet. The base economic case for both the vertical and horizontal wells was constructed assuming the same gas price, operating costs, state taxes, revenue interest, and working interest. The capital investment, initial gas production, and gas production decline rate are measured and/or estimated from well data since each of these factors is highly sitespecific, depending on location, drilling plan, problems in drilling and/or well completion, the number of natural fractures encountered, and reservoir pressure.

The base case calculations were expanded to evaluate the effect on the economic results due to higher or lower values for: capital investment, gas price, and initial gas production. The results of these sensitivity calculations are presented graphically to provide a direct comparison of horizontal and vertical well economic results across a wide range of gas prices, capital investments, and initial gas production. The sensitivity charts can therefore be used to quickly evaluate the economic potential for drilling and completing either a conventional vertical well or a horizontal well.

\subsection{Economic Assumptions}

Operating Costs

Operating costs are assumed to be $\$ 3,600$ per year for the life of the well. 
State Taxes

State taxes are 8 percent of the revenue to the working interest.

Revenue and Working Interest

Revenue to the working interest is assumed to be 87.5 percent (making the royalty 12.5 percent). The working interest is taken to be 100 percent.

Gas Price

Both the BDM/Cabot and BDM/CNGD horizontal wells were planned in early 1988 and the proposal was submitted to the Department of Energy in August 1988. In that year, 1988, the average wellhead price of West Virginia gas was $\$ 3.05 / \mathrm{Mcf}$. For this analysis, the base case economics were calculated on the basis of a constant $\$ 3.00 / \mathrm{Mcf}$ over the economic life of each well. The sensitivity calculations reflect both current (1992) prices (about $\$ 2.00 / \mathrm{Mcf}$ ) as well as historical higher prices for West Virginia gas of $\$ 4.00 / \mathrm{Mcf}$. Economic results were therefore generated and are presented with gas prices ranging from $\$ 2.00 / \mathrm{Mcf}$ to $\$ 4.00 / \mathrm{Mcf}$.

Capital Investment

Horizontal well drilling and completion represent an evolving technology for application to Appalachian oil and gas deposits. As such, the cost of the first horizontal well drilled by one operator will most likely be high, and the subsequent wells will likely be lower in cost as the operator learns what works and what does not work in field applications of the technology.

The two wells designed, drilled, and completed by BDM reflect the learning curve effect. The BDM/Cabot well was completed in 1989 at a cost of $\$ 921,211$. The second well, BDM/CNGD, was completed in 1990 for a total cost of $\$ 616,495$, a reduction in expenditures of about one- 
third. Major savings were made in the stimulation costs as depicted in Figure 12.1. Detailed costs for the two wells are shown in Table 12.1.

Based on the two horizontal wells discussed in this report and the earlier experimental well drilled with the Department of Energy (Recovery Efficiency Test Final Report, February, 1989, U.S. Dept. of Energy, Morgantown Energy Technology Center), BDM estimates that future horizontal wells similar to these three wells can be drilled and completed by BDM or some other experienced operator at an average cost equal to that of the BDM/CNGD well, plus or minus $\$ 100,000$. The base case economics therefore assume a completed cost of $\$ 616,495$. For the sensitivity analysis, capital investment ranges from $\$ 516,495$ to $\$ 716,495$.

Each of the three wells drilled by BDM have encountered hundreds of natural fractures containing hydrocarbons and each well has delivered commercial quantities of natural gas. This is due to the inherent advantage of the horizontal well which is designed to be drilled in a direction needed to intersect the natural fractures in the Devonian Shale formation. The probability of intersecting these fractures with a horizontal well is far greater than drilling into and/or near the fracture with a vertical well. With the appropriate geoscience analysis conducted to design the direction of the horizontal well, it is unlikely that the horizontal well will ever be "dry", that is, some gas or oil will likely be produced from each horizontal well, however, some of these wells may not be commercial.

In contrast, nearly every vertical Devunian Shale well drilled in the Appalachian area is completed regardless of gas shows during drilling or the interpretation of the logs after drilling. Experience has shown that it is possible to stimulate the well and thereby fracture into a natural fracture system(s) to achieve commercial production. Many of the completed wells are plugged and abandoned in a short period, a year or less, after production reveals they are not economic.

Statistics on vertical wells completed and rapidly abandoned are not available for the Appalachian area. In some areas, up to 90 percent of the wells drilled prove to be commercially viable. However, for 


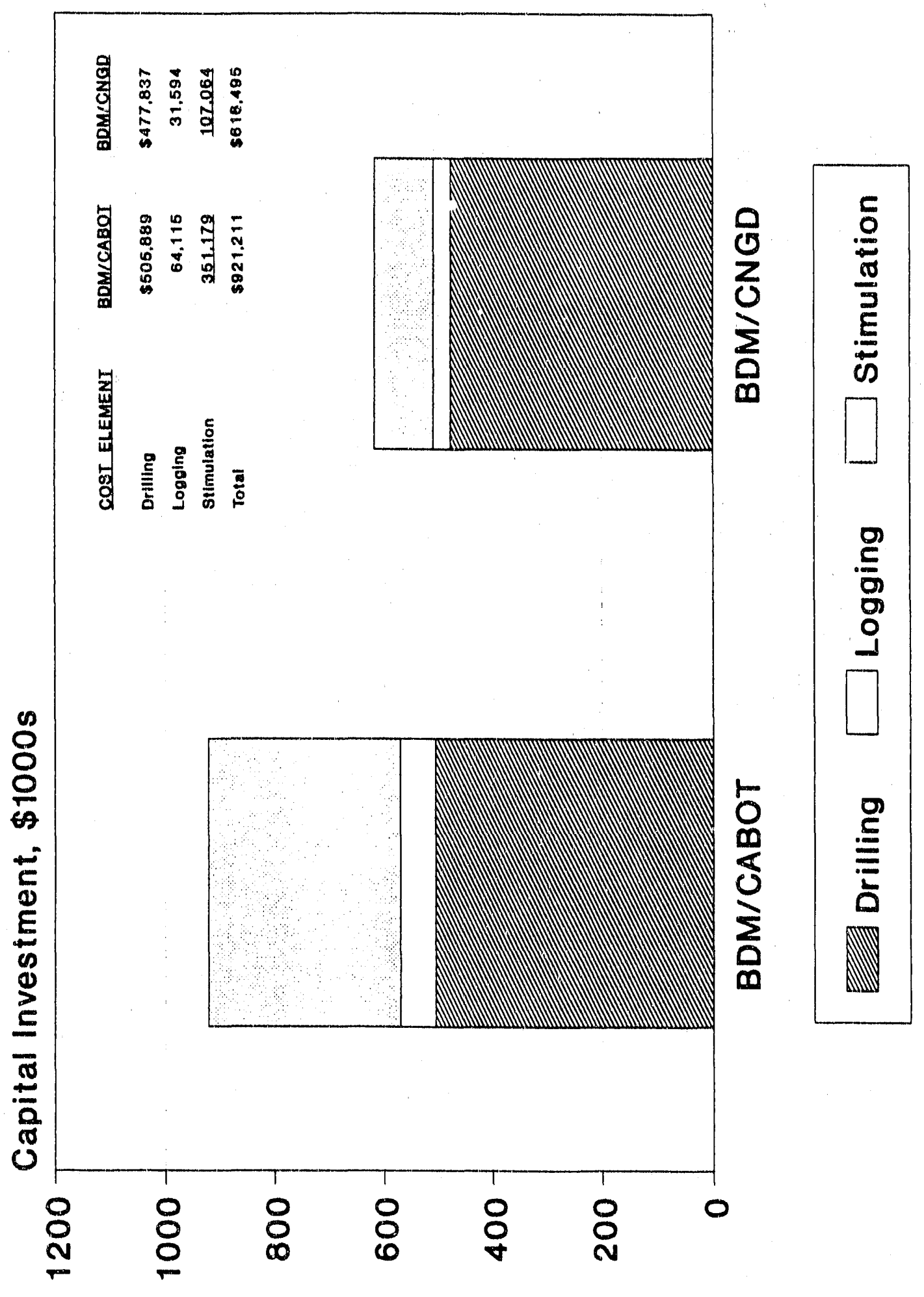


Table 12.1 - Cost Data BDM/Cabot and BDM/CNGD Horizontal Wells

DRILLING ACTIVITIES

ITEM DESCRIPTION

Drilling \& Services

Directional Driller Services

Steering Tool \& Directional Tool Rental

Directional Consultant Engineer - GSM

Rentals (Rearners, Stabilizers, Other)

Drilling Fluid Additives

Tubulars

Cementing

External Casing Packers \& Port Collars

Build Location, Reclamation \& Dozer

Mud Logging

Field Engineer (Vertical Hole)

Drill Pipe Inspection

Power Tongs

Permit \& Survey

Neter Setup \& Testing

Miscellaneous (Trucking \& Field Services)

DRILLING SUBTOTAL

CORING AND LOGGING ACTIVITIES

Coring

Shallow Logging

Deep Logging

CORINGLOGGING SUBTOTAL

STIMULATION ACTIVITIES

Setup \& Testing ECP's \& PC's

Dozer \& Road Work

Production Tubing, Tank Rental \& Water Hauling

Video Camera Runs

Operate ECP's \& PC's Services

Fishing Equipment

Frac Fluids \& Stimulation Equipment

Perforations

Field Engineer

Tool Rental \& Testing

Pip Disposal/Reclamation

Clean-Up

Trucking \& Miscellaneous

STIMULATION SUBTOTAL

GRAND TOTAL HORIZONTAL WELL COST
BDM/CABOT/DOE BDM/CNGD/DOE

205,575

195,600

33,757

28,907

7,085

3,558

9,300

89,680

13,681

19,277

57,172

11,183

7,448

5,303

630

7,525

2,438

3,370

35,000

13,565

58,716

12,572

59,074

13,691

36,622

19,513

13,968

2,766

0

4,034

629

0

12,086

505,888

477,837

23,212

40,933

5,000

26,594

64,145

31,594

6,074

28,792

4,890

1,365

19,382

14,620

2,810

27,936

10,789

150,943

13,977

24,910

18,464

4,904

59,183

6,918

351,178

107,063

15,119

29,144

3,952

1,071

5,500

7,094

406

921,211

616,495 
this analysis, it is assumed that two-thirds of the Devonian Shale vertical wells are commercial gas wells. The remaining one-third of the wells are therefore considered in the analysis to be dry holes, and the cost of these dry holes included in this comparative analysis.

A single conventional vertical well, drilled and completed in the Devonian Shale, costs approximately $\$ 200,000$, plus or minus $\$ 25,000$. In addition, since one out of every three wells drilled and completed is considered in this analysis to be a dry hole, the average vertical well cost is increased by $\$ 100,000$, to an average cost of $\$ 300,000$ which includes the dry hole costs. For the sensitivity analysis, the average cost of a vertical well ranges from $\$ 275,000$ to $\$ 325,000$.

\section{Gas Production}

Based on the analysis of 282 conventional vertical wells, the average Devonian Shale well averaged $71 \mathrm{Mcf} /$ day during the first full year of gas production. These wells declined at an average rate of $6.5 \% /$ year.

The BDM/Cabot well was placed on production in May 1990 and reached a peak monthly production rate in July 1990 of $115 \mathrm{Mcf} /$ day. Production during the first year of production averaged $88 \mathrm{Mcf} /$ day. Examination of the monthly production data, Figure 12.2, shows that the $\mathrm{BDM} / \mathrm{Cabot}$ well has a very gradual decline in gas production; $3.5 \% / y e a r$ as compared with $6.5 \%$ year for the average vertical well. This more gradual reduction in the rate of decline is most likely due to the increased drainage area of a horizontal well as compared with the conventional vertical well.

The BDM/CNGD well was placed on production in December 1991, therefore only a few weeks of production information is available at the time of this analysis. Production tests conducted prior to, and after, completion showed the well was capable of delivering in excess of $400 \mathrm{Mcf} /$ day. Only two of four productive intervals have been completed to date, and these two intervals have produced in excess of $100 \mathrm{Mcf} / \mathrm{day}$. This well has significant additional production potential over that displayed in the early production history. For this analysis, it is assumed 


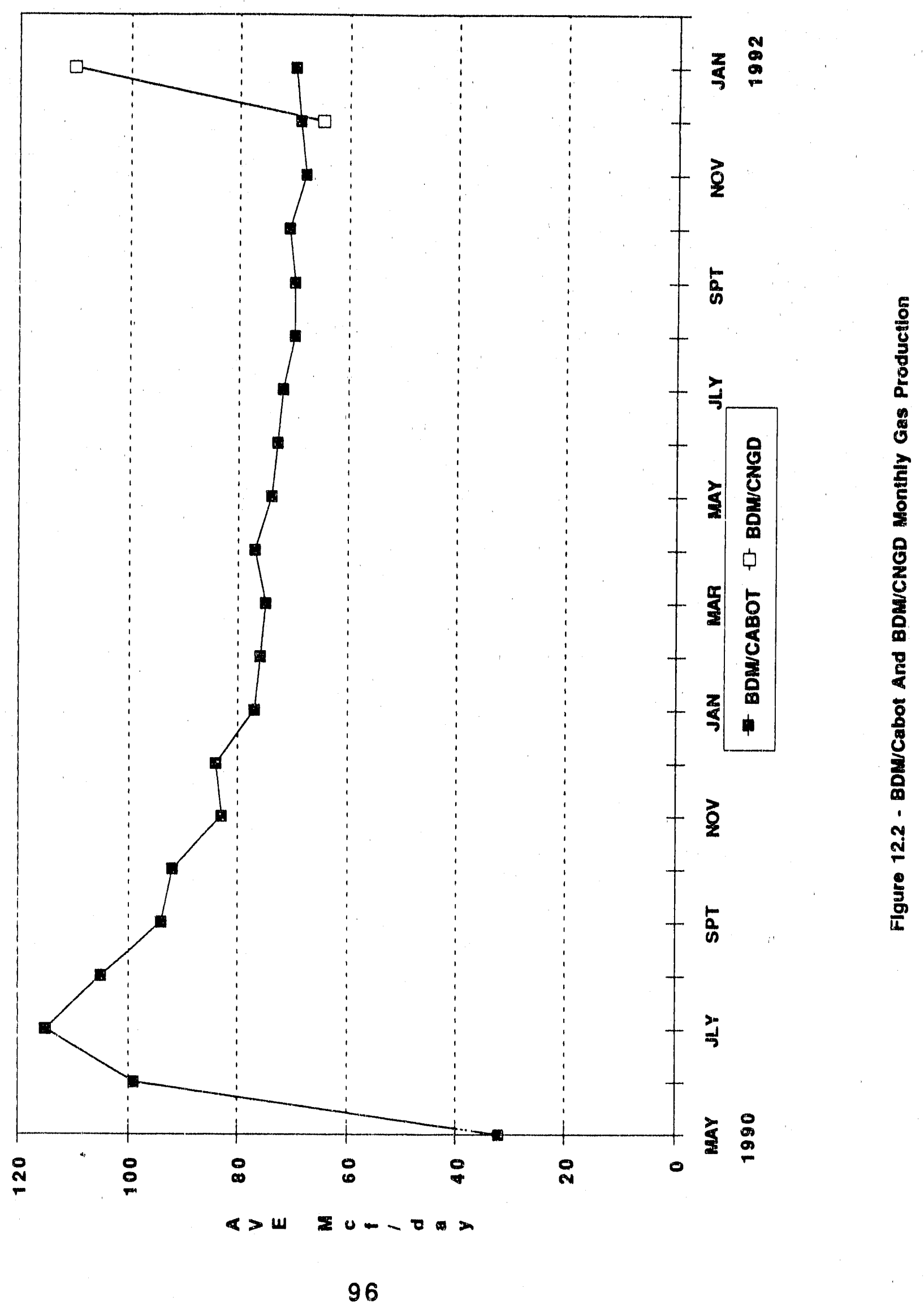


that this well will average $140 \mathrm{Mcf} /$ day in gas and equivalent oil production over its first full year of operation. While the decline from the year 1 production estimate may be similar to the BDM/Cabot well of $3.5 \% / y e a r$, a more conservative decline rate of $6.5 \% / y e a r$ was assumed in the economic analysis.

The gas production estimates used in the economic analyses for the BDM/Cabot, BDM/CNGD and the average vertical well are presented in Figure 12.3.

\subsection{Economic Results}

\section{Cash Flow Analysis}

The base case economic analyses is displayed in Figure 12.4 and detailed in Tables 12.2, 12.3, and 12.4 for the BDM/Cabot, BDM/CNGD, and the average well cases.

As shown in these displays, the increase in the gas production achieved by the BDM/Cabot well as compared with the average vertical well is not sufficient to completely overcome the learning curve costs associated with this first well. The well is marginally economic under the assumptions used to generate the analysis. Experience has shown that the first horizontal well will be high relative to the costs of the subsequent wells.

The BDM/CN:GD well represents the cost improvements that can be realized by the application of lessons learned from the first well. This horizontal well is projected to be economic using the base case assumptions. At about two times the cost of the average vertical well, this horizontal well also is expected to have about two times the productive capacity of the average vertical well from the intervals completed to date. Two of the highest potential intervals are not yet completed, and the marginal cost of completion relative to the gas production potential appears to be quite favorable. If completed by CNGD, the economics of this well will likely be significantly enhanced over the analysis presented in this report. 


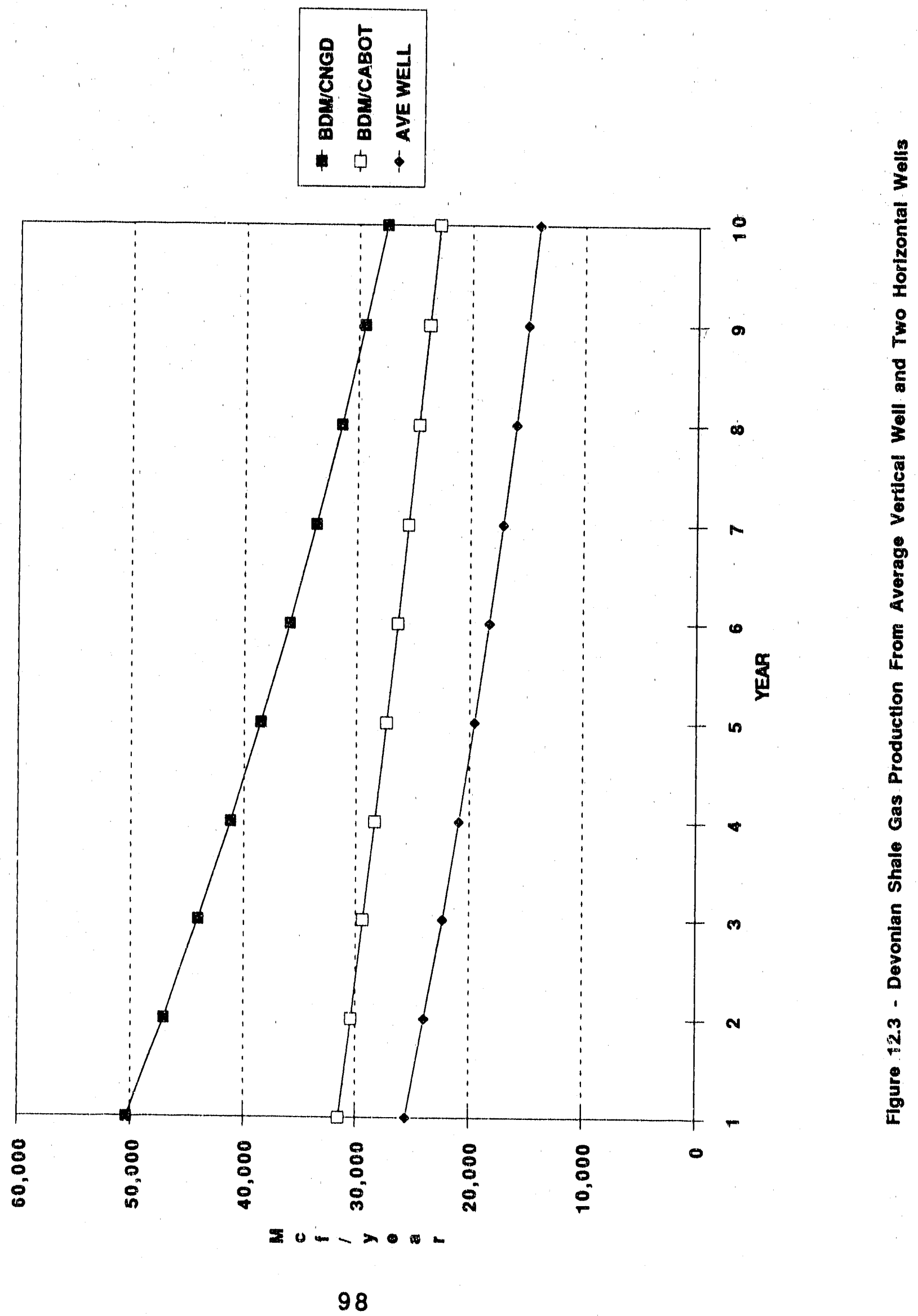




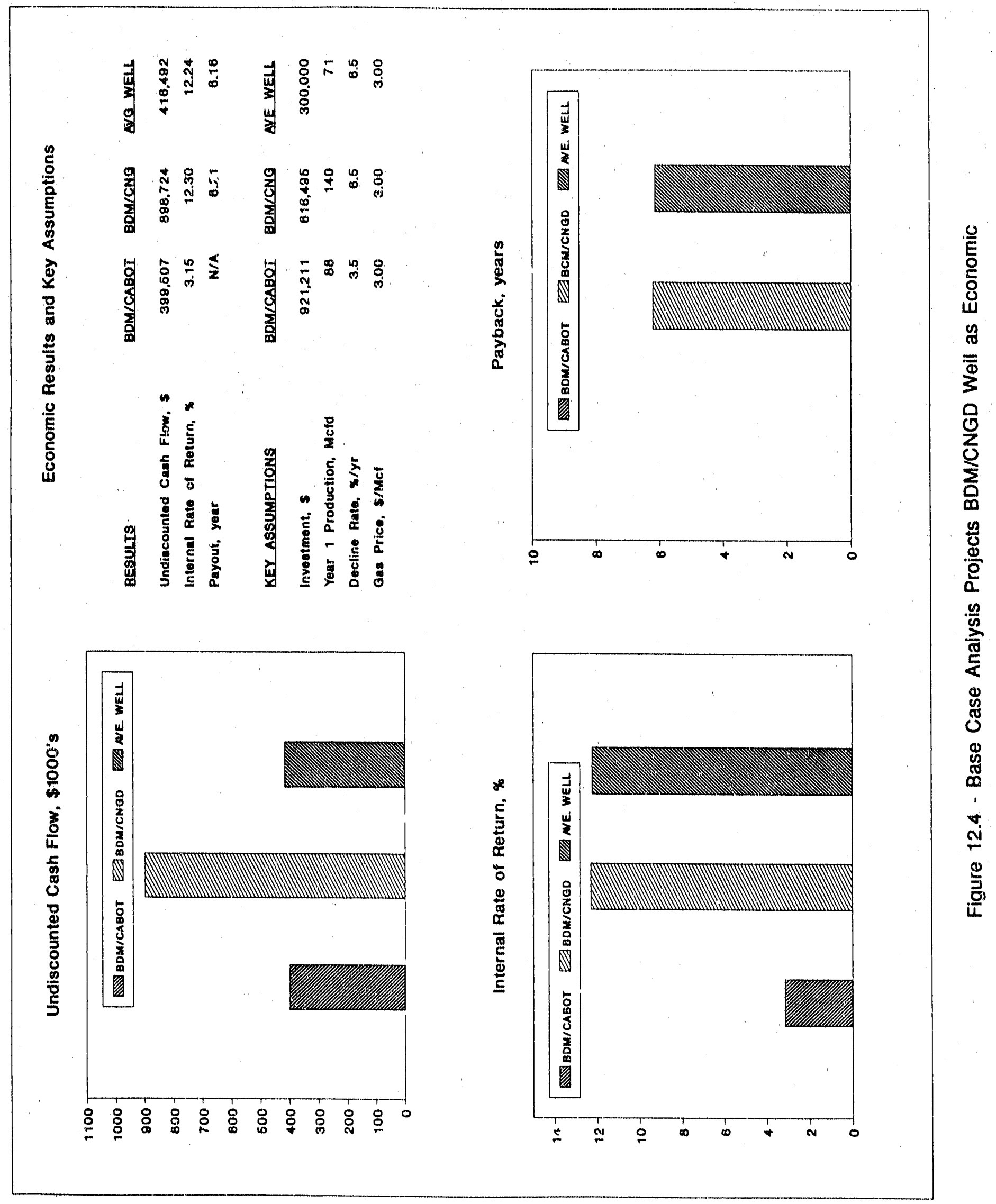


Table 12.2 - Average Vertical Well Cash Flow Analysis (Base Case)

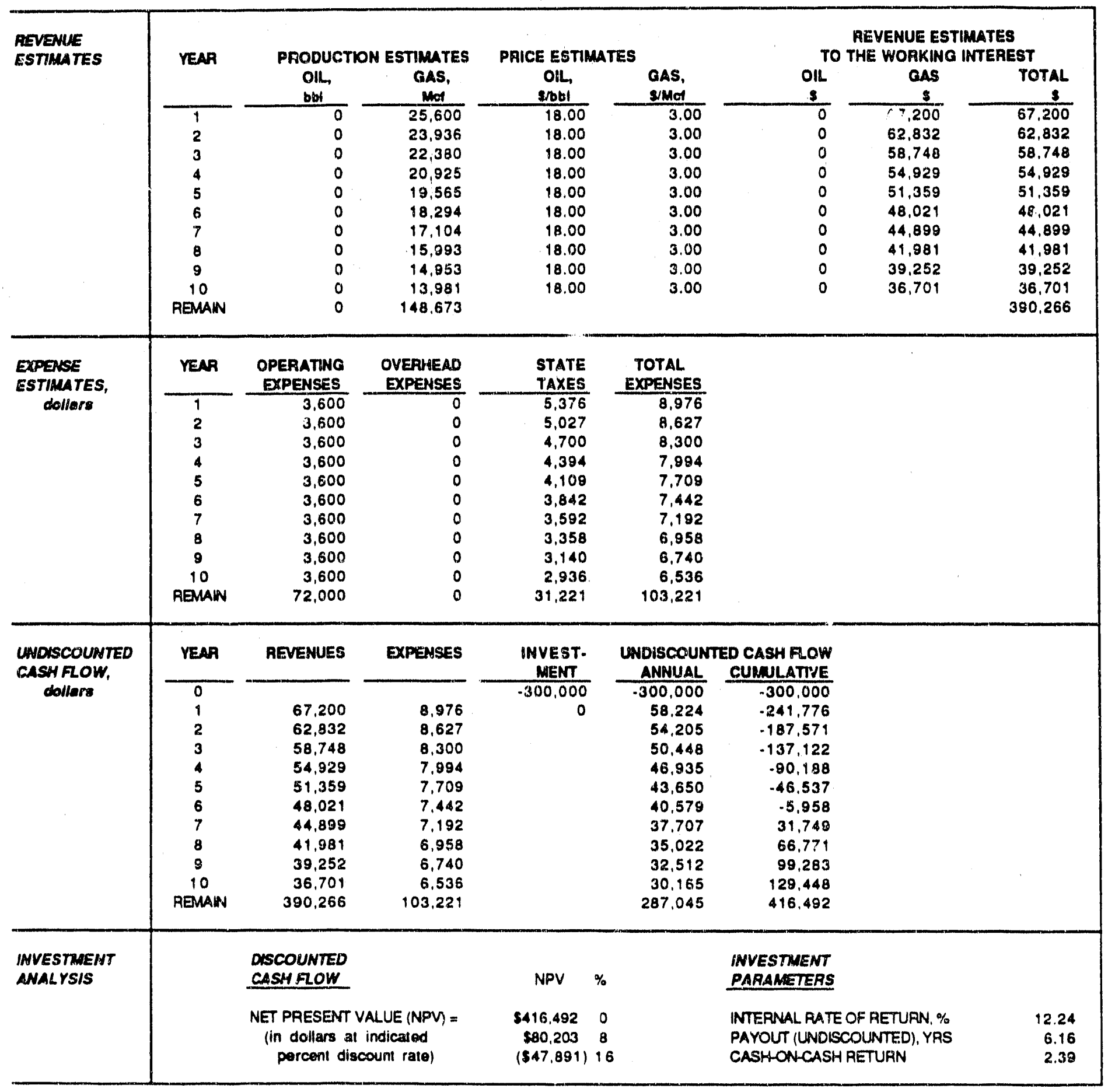

18-Mar-92 
Table 12.3 - BDM/CNGD Horizontal Well Cash Flow Analysis (Base Case)

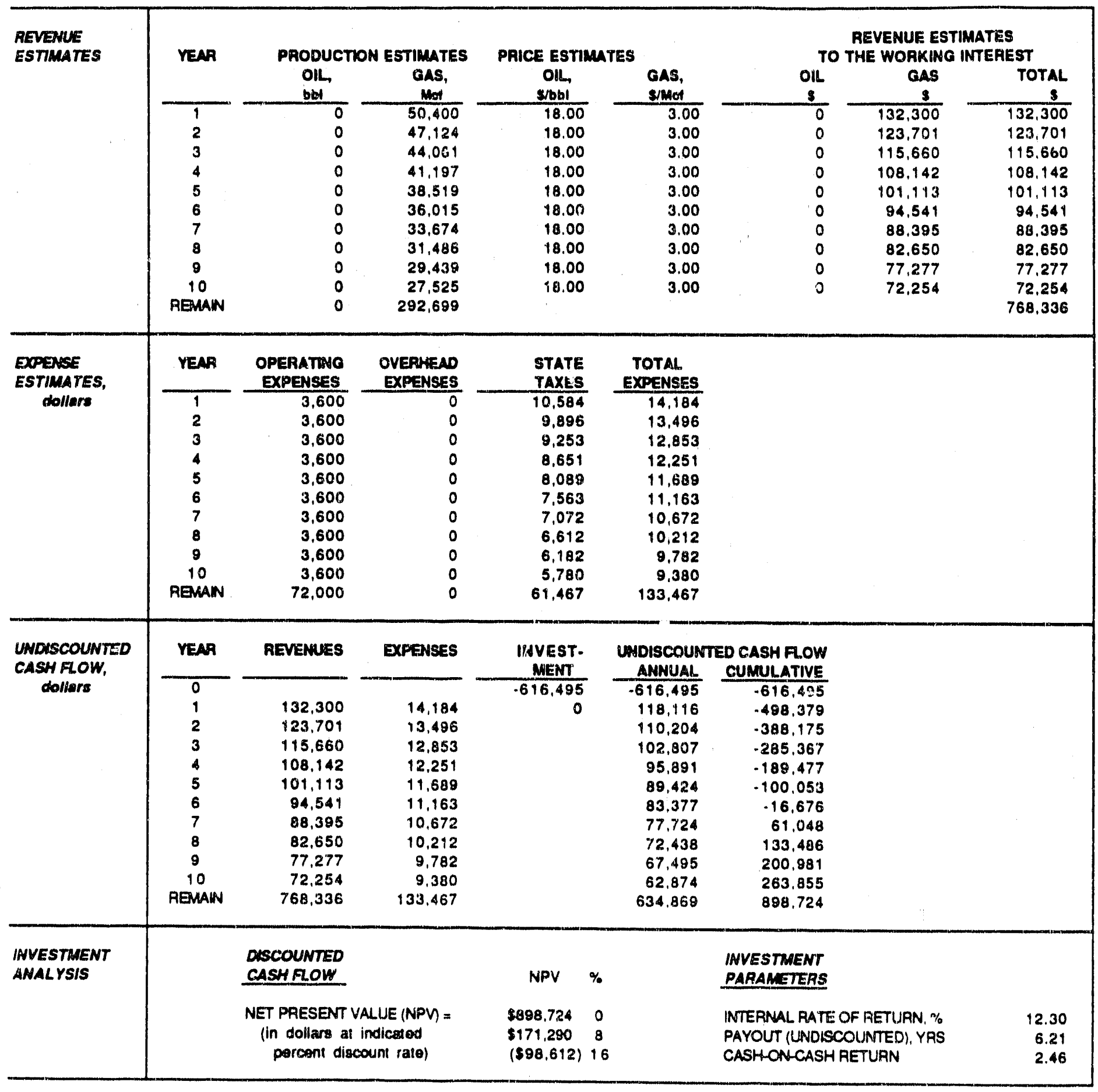


Table 12.4 - BDM/Cabot Horizontal Well Cash Flow Analysis (Base Case)

\begin{tabular}{|c|c|c|c|c|c|c|c|c|}
\hline \multirow[t]{13}{*}{$\begin{array}{l}\text { REVENLE } \\
\text { ESTMMATES }\end{array}$} & \multirow[t]{2}{*}{ YEAA } & \multicolumn{2}{|c|}{ PAODUCTION ESTIMATES } & \multicolumn{2}{|c|}{ PAICE ESTIMATES } & \multicolumn{3}{|c|}{$\begin{array}{c}\text { REVENUE ESTIMATES } \\
\text { TO THE WORKMG INTEREST }\end{array}$} \\
\hline & & OIL, & $\begin{array}{l}\text { GAS, } \\
\text { Mint }\end{array}$ & $\begin{array}{c}\text { Oll. } \\
\text { subil }\end{array}$ & $\begin{array}{l}\text { GAS, } \\
\text { S/MCA }\end{array}$ & $\underset{s}{\text { OIL }}$ & GAS & TOTAL \\
\hline & 1 & 0 & 31,536 & 18.00 & $\frac{3.00}{3.00}$ & 0 & 82.782 & 82.782 \\
\hline & 2 & 0 & 30,432 & 18.00 & 3.00 & 0 & 79,885 & 79,885 \\
\hline & 3 & 0 & 29,367 & 18.00 & 3.00 & 0 & 77,089 & 77,089 \\
\hline & 4 & 0 & 28,338 & 18.00 & 3.00 & 0 & 74,391 & 74,391 \\
\hline & 5 & 0 & 27,347 & 18.00 & 3.00 & 0 & 71,787 & 71.787 \\
\hline & 6 & 0 & 26.390 & 18.00 & 3.00 & 0 & 69,274 & 69,274 \\
\hline & 7 & 0 & 25,467 & 18.00 & 3.00 & 0 & 66,850 & 66,850 \\
\hline & 8 & 0 & 24,575 & 18.00 & 3.00 & 0 & 64,510 & 64,510 \\
\hline & 9 & 0 & 23,795 & 18.00 & 3.00 & 0 & 62,252 & 62,252 \\
\hline & 10 & 0 & 22,885 & 18.00 & 3.00 & 0 & 60,073 & 60,073 \\
\hline & REMAN & 0 & 321,548 & & & & & 844,062 \\
\hline \multirow{12}{*}{$\begin{array}{l}\text { EXPENSE } \\
\text { ESTIMATES, } \\
\text { dollars }\end{array}$} & YEAR & $\begin{array}{l}\text { OPERATHNO } \\
\text { EXPENSES }\end{array}$ & $\begin{array}{l}\text { OVERHEAD } \\
\text { EXPENSES }\end{array}$ & $\begin{array}{l}\text { STATE } \\
\text { TAXES }\end{array}$ & $\begin{array}{l}\text { TOTAL. } \\
\text { EXPENSES }\end{array}$ & & & \\
\hline & 1 & 3,600 & 0 & 6,623 & 10,223 & & & \\
\hline & 2 & 3,600 & 0 & 6,391 & 9,991 & & & \\
\hline & $\mathbf{3}$ & 3,600 & 0 & 6.167 & 0,767 & & & \\
\hline & 4 & 3,600 & 0 & 5,951 & 9,551 & & & \\
\hline & 5 & 3,600 & 0 & 5,743 & 9,343 & & & \\
\hline & 6 & 3,600 & 0 & 5,542 & 9,142 & & & \\
\hline & 7 & 3,600 & 0 & 5,348 & $8,948^{\prime}$ & & & \\
\hline & 8 & 3,600 & 0 & 5,161 & 8,761 & & & \\
\hline & 9 & 3,600 & 0 & 4,980 & 8,580 & & & \\
\hline & 10 & 3,600 & 0 & 4,806 & 8,406 & & & \\
\hline & REMAN & 72,000 & 0 & 67,525 & 139,525 & & & \\
\hline \multirow{13}{*}{$\begin{array}{l}\text { UNDISCOUNTED } \\
\text { CASH FLOW, } \\
\text { doliars }\end{array}$} & YEAP & REVENUES & EXPENSES & $\begin{array}{l}\text { INVEST. } \\
\text { MENT }\end{array}$ & $\begin{array}{l}\text { UNDISCOUN } \\
\text { ANMUAL }\end{array}$ & $\begin{array}{l}\text { ED CASH FLOW } \\
\text { CUMULATIVE }\end{array}$ & & \\
\hline & 0 & & & .921 .211 & $.021,211$ & -921.211 & & \\
\hline & 1 & 82,782 & 10,223 & 0 & 72,559 & $-848,652$ & & \\
\hline & 2 & 79,885 & 9,991 & & 69,894 & $.778,758$ & & \\
\hline & 3 & 77.089 & 9,767 & & 67.322 & $.711,436$ & & \\
\hline & 4 & 74,391 & 9,551 & & 64,839 & $.6 \$ 6.597$ & & \\
\hline & 5 & 71.787 & 9.343 & & 62,444 & $.584,153$ & & \\
\hline & 6 & 68.274 & 9,142 & & 60,132 & $.524,020$ & & \\
\hline & 7 & 66,850 & 8,948 & & 57,902 & -466.119 & & \\
\hline & 8 & 64,510 & 8,761 & & 55,749 & .410 .369 & & \\
\hline & 9 & 62,252 & 8,580 & & 53,672 & $-356,697$ & & \\
\hline & 10 & 60,073 & 8,406 & & 51,667 & $.305,030$ & & \\
\hline & REMAIN & 844,062 & 139,525 & & 704.537 & 389,507 & & \\
\hline \multirow[t]{2}{*}{$\begin{array}{l}\text { INVESTINENT } \\
\text { ANAL YSIS }\end{array}$} & \multicolumn{3}{|c|}{$\begin{array}{l}\text { DSBCOUNTED } \\
\text { CASHFLOW }\end{array}$} & \multicolumn{5}{|c|}{$\begin{array}{l}\text { INVESTMENT } \\
\text { PARAMETERS }\end{array}$} \\
\hline & & \multicolumn{2}{|c|}{$\begin{array}{l}\text { NET PRESENT VALUE (NPY) = } \\
\text { (in dollars at indicaled } \\
\text { percent discount rate) }\end{array}$} & $\begin{array}{c}\$ 399,507 \\
(\$ 322,084) \\
(\$ 554,450)\end{array}$ & & \multicolumn{2}{|c|}{$\begin{array}{l}\text { INTEANAL AATE OF RETURN, \% } \\
\text { PAYOUT (UNDISCOUNTED), YRS } \\
\text { CASH-ON_CASH RETUFN }\end{array}$} & $\begin{array}{r}3.15 \\
10.00 \\
1.43\end{array}$ \\
\hline
\end{tabular}




\section{Sensitivity Arralyses}

Sensitivity analyses results are presented graphically in Figures 12.5, 12.6, and 12.7. Each figure represents the key economic results using a different constant gas price; Figure 12.5 is the base case results calculated at a price of $\$ 3.00 / \mathrm{Mcf}$; Figure 12.6 is the low gas price case of $\$ 2.00 / \mathrm{Mcf}$; while Figure 12.7 is the high gas price case using $\$ 4.00 / \mathrm{Mcf}$.

E :ch of the sensitivity figures contains similar information concerning the key assumptions used in the analysis. Economic results important in an investment decision are graphically presented. For this report, undiscounted cash flow, internal rate of return, and payout were selected as the investment criteria to be displayed.

A key variable in the calculations is the gas production realized from the well. Only limited information is now available concerning the performance of horizontal wells drilled and completed in the Appalachian Basin. Accordingly, production responses were selected to encompass the likely ranges of production responses. A value of 140 Mcf/day was selected to represent a medium horizontal well case, with production ranging from $90 \mathrm{Mcf} / \mathrm{day}$ in the low case to $190 \mathrm{Mcf} /$ day in the high case. These initial rates of production were declined at an average rate of $6.5 \% / y e a r$. In contrast, the average vertical well represents a data base of 282 wells. For this analysis, the year 1 vertical well production was held constant at $71 \mathrm{Mcf} / \mathrm{day}$, and this rate also declined at $6.5 \% / y e a r$. These assumptions simplify the data presentation and permit a direct visual estimate of the economic potential of a horizontal well as compared with an average vertical well.

For example, as shown in Figure 12.5 ( $\$ 3.00 / \mathrm{Mcf}$ base case), the horizontal well payout and internal rate of return is comparable to the average vertical well if: (1) the horizontal well produces about 140 Mct/day in year 1, and (2) the well can be drilled and completed for a cost of between $\$ 500,000$ and $\$ 700,000$.

At $\$ 2.00 /$ Mcf, Figure 12.6, the horizontal well producing 140 Mct/day and the conventional vertical well are similar and each 


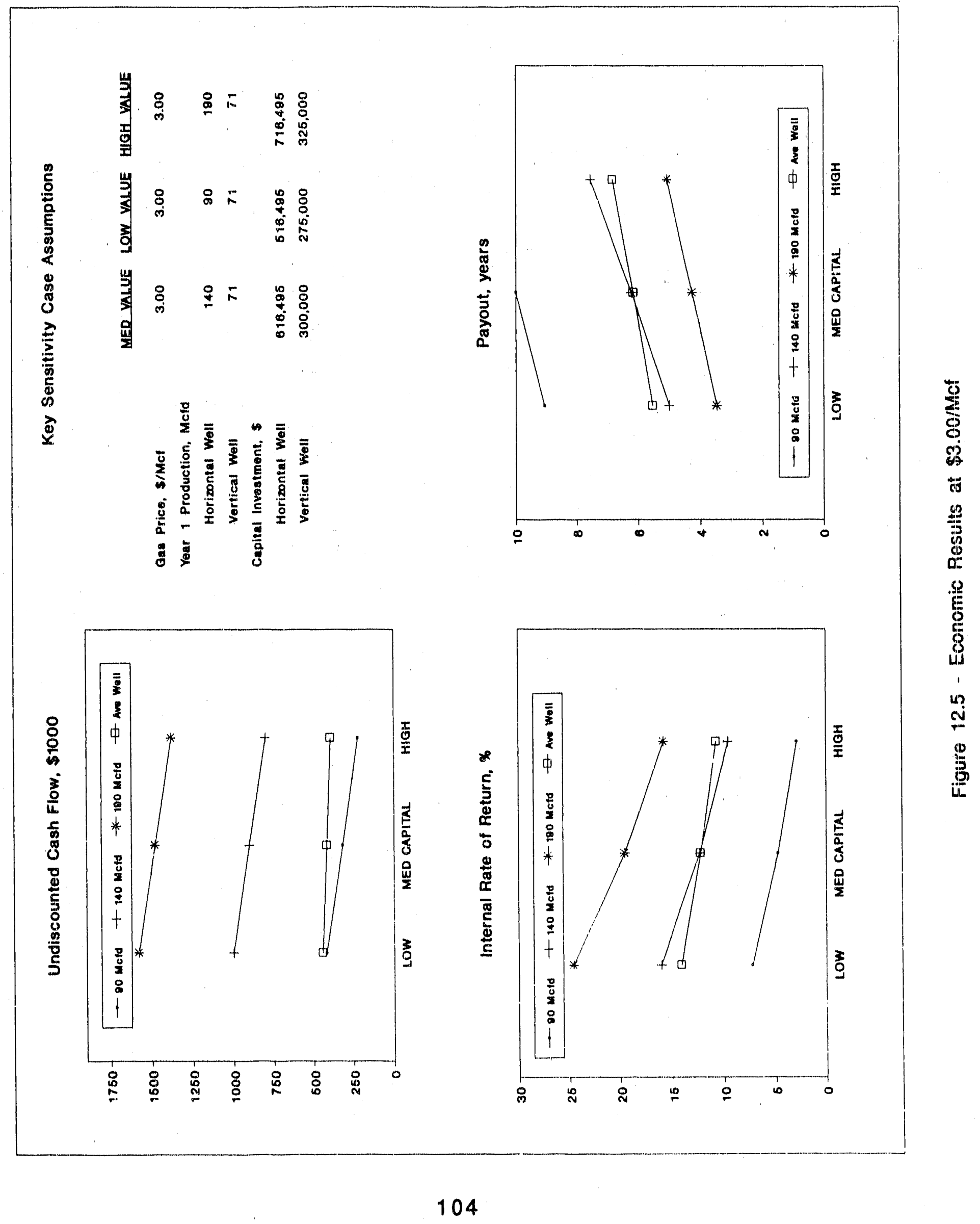




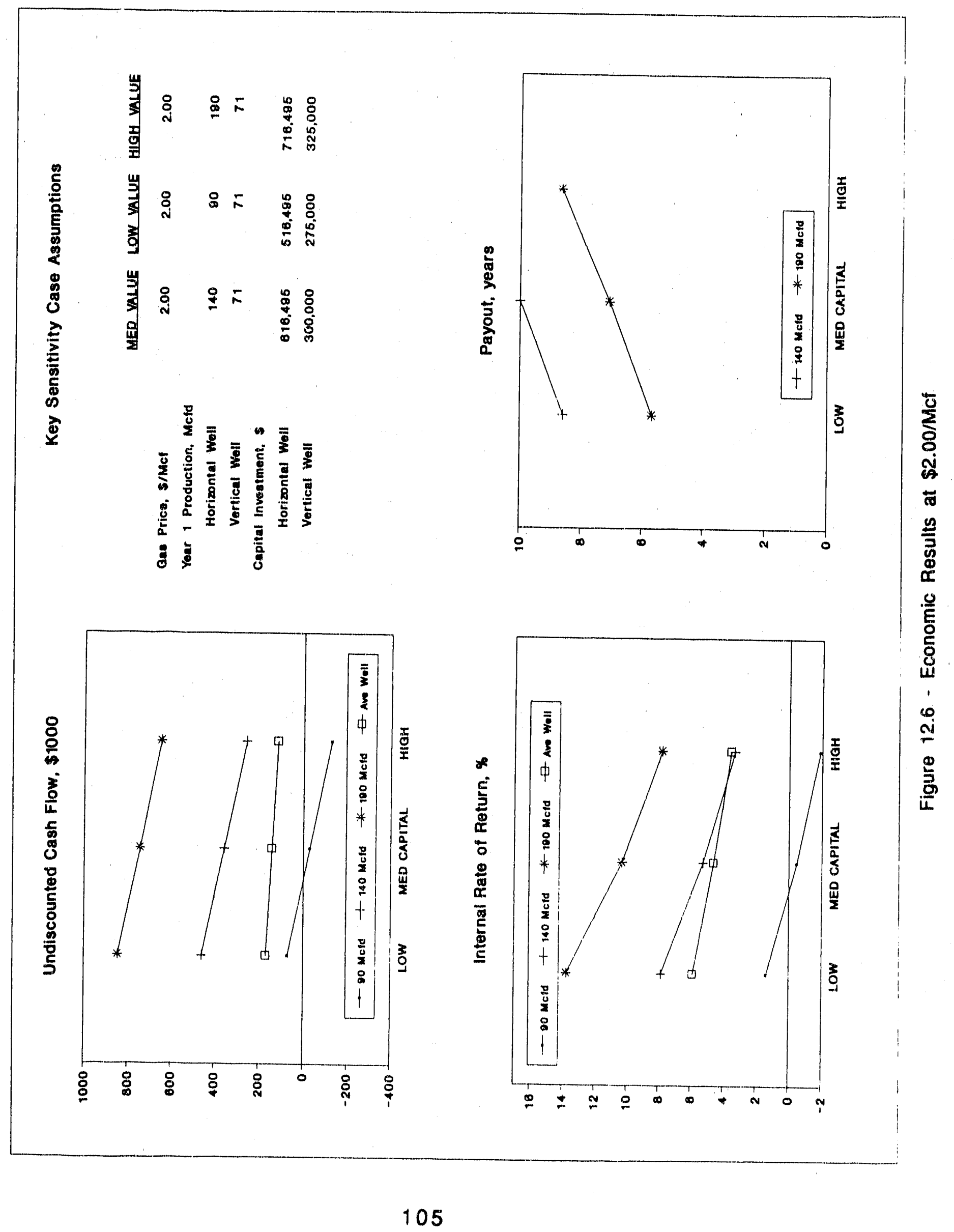




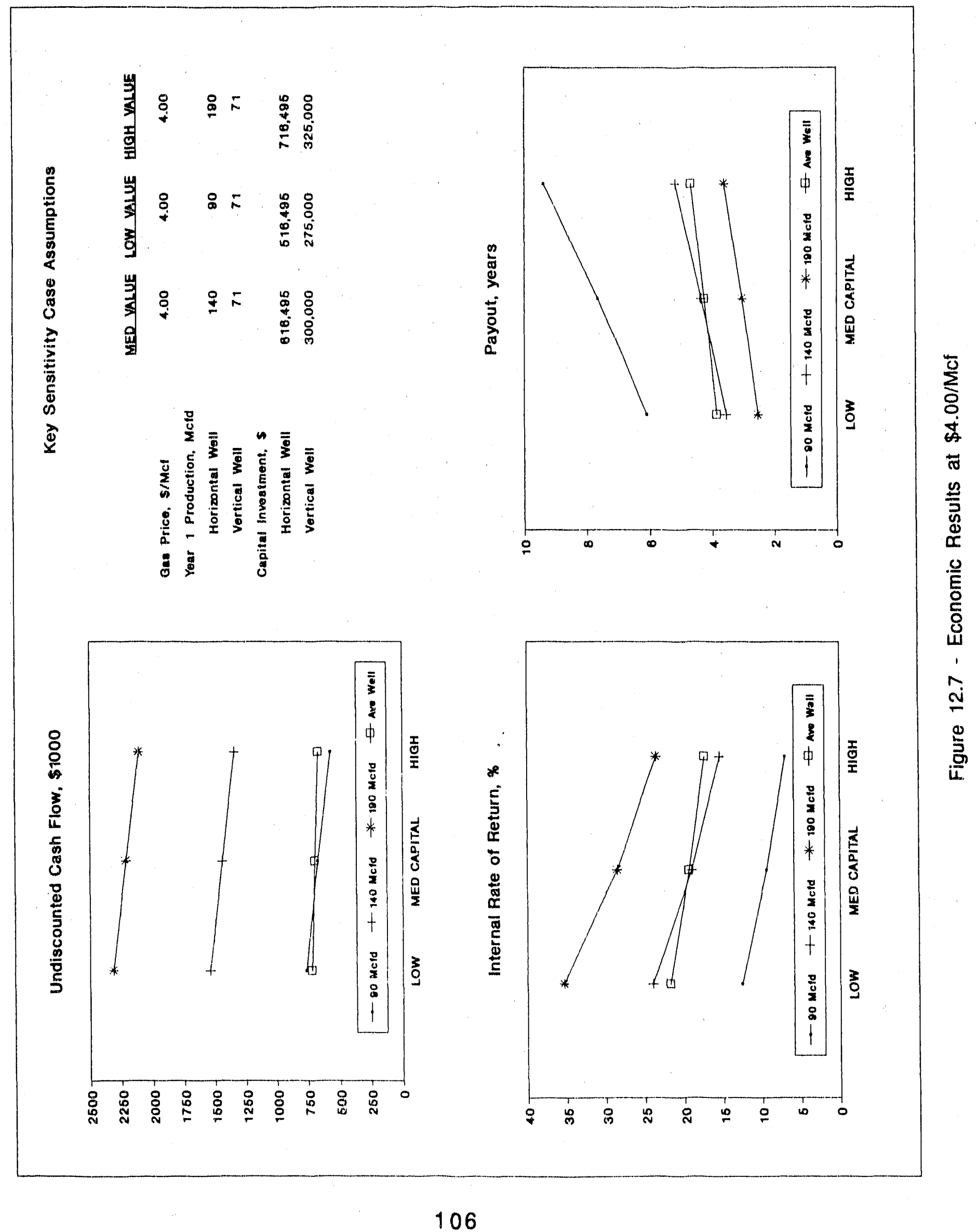


marginally attractive economically. While each has a positive internal rate of return, the cash flow is not sufficient to payout either well within ten years. At $\$ 2.00 / \mathrm{Mcf}$, unly the horizontal well producing $190 \mathrm{Mcf} /$ day during year 1 will generate the cash flow required to payout the capital investment within eight years.

At $\$ 4.00 /$ Mcf, Figure 12.7, all of the wells are economic over a wide range of capital investments and initial rates of gas production. For example, the horizontal well producing $140 \mathrm{Mct} /$ day is once again similar to the average vertical well with both yielding a payout in 4 to 5 years and an internal rate of return of about $20 \%$.

The economic sensitivity Figures $12.5,12.6$, and 12.7 provide a direct comparison of horizontal and vertical well economics across a wide range of economic conditions. These figures can be used to rapidly estimate the economic potential of either type of well given expectations concerning the cost of the well, gas production, and future gas prices.

\subsection{CONCLUSIONS}

Two horizontal wells were planned, sited, drilled, completed, stimulated, and placed in production quite successfully. The technology to drill and complete horizontal wells was improved from the first to the second well, leading to increased rates of penetration during angle building and improved steering tool performance. The completion length of the open hole interval was found to be a critical factor to be considered in the stimulation plans. In general, a fracture length of about 350 feet is a reasonable interval to attempt to complete in Devonian Shale horizontal wells completed open hole.

BDMESC had originally planned to evaluate, by comparison in the same wellbore, the difference (if any) between openhole stimulations and limited entry stimulations through cemented and perforated casing. This was not attempted in the two wells drilled in this program at the request of our industry partners as adding additional complexity to the project. The change in completion plans to all open hole completions was approved by the DOE and the limited entry technique was not attempted. 
Application of horizontal drilling and completion technologies will depend on both the expected future gas price and identification of appropriate targets.

A decision to invest in a conventional vertical well or in the evolving horizontal well technology is highly site-specific and will depend on thie technical information then at hand concerning the nature of the resource to be drilled. If the well can be located on or near a natural fracture system, a conventional vertical well may be selected. The horizontal well will increase the probability of intersecting natural fractures in areas not as well defined, and may be selected instead of the vertical well if the costs of the well can be controlled to between $\$ 500,000$ and $\$ 700,000$ and if the well is likely to initially yield at least $140 \mathrm{Mcf} /$ day of natural gas, depending on the expected value of natural gas.

At an expected natural gas price of $\$ 2.00 / \mathrm{Mcf}$, it would be economically difficult to justify any new Devonian Shale well. At $\$ 3.00 / \mathrm{Mcf}$, the economics become marginally attractive considering the relatively low yields from other investment opportunities available in 1992. At $\$ 4.00 / \mathrm{Mcf}$, either the conventional or horizontal well of the type described in this analysis becomes commercially viable. The choice between vertical or horizontal then becomes a question of how much confidence the operator has in the geologic analyses that must precede the siting of either type of well. 


\subsection{REFERENCES}

1. Overbey, W.K. Jr., Salamy, S.P., Locke, C.D., Recovery Efficiency Test Final Report, "U.S. Department of Energy, Contract DEAC21-85MC22002, Morgantown, West Virginia, February, 1989.

2. Overbey, W.K. Jr., Reeves, T.K., Locke, C.D., Salamy, S.P., "Selection of a Geographic Area and Specific Site for a Horizontal Well in Putnam County, West Virginia," U.S. Department of Energy, Contract DE-AC21-89MC25115, Morgantown, West Virginia, November, 1989.

3. Reeves, T.K., Overbey, W.K. Jr., Locke, C.D., Salamy, S.P., "Selection of Area and a Specific Site for Drilling a Horizontal Well in Calhoun County, West Virginia:" U.S. Department of Energy, Contract DE-AC21-89MC25115, Morgantown, West Virginia, September, 1990.

4. Overbey, W.K., Carden, R.S., Locke, C.D., Salamy, S.P., "Drilling, Completion, Stimulation, and Testing of Hardy HW\#1 Well, Putnam county, West Virginia," U.S. Department of Energy, Contract DE-AC21-89MC25115, Morgantown, West Virginia, March, 1992.

5. Overbey, W.K., Carden, R.S., Locke, C.D., Salamy, S.P., "Drilling Completion, Stimulation, and Testing of BDM/CNGD Well \#3997, Lee District, Calhoun County, West Virginia," U.S. Department of Energy, Contract DE-AC21-89MC25115, Morgantown, West Virginia, March, 1992. 

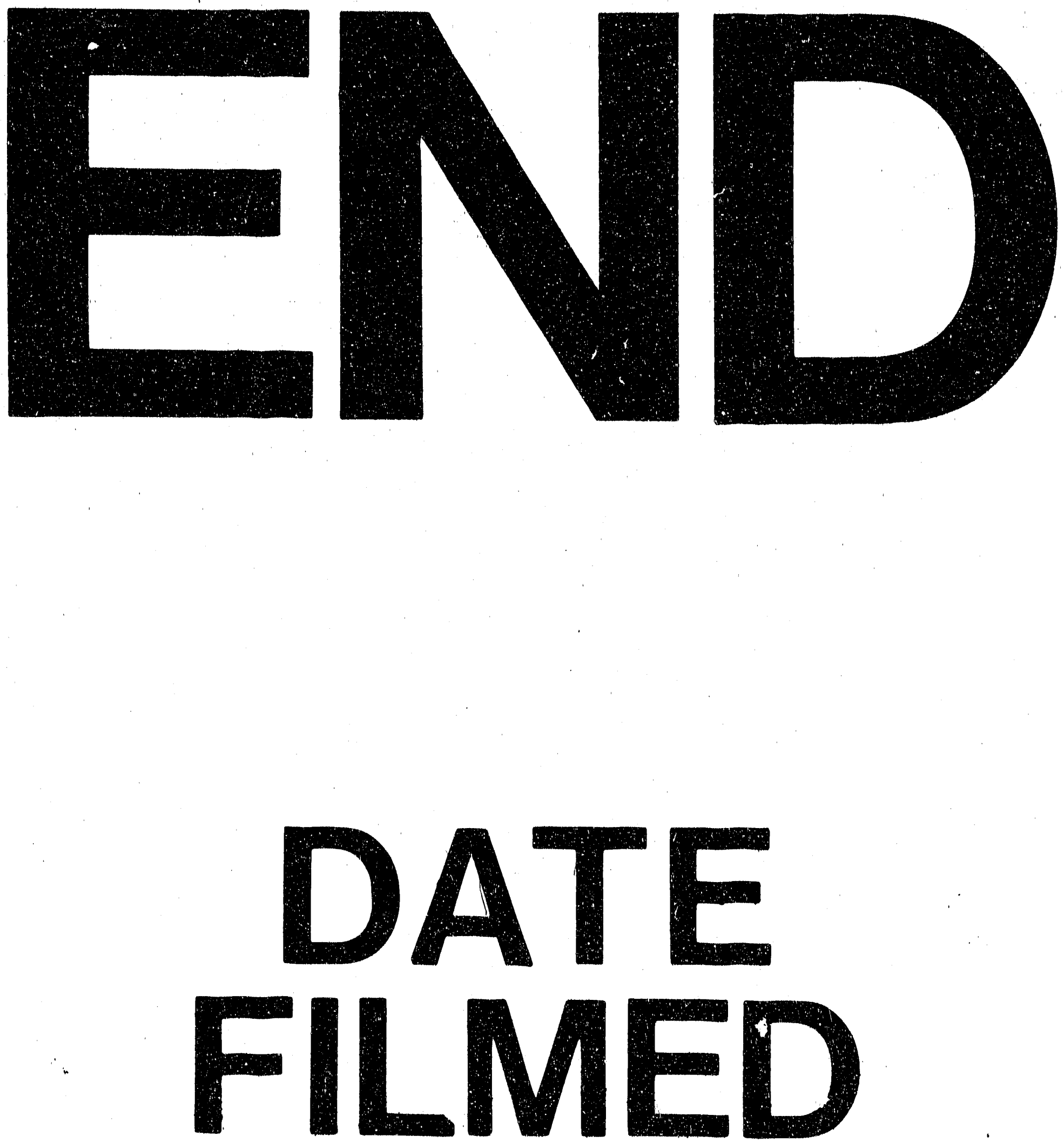

I

$\$$

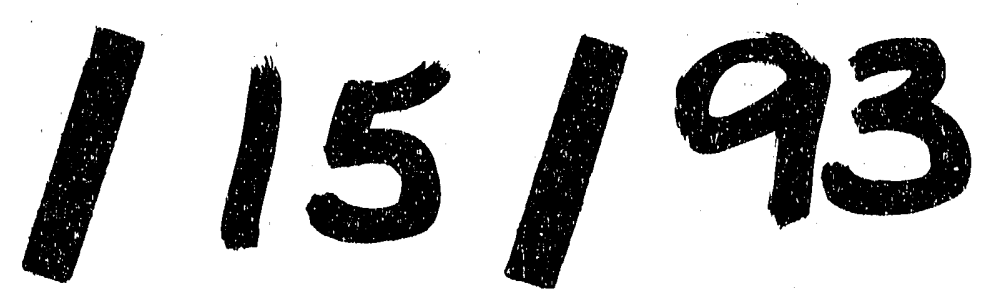


